University of Tennessee Health Science Center UTHSC Digital Commons

$12-2008$

\title{
TorsinA and the Pathophysiology of DYT1 Dystonia
}

Yu Zhao

University of Tennessee Health Science Center

Follow this and additional works at: https://dc.uthsc.edu/dissertations

Part of the Neurosciences Commons

\section{Recommended Citation}

Zhao, Yu , "TorsinA and the Pathophysiology of DYT1 Dystonia" (2008). Theses and Dissertations (ETD). Paper 366. http://dx.doi.org/10.21007/etd.cghs.2008.0380.

This Dissertation is brought to you for free and open access by the College of Graduate Health Sciences at UTHSC Digital Commons. It has been accepted for inclusion in Theses and Dissertations (ETD) by an authorized administrator of UTHSC Digital Commons. For more information, please contact jwelch30@uthsc.edu. 


\title{
TorsinA and the Pathophysiology of DYT1 Dystonia
}

\begin{abstract}
The goal of my dissertation work was to examine the systems biology of torsinA, a DYT1 dystoniaassociated protein, by using rodent model systems. TorsinA is a putative ATPase associated with a variety of cellular activities (AAA+). Deletion of glutamic acid residue 302/303 in TOR1A is causally associated with many cases of early-onset primary dystonia.
\end{abstract}

In our work, transient forebrain ischemia and sciatic nerve transection were used as central and peripheral neural perturbations, respectively, to gain insight into the in vivo role(s) of torsinA. Moreover, transgenic mouse models that overexpress either human mutant torsinA (hMT) or wild-type torsinA (hWT) were used to analyze the behavioral, morphological, neurochemical, and brain metabolical consequences of increased mutant torsinA burden.

After transient forebrain ischemia and sciatic nerve transection, torsinA expression levels were temporally increased in both the central and peripheral nervous systems. In the hippocampus and dorsal root ganglion, increased torsinA immunoreactivity was found located in neuronal populations such as projection neurons, interneurons, and ganglion cells, and in glial elements such as reactive astrocytes and satellite cells. These results suggest that torsinA participates in the response of neural tissue to central and peripheral insults, and that limited recruitment of intact functional torsinA might contribute to the onset of DYT1 dystonia in TOR1A $\triangle$ GAG mutation carriers. The striking induction of torsinA in astrocytes and satellite cells points to the potential involvement of glial elements in the pathobiology of DYT1 dystonia.

In the DYT1 transgenic mice, mutant torsinA burden resulted in prolonged traversal times and more slips on a raised-beam task; widened hind-base width; increased dopamine turnover in the striatum, and a shift in brain energy demand from the basal ganglia to olivocerebellar pathways. However, no morphological alterations were detected in the mutant mice with either light or electron microscopy. Our neurochemical findings in DYT1 transgenic mice are compatible with previous postmortem neurochemical studies of human DYT1 dystonia. Increased striatal dopamine turnover in torsinA mutant mice suggests that the nigrostriatal pathway may be a site of functional neuropathology in DYT1 dystonia. The relatively attenuated energy demand in basal ganglion output regions may be a manifestation of a primary functional abnormality in the nigrostriatal system of DYT1 mutation carriers and the relatively elevated energy demand in cerebellar cortex might be a compensatory response to dysfunction of the basal ganglia.

\section{Document Type}

Dissertation

\section{Degree Name}

Doctor of Philosophy (PhD)

\section{Program}

Neuroscience

\section{Research Advisor}

Mark S. LeDoux, Ph.D.

\section{Keywords}

TOR1A, Dystonia, TorsinA, Nigrostriatal, Dopamine, Reactive astrocytes, Hippocampus, Satellite cells, 
Dorsal root ganglia

\section{Subject Categories}

Medical Sciences | Medicine and Health Sciences | Neurosciences 


\title{
TORSINA AND THE PATHOPHYSIOLOGY OF DYT1 DYSTONIA
}

\author{
A Dissertation \\ Presented for \\ The Graduate Studies Council \\ The University of Tennessee \\ Health Science Center \\ In Partial Fulfillment \\ Of the Requirements for the Degree \\ Doctor of Philosophy \\ From The University of Tennessee
}

By

Yu Zhao

December 2008 
Chapter 2 (C) 2008 by International Brain Research Organization.

Chapter 3 C 2008 partially by Elsevier Inc.

All other material (C) 2008 by Yu Zhao

All rights reserved 


\section{DEDICATION}

To my incredibly supportive husband Qiuye Zhang;

To my dear sweet children: George Zhang and Jayson Zhang;

And to my parents: Zongqi Zhao and Xuying Yang. 


\section{ACKNOWLEDGEMENTS}

First of all, I would like to thank my research advisor and mentor, Dr. Mark LeDoux, for the training I received in his lab. Thanks for his supervision, advice and encouragement for the research projects. I also thank him for the time he spent guiding me writing, editing and revising the manuscripts.

I would also thank the members in my committee, Drs. Thaddeus Nowak Jr., Anton Reiner, Robert Waters, Ramin Homayouni, and Dominic Desiderio, for their valuable and critical comments and advice on my qualifying exam, research proposal and dissertation formulation.

I thank all the members in Dr. LeDoux's lab, Dr. Jianfeng Xiao, Dr. Suzhen Gong, and Mike Decuypere, for technical help, assistance, and suggestions. In particular, I thank Dr. Jianfeng Xiao for studies of torsinA transcript expression after 4-vessel occlusion described in Chapter 2 and Mike Decuypere for maintaining and running our high-pressure liquid chromatography equipment which was required to the neurochemical analyses detailed in Chapter 3. I also thank former and current members of Dr. Nowak's laboratories (Drs. Masayuki Ueda, Yue Wang, and Liang Zhao) for generating the 4-vessel occlusion model and related data analysis.

During my Ph.D. studies, I have benefited from several faculty members in the Department of Anatomy and Neurobiology, including Drs. Robert Foehring and Dominic Desiderio for their cellular neuroscience class, Drs. Mark Bevan and Robert Williams for their morphological neuroscience class, Dr. Melburn Park for the techniques in neuroscience class, Drs. Angela Cantrell and Thomas Schikorski for the neuroscience seminar class, and Dr. William Armstrong for his neuroscience symposium. I am especially grateful to Dr. Joseph Callaway, neuroscience graduate program director, who provided me with direction and help.

My thanks are extended to the staff in the Departments of Neurology and Anatomy and Neurobiology, including Kathy Troughton for her training and help with confocal and electron microscopy, Brenda Smith for her administrative help in graduate school; and Mary Reed, Bobbie Scott, Sharon Williams, and Frances Grigsby for their help in reagent purchasing and administrative work.

I especially thank my husband, my parents, and my sister. Without their incredible love and support, I would not accomplish my graduate training.

I thank Dystonia Medical Research Foundation and the National Institute of Neurological Disorders and Stroke for financial support (R01-NS048458 and R03NS050185 to MSL, and R01-NS032344 to TSN). 


\begin{abstract}
The goal of my dissertation work was to examine the systems biology of torsinA, a DYT1 dystonia-associated protein, by using rodent model systems. TorsinA is a putative $\underline{A}$ TPase associated with a variety of cellular activities (AAA + ). Deletion of glutamic acid residue 302/303 in TOR $1 A$ is causally associated with many cases of earlyonset primary dystonia.

In our work, transient forebrain ischemia and sciatic nerve transection were used as central and peripheral neural perturbations, respectively, to gain insight into the in vivo role(s) of torsinA. Moreover, transgenic mouse models that overexpress either human mutant torsin A (hMT) or wild-type torsinA (hWT) were used to analyze the behavioral, morphological, neurochemical, and brain metabolical consequences of increased mutant torsinA burden.

After transient forebrain ischemia and sciatic nerve transection, torsin $\mathrm{A}$ expression levels were temporally increased in both the central and peripheral nervous systems. In the hippocampus and dorsal root ganglion, increased torsinA immunoreactivity was found located in neuronal populations such as projection neurons, interneurons, and ganglion cells, and in glial elements such as reactive astrocytes and satellite cells. These results suggest that torsinA participates in the response of neural tissue to central and peripheral insults, and that limited recruitment of intact functional torsin A might contribute to the onset of DYT1 dystonia in TOR1A $\triangle \mathrm{GAG}$ mutation carriers. The striking induction of torsinA in astrocytes and satellite cells points to the potential involvement of glial elements in the pathobiology of DYT1 dystonia.

In the DYT1 transgenic mice, mutant torsinA burden resulted in prolonged traversal times and more slips on a raised-beam task; widened hind-base width; increased dopamine turnover in the striatum, and a shift in brain energy demand from the basal ganglia to olivocerebellar pathways. However, no morphological alterations were detected in the mutant mice with either light or electron microscopy. Our neurochemical findings in DYT1 transgenic mice are compatible with previous postmortem neurochemical studies of human DYT1 dystonia. Increased striatal dopamine turnover in torsinA mutant mice suggests that the nigrostriatal pathway may be a site of functional neuropathology in DYT1 dystonia. The relatively attenuated energy demand in basal ganglion output regions may be a manifestation of a primary functional abnormality in the nigrostriatal system of DYT1 mutation carriers and the relatively elevated energy demand in cerebellar cortex might be a compensatory response to dysfunction of the basal ganglia.
\end{abstract}




\section{TABLE OF CONTENTS}

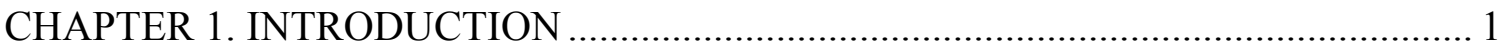

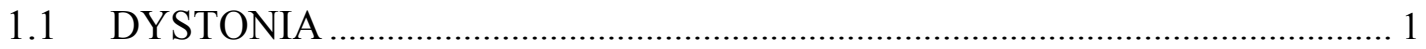

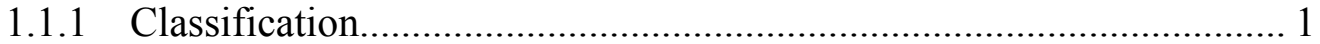

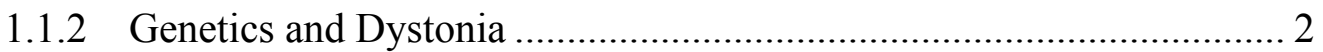

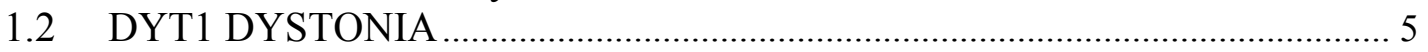

1.2.1 Neuropathology in DYT1 Dystonia...................................................... 6

1.2.2 Neurochemical Studies in DYT1 Dystonia............................................. 6

1.2.3 Neuroimaging Studies in DYT1 Dystonia …………………............. 7

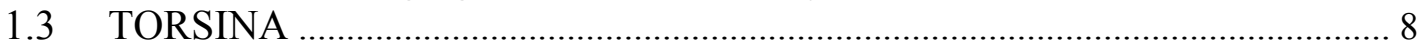

1.4 ANIMAL MODELS OF DYT1 DYSTONIA ……………………………........ 11

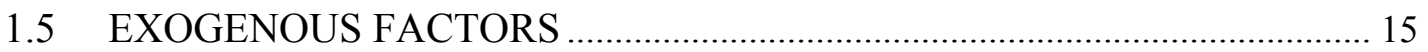

1.5.1 Perturbations and Secondary Dystonia …………………………..... 15

1.5.2 Inciting Factors of Primary Dystonia................................................ 16

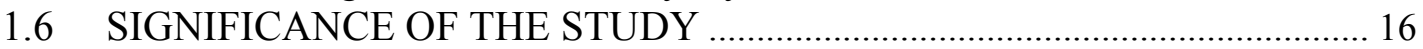

\section{CHAPTER 2. TORSINA EXPRESSION AFTER NEURAL PERTURBATIONS TO} THE CENTRAL AND PERIPHERAL NERVOUS SYSTEMS............... 18

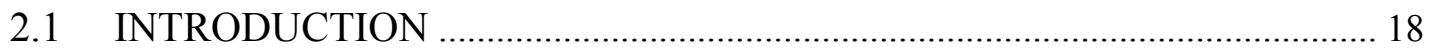

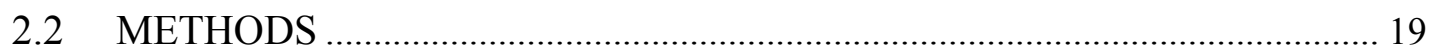

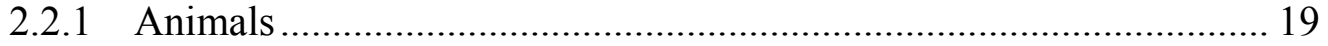

2.2.2 Transient Forebrain Ischemia ....................................................... 20

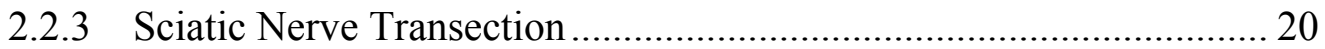

2.2.4 Relative Quantitative Real-time RT-PCR (QRT-PCR) ...................... 21

2.2.5 In situ Hybridization ...................................................................... 23

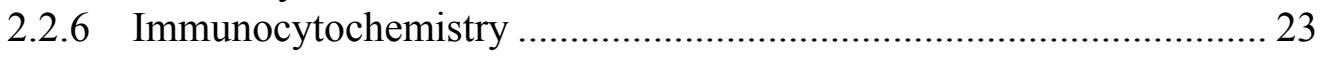

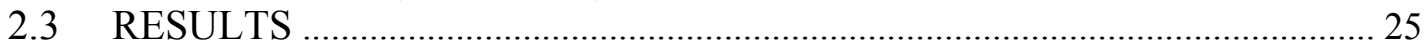

2.3.1 TorsinA Transcript Was Up-regulated after Transient Forebrain

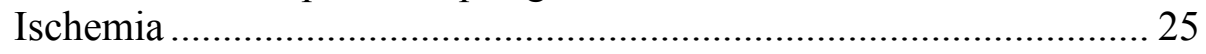

2.3.2 TorsinA Was Up-regulated in Hippocampal Astrocytes and Interneurons ............................................................................. 30

2.3.3 TorsinA Transcript and Protein Were Up-regulated in Bilateral DRG after Unilateral Sciatic Nerve Transection ................................ 38

2.3.4 TorsinA and Vimentin Co-localize in Neuronal and Glial Elements

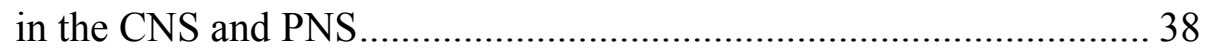

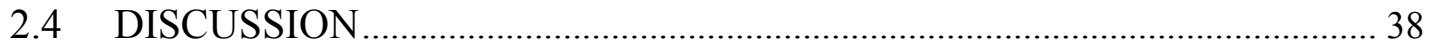

2.4.1 Post-ischemic TorsinA Expression in the CNS …………………....... 44

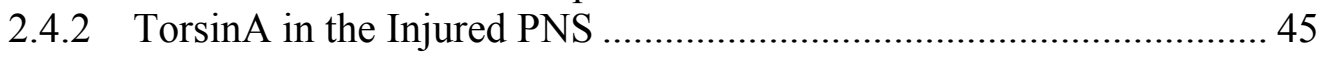

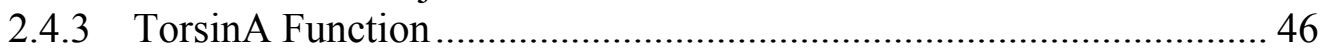

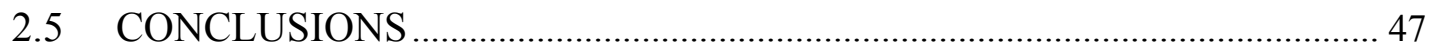




\section{CHAPTER 3. BEHAVIOR, MORPHOLOGICAL, NEUROCHEMICAL, AND}

METABOLIC FEATURES OF DYT1 $\triangle$ GAG TRANSGENIC MICE ... 48

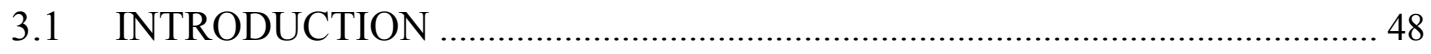

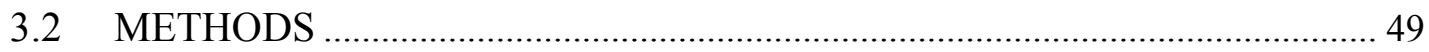

3.2.1 DYT1 Transgenic Mouse Model and Genotyping................................ 49

3.2.2 Northern Blot Hybridization ............................................................. 51

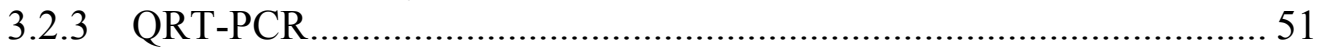

3.2.4 Behavioral Assessment .................................................................... 51

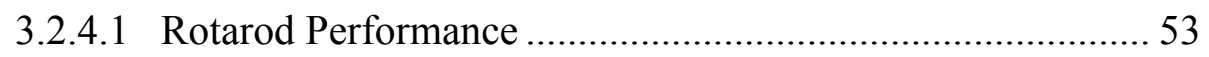

3.2.4.2 Footprint Analysis............................................................... 53

3.2.4.3 Tail Suspension.................................................................. 53

3.2.4.4 Vertical Rope Climb .......................................................... 53

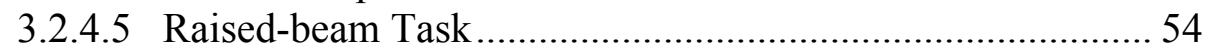

3.2.5 Confocal Microscopy ………………………….............................. 54

3.2.6 Electron Microscopy ............................................................................ 54

3.2.7 HPLC-EC Analysis of Monoamines and Their Metabolites ............... 55

3.2.8 2-DG Autoradiography and CO Histochemistry .................................. 56

3.2.8.1 Tissue Collection ................................................................... 56

3.2.8.2 Image Acquisition and Glucose Utilization (GU)

Densitometric Analysis ........................................................ 56

3.2.8.3 CO Histochemistry .............................................................. 56

3.2.8.4 Preparation of CO Standards and Biochemical Assay of CO Activity ........................................................................... 57

3.2.8.5 CO Densitometric Analysis ................................................... 57

3.2.9 Statistical Analyses ..................................................................... 57

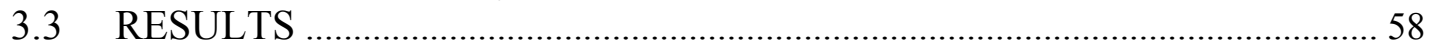

3.3.1 TorsinA Expression in DYT1 Transgenic Mice …………………...... 58

3.3.2 Motor Dysfunction in DYT1 Transgenic Mice ................................... 60

3.3.3 No Cytoplasmic Inclusion Bodies and Nuclear Envelope Vesicles

Were Found in DYT1 Transgenic Mice ……………………................. 60

3.3.4 Neurochemical Phenotype of DYT1 Transgenic Mice......................... 64

3.3.5 Brain Metabolic Abnormalities in DYT1 Transgenic Mice ................. 64

3.3.5.1 CO Activity in DYT1 Transgenic Mice.................................... 64

3.3.5.2 GU in ROIs in DYT1 Transgenic Mice................................... 67

3.3.5.3 Correlation Analysis ............................................................ 67

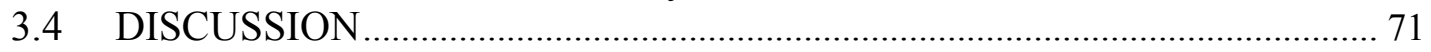

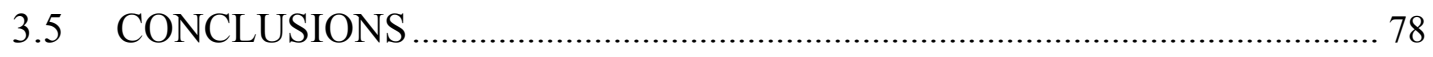

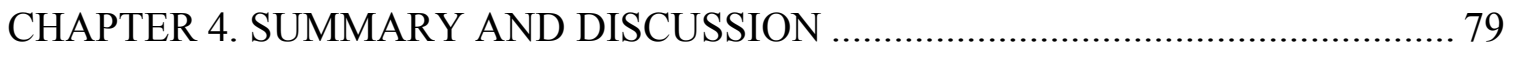

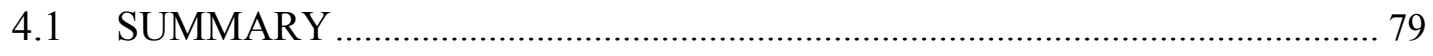

4.2 DISCUSSION …………………………………………………………… 80

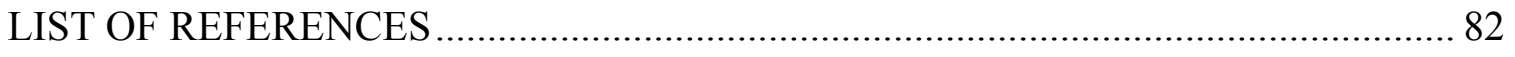

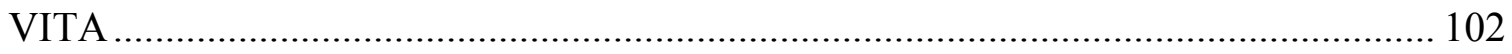




\section{LIST OF TABLES}

Table 1-1. Molecular classification of dystonia ...................................................... 3

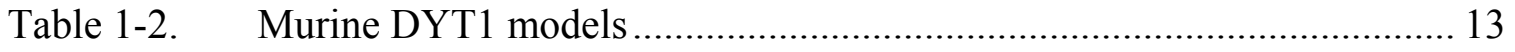

Table 2-1. Probe and primers used for QRT-PCR, and primers used to generate in situ hybridization probes................................................................ 22

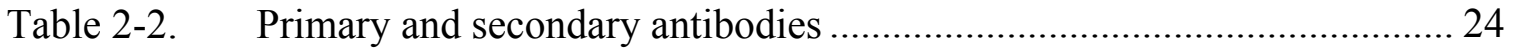

Table 3-1. Probe and primers used for QRT-PCR, and primers used for generation of Northern blot probes ............................................................... 50

Table 3-2. Relative levels of human and mouse torsinA transcripts in DYT1 transgenic mice .................................................................... 59

Table 3-3. CO activity distribution in ROIs in DYT1 transgenic mice .................... 68

Table 3-4. GU distribution in ROIs in DYT1 transgenic mice .............................. 70

Table 3-5. Pearson correlations between neuroanatomically-connected nuclei in DYT1 transgenic mice 


\section{LIST OF FIGURES}

Figure 1-1. Alignment of human, rat, and mouse torsinA amino-acid sequences........ 9

Figure 2-1. QRT-PCR analysis of regional torsinA expression after transient forebrain ischemia.

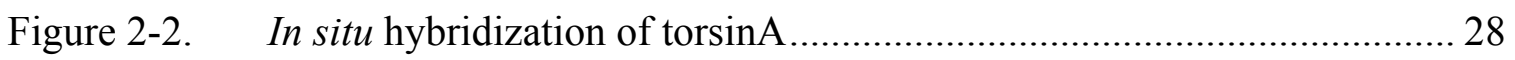

Figure 2-3. Quantitative in situ hybridization analysis of hippocampal torsinA transcript levels

Figure 2-4. Quantitative in situ hybridization analysis of torsinA transcript levels in $\mathrm{SNpc}$

Figure 2-5. Distribution of torsinA immunoreactivity and comparison with other

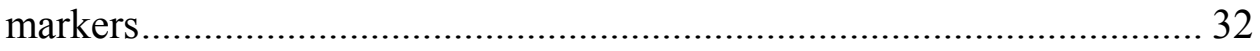

Figure 2-6. Cellular localization of torsin A immunoreactivity in glia ......................... 33

Figure 2-7. Cellular localization of torsinA immunoreactivity in interneurons .......... 34

Figure 2-8. Immunoperoxidase detection of torsinA in post-ischemic hippocampus . 36

Figure 2-9. Temporal profiles of torsinA mRNA expression in DRG after unilateral

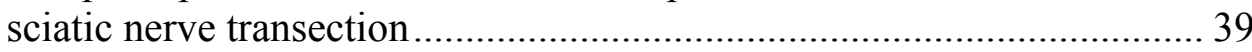

Figure 2-10. Immunocytochemical localization of torsinA expression in DRG after unilateral sciatic nerve transection........................................................ 40

Figure 2-11. Co-localization of torsinA and GFAP in satellite cells............................ 42

Figure 2-12. Co-localization of torsinA and vimentin after ischemia and sciatic nerve transection

Figure 3-1. Genotyping and Northern blot analysis of hWT, hMT1, and hMT2

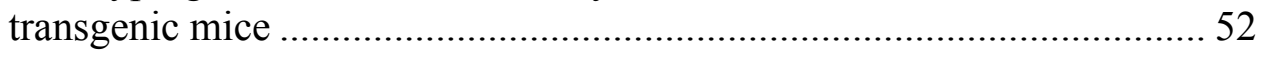

Figure 3-2. Behavioral analysis of motor functioning in DYT1 transgenic mice ....... 61

Figure 3-3. Cellular localization of torsinA and ubiquitin immunoreactivity in neurons

Figure 3-4. Electron microscopic images of the nuclear envelopes in DYT1 transgenic mice 
Figure 3-5. Quantitative HPLC-EC analysis of monoamines and their metabolites in DYT1 transgenic mice. 65

Figure 3-6. Dopamine turnover in the striatum of DYT1 transgenic mice 66 


\section{LIST OF ABBREVIATIONS}

\begin{tabular}{|c|c|}
\hline $\begin{array}{l}\text { AAA+ } \\
\text { AInt }\end{array}$ & $\begin{array}{l}\text { ATPases associated with a variety of cellular activities } \\
\text { anterior interposed nucleus }\end{array}$ \\
\hline ANOVA & analysis of variance \\
\hline APTD & anterior pretectal nucleus, dorsal \\
\hline ATP1A3 & $\alpha-3$ subunit of the $\mathrm{Na}^{+} / \mathrm{K}^{+}$ATPase \\
\hline BA & Brodmann area \\
\hline BLA & basolateral amygdaloid nucleus, anterior \\
\hline CA3poly & polymorphic layer of CA3 \\
\hline $\mathrm{Cg}$ & cingulum \\
\hline $\mathrm{CHem}$ & cerebellar hemisphere \\
\hline CK2 & casein kinase 2 \\
\hline $\mathrm{CO}$ & cytochrome oxidase \\
\hline CNS & central nervous system \\
\hline CPuRD & caudate putamen, rostral dorsal \\
\hline CPuRV & caudate putamen, rostral ventral \\
\hline $\mathrm{CPuC}$ & caudate putamen, caudal \\
\hline cRNA & complementary RNA \\
\hline $\mathrm{C}_{\mathrm{T}}$ & threshold cycle \\
\hline DA & dopamine \\
\hline DC & direct current \\
\hline DCN & dorsal cochlear nucleus \\
\hline DG & dentate gyrus \\
\hline DLG & dorsal lateral geniculate nucleus \\
\hline DOPAC & 3, 4-dihydroxyphenylacetic acid \\
\hline DPX & 1, 3 diethyl-8-phenylxanthine \\
\hline DRG & dorsal root ganglia \\
\hline DT-MRI & diffusion tensor magnetic resonance imaging \\
\hline EPI & epinephrine \\
\hline ER & endoplasmic reticulum \\
\hline FA & fractional anisotropy \\
\hline FDG & fluorodeoxyglucose \\
\hline GCH1 & guanosine triphosphate cyclohydrolase I \\
\hline GFAP & glial fibrillary acidic protein \\
\hline GL & granular layer of cerebellum \\
\hline $\mathrm{H}$ & hilus of dentate gyrus \\
\hline HPLC-EC & high-performance liquid chromatography with electrochemical detection \\
\hline HVA & homovanillic acid \\
\hline IC & inferior colliculus \\
\hline iDG & inner blade of dentate gyrus \\
\hline InG & intermedial gray, superior colliculus \\
\hline IOD & inferior olive, dorsal accessory nucleus \\
\hline IOM & inferior olive, medial nucleus \\
\hline IP & intraperitoneal \\
\hline
\end{tabular}




$\begin{array}{ll}\text { IPC } & \text { interpeduncular nucleus, caudal subnucleus } \\ \text { IR } & \text { immunoreactivity } \\ \text { KLC } & \text { kinesin light chain } \\ \text { LAP1 } & \text { lamina-associated polypeptide 1 } \\ \text { Lat } & \text { lateral cerebellar nucleus } \\ \text { LC } & \text { locus ceruleus } \\ \text { LD } & \text { laterodorsal thalamic nucleus } \\ \text { LGP } & \text { lateral globus pallidus } \\ \text { LSO } & \text { lateral superior olive } \\ \text { LULL1 } & \text { lumenal domain like LAP1 } \\ \text { LVe } & \text { lateral vestibular nucleus } \\ \text { M1 } & \text { primary motor cortex } \\ \text { M2 } & \text { secondary motor cortex } \\ \text { Med } & \text { medial cerebellar nucleus } \\ \text { MG } & \text { medial geniculate nucleus } \\ \text { MGP } & \text { medial globus pallidus } \\ \text { ML } & \text { molecular layer of cerebellum } \\ \text { MR-1 } & \text { myofibrillogenesis regulator 1 } \\ \text { MVe } & \text { medial vestibular nucleus } \\ \text { NE } & \text { norepinephrine } \\ \text { O.D. } & \text { optical density } \\ \text { oDG } & \text { outer blade of dentate gyrus } \\ \text { PAG } & \text { periaqueductal gray } \\ \text { PB } & \text { phosphate buffer } \\ \text { PBS } & \text { phosphate-buffered saline } \\ \text { PCL } & \text { Purkinje cell layer of cerebellum } \\ \text { PET } & \text { positron emission tomography } \\ \text { PKC } & \text { protein kinase C } \\ \text { Pn } & \text { pontine nucleus } \\ \text { PnO } & \text { pontine reticular nucleus, oral } \\ \text { PNS } & \text { peripheral nervous system } \\ \text { Po } & \text { posterior thalamic nuclear group } \\ \text { PPN } & \text { pedunculopontine nucleus } \\ \text { PRKRA } & \text { protein kinase, interferon-inducible double-stranded RNA-dependent } \\ & \text { activator } \\ \text { QRT-PCR } & \text { relative quantitative real-time RT-PCR } \\ \text { RMCC } & \text { red nucleus, magnocellular caudal } \\ \text { RMCR } & \text { red nucleus, magnocellular rostral } \\ \text { RMg } & \text { raphe magnus nucleus } \\ \text { ROI } & \text { region of interest } \\ \text { RRX } & \text { rhodamine red-X } \\ \text { Rt } & \text { reticular thalamic nucleus } \\ \text { S1BF } & \text { somatosensory 1, barrel field } \\ \text { S1FL } & \text { somatosensory 1, forelimb } \\ \text { S1HL } & \text { somatosensory 1, hindlimb } \\ \text { S2 } & \text { secondary somatosensory cortex } \\ & \end{array}$




$\begin{array}{ll}\text { SGCE } & \varepsilon \text {-sarcoglycan } \\ \text { SLM } & \text { stratum lacunosum-moleculare } \\ \text { SMA } & \text { supplementary motor areas } \\ \text { SNpc } & \text { substantia nigra pars compacta } \\ \text { SNR } & \text { substantia nigra, reticular } \\ \text { SO } & \text { stratum oriens } \\ \text { SOS } & \text { sodium octylsulphonate } \\ \text { SR } & \text { stratum radiatum } \\ \text { STh } & \text { subthalamic nucleus } \\ \text { SuG } & \text { superficial gray, superior colliculus } \\ \text { TAF1 } & \text { TATA-binding protein-associated factor 1 } \\ \text { TH } & \text { tyrosine hydroxylase } \\ \text { TMD } & \text { transmembrane domain } \\ \text { VA } & \text { ventral anterior thalamic nucleus } \\ \text { VL } & \text { ventrolateral thalamic nucleus } \\ \text { VLG } & \text { ventrolateral geniculate nucleus } \\ \text { VM } & \text { ventromedial thalamic nucleus } \\ \text { VP } & \text { ventral posteral thalamic nucleus } \\ \text { 2-DG } & \text { 2-deoxy-D-glucose } \\ \text { 3-NPA } & \text { 3-nitropropionic acid } \\ \text { 4-VO } & \text { 4-vessel occlusion } \\ \text { 5-HIAA } & \text { 5-hydroxyindoleacetic acid } \\ \text { 5-HT } & \text { serotonin }\end{array}$




\section{CHAPTER 1. INTRODUCTION}

\subsection{DYSTONIA}

Dystonia has been defined by the Scientific Advisory Board of Dystonia Medical Research Foundation as a syndrome of sustained involuntary muscle contractions; it frequently causes twisting and repetitive movements, or abnormal movements and postures (1988). It is generally accepted that dystonia is caused by a dysfunction of the central nervous system with a resultant failure to "relax" muscles that are not required for a particular motor act; that failure results in simultaneous contraction of opposing muscles. Dystonia tends to improve with relaxation, sleep, or sensory tricks, and intensify with action. Dystonia does not discriminate, and affects humankind of all ages, both genders, and racial backgrounds. Dystonia affects over 300,000 people in North America, and is the third most-common movement disorder after Parkinson's disease and tremor in the United States (Dystonia Medical Research Foundation).

Dystonia is a syndrome associated with a heterogeneous collection of genes and disorders. Dystonia may be idiopathic (i.e., primary) or secondary to acquired insults to the CNS and PNS such as trauma, metabolic disorders, and stroke. Dystonia may also be associated with other neurological disorders such as Huntington's disease, Parkinson's disease, Lesch-Nyhan syndrome, and ataxia telangiectasia. Primary dystonia can be classified by age of onset as early- or late-onset dystonia, and by topographic distribution as focal, segmental, multifocal, and generalized (Nemeth, 2002; Tarsy and Simon, 2006).

The severity of the dystonic symptoms may show a modest variability during the course of each day. Dystonia may be associated with pain, functional disability, and a significantly impaired quality of life. In general, the primary dystonias are not associated with intellectual impairment or shortened lifespan. At present, there are no permanent cures for dystonia. However, a variety of treatments is available to improve the symptoms. Treatment options include dopamine-depleting agents such as tetrabenazine, anticholinergics, benzodiazepines, botulinum toxin injections, deep-brain stimulation, and physical therapy (Klein and Ozelius, 2002; Tarsy and Simon, 2006).

\subsubsection{Classification}

The heterogeneity of dystonia has prompted the development of several classification schemes. Classically, dystonia can be clinically classified in three ways: by the age of symptom onset as early-onset and adult-onset; by topographic distribution as focal, segmental, multifocal, generalized, and hemidystonia; and etiologically as primary, dystonia-plus, heredodegenerative, and secondary; and genetically according to the monogenic gene mutation (Fahn et al., 1998; de Carvalho Aguiar and Ozelius, 2002; Tarsy and Simon, 2006). 
Based on data from patients with primary torsion dystonia (Bressman et al., 1998; 2000), if symptoms begin before the age of 26, dystonia is classified as early-onset dystonia, whereas, if symptoms begin after 26 years of age, dystonia is classified as lateonset dystonia. The age of onset is very important for prognosis and counseling. Earlyonset dystonia can be rapidly progressive,; it often begins in a leg and commonly spreads to involve other parts of the body. In contrast, late-onset dystonia often remains focallydistributed.

Dystonia can also be classified following the topographic distribution of the affected region. The term "focal" is applied when only a single body part is affected. More specific terms are also used to describe focal dystonias which affect a single body part, such as blepharospasm (eyes), cervical dystonia (neck, also called torticollis), or laryngeal dystonia (larynx, also called spasmodic dysphonia). When two or more contiguous body parts are involved, it is called segmental dystonia; for example, cranialcervical dystonia, crural dystonia, or brachial dystonia. In multifocal dystonia, two or more noncontiguous body parts are involved. Generalized dystonia refers to dystonia, which involves the legs, or one leg and the trunk, in addition to one other area of the body. The term "hemidystonia" is used to denote involvement of the arm and leg on the same side of the body.

Etiologically, dystonia is classified as primary, dystonia-plus, heredodegenerative and secondary. Primary dystonia includes syndromes in which dystonia is the sole phenotypic manifestation with the exception that tremor can be present as well. The "dystonia-plus" category includes syndromes with other neurological manifestations in which no evidence of neurodegeneration has been identified, such as dopa-responsive dystonia, and myoclonus-dystonia. Heredodegenerative dystonia includes syndromes in which dystonia occurs in the setting of neurodegenerative diseases such as Parkinson's disease, multiple system atrophy, and Huntington's disease. Secondary dystonia includes syndromes in which dystonia is the manifestation of a structural or metabolic abnormality of the brain or peripheral nervous system. Secondary dystonia can be associated with strokes, brain tumors, neurotoxins, infectious (e.g., human immunodeficiency virus), and demyelinating disorders (e.g., multiple sclerosis, and neoplasic diseases).

\subsubsection{Genetics and Dystonia}

Over 16 forms of hereditary dystonia (DYT1-16; Table 1-1) have been described to date (Klein and Ozelius, 2002; Nemeth, 2002; Breakefield et al., 2008). Within those 16 hereditary disorders included in the DYT classification scheme, only DYT1, DYT2, DYT4, DYT6, DYT7, and DYT13 are genuine subtypes of primary dystonia. DYT1, DYT2, DYT4, and DYT6 often begin focally prior to generalization. However, DYT7 and DYT13 typically persist as focal dystonias. DYT5, DYT11, DYT12, DYT14, DYT15, and DYT16 belong to dystonia-plus family, because additional neurological features are present in addition to dystonia. For example, DYT5, DYT12, and DYT16 frequently exhibit Parkinsonism, and DYT11 and DYT15 often present with myoclonus. 
Table 1-1. Molecular classification of dystonia.

\begin{tabular}{|c|c|c|c|c|c|c|c|}
\hline Locus & Designation & ОМIM & $\begin{array}{c}\text { Chromosomal } \\
\text { location }\end{array}$ & Gene & $\begin{array}{c}\text { Mode of } \\
\text { inheritance }\end{array}$ & Clinical characteristics & Reference \\
\hline DYT1 & $\begin{array}{l}\text { Dystonia 1; early-onset primary } \\
\text { dystonia; Oppenheim's dystonia }\end{array}$ & 128100 & $9 q 32-34$ & TorsinA (TOR1A) & $\begin{array}{l}\mathrm{AD} \text {, incomplete } \\
\text { penetrance }\end{array}$ & $\begin{array}{l}\text { Early-onset generalized, usually starts in a } \\
\text { limb }\end{array}$ & $\begin{array}{l}\text { Ozelius et al., } \\
1997\end{array}$ \\
\hline DYT2 & Dystonia 2 ; autosomal recessive & 224500 & Unknown & Unknown & AR & Early-onset, generalized or segmental & Zlotogora, 2004 \\
\hline DYT3 & $\begin{array}{l}\text { Dystonia 3; X-linked dystonia- } \\
\text { parkinsonism; 'lubag' }\end{array}$ & 314250 & $\mathrm{Xq} 13.1$ & $\begin{array}{l}\text { TATA-binding } \\
\text { protein-associated } \\
\text { factor-1 (TAF1) }\end{array}$ & $\mathrm{XR}$ & $\begin{array}{l}\text { Only discriped in individuals from } \\
\text { Philipines; usually male; Segmental or } \\
\text { generalized dystonia with parkinsonism } \\
\text { unresponsive to L-dopa; progressive } \\
\text { neurodegenerative syndrome }\end{array}$ & $\begin{array}{l}\text { Makino et al., } \\
2007\end{array}$ \\
\hline DYT4 & Dystonia 4; "non-DYT1" & 128101 & Unknown & Unknown & $\mathrm{AD}$ & $\begin{array}{l}\text { Single large Australian family; laryngeal } \\
\text { and cervical dystonia }\end{array}$ & $\begin{array}{l}\text { Ahmad et al., } \\
1993\end{array}$ \\
\hline $\begin{array}{l}\text { DYT5 } \\
\text { GCH1 }\end{array}$ & $\begin{array}{l}\text { Dystonia 5; dopa-responsive } \\
\text { dystonia-parkinsonism }\end{array}$ & 128230 & $\begin{array}{l}14 \mathrm{q} 22.1- \\
\mathrm{q} 22.2\end{array}$ & $\begin{array}{l}\text { GTP } \\
\text { cyclohydrolase I } \\
\text { (GCH1) }\end{array}$ & $\begin{array}{l}\mathrm{AD} \text {, incomplete } \\
\text { penetrance }\end{array}$ & $\begin{array}{l}\text { Dystonia with concurrent or subsequent } \\
\text { parkinsonism, diurnal worsening of } \\
\text { symptoms and a dramatic response to L- } \\
\text { dopa }\end{array}$ & $\begin{array}{l}\text { Ichinose et al., } \\
1994\end{array}$ \\
\hline $\begin{array}{l}\text { DYT5 } \\
\text { TH }\end{array}$ & Segawa syndrome & 191290 & $11 \mathrm{p} 15.5$ & $\begin{array}{l}\text { Tyrosine } \\
\text { hydroxylase }\end{array}$ & AR & Same as DYT5/GCH1 & $\begin{array}{l}\text { Ludecke et al., } \\
1995\end{array}$ \\
\hline DYT6 & $\begin{array}{l}\text { Dystonia 6; adolescent-onset of } \\
\text { mixed type }\end{array}$ & 602629 & $8 \mathrm{p} 21-\mathrm{q} 22$ & Unknown & $\mathrm{AD}$ & $\begin{array}{l}\text { Adolescent-onset, mostly segmental PTD, } \\
\text { rarely generalizes }\end{array}$ & $\begin{array}{l}\text { Almasy et al., } \\
1997\end{array}$ \\
\hline DYT7 & Dystonia 7; adult-onset focal & 602124 & $18 \mathrm{p} 11.3$ & Unknown & $\begin{array}{l}\mathrm{AD} \text {, incomplete } \\
\text { penetrance }\end{array}$ & $\begin{array}{l}\text { Adult-onset focal dystonia (torticollis, } \\
\text { writer's cramp, dysphonia, or } \\
\text { blepharospasm) }\end{array}$ & $\begin{array}{l}\text { Leube et al., } \\
1996\end{array}$ \\
\hline DYT8 & $\begin{array}{l}\text { Dystonia } 8 \text {; paroxysmal dystonic } \\
\text { choreoathetosis; paroxysmal } \\
\text { non-kinesigenic dyskinesia }\end{array}$ & 118800 & $2 q 35$ & $\begin{array}{l}\text { Myofibrillogenesis } \\
\text { regulator-1 (M } \\
\text { R1) }\end{array}$ & $\begin{array}{l}\mathrm{AD} \text {, incomplete } \\
\text { penetrance }\end{array}$ & $\begin{array}{l}\text { Attacks of dystonia/choreoathetosis, } \\
\text { precipitated by stress, fatigue, alcohol, and } \\
\text { chocolate }\end{array}$ & $\begin{array}{l}\text { Rainier et al., } \\
2004 \text {; } \\
\text { Djarmati et al., } \\
2005\end{array}$ \\
\hline DYT9 & $\begin{array}{l}\text { Dystonia } 9 \text {; paroxysmal } \\
\text { choreoathetosis with episodic } \\
\text { ataxia and spasticity }\end{array}$ & 601042 & $1 \mathrm{p} 21-\mathrm{p} 13.3$ & Unknown & $\mathrm{AD}$ & $\begin{array}{l}\text { Attacks of dystonia, parasthesias, double } \\
\text { vision, precipitated by exercise, stress, and } \\
\text { alcohol; spastic paraplegia between attacks }\end{array}$ & $\begin{array}{l}\text { Auburger et al., } \\
1996\end{array}$ \\
\hline DYT10 & $\begin{array}{l}\text { Dystonia 10; paroxysmal } \\
\text { kinesigenic choreoathetosis }\end{array}$ & 128200 & $16 \mathrm{p} 11.2-\mathrm{q} 12.1$ & Unknown & $\begin{array}{l}\mathrm{AD} \text {, incomplete } \\
\text { penetrance }\end{array}$ & $\begin{array}{l}\text { Attacks of dystonia/choreoathetosis, } \\
\text { brought on by sudden movements; respond } \\
\text { to anticonvulsant therapy }\end{array}$ & $\begin{array}{l}\text { Tomita et al., } \\
1999\end{array}$ \\
\hline
\end{tabular}


Table 1-1. (Continued).

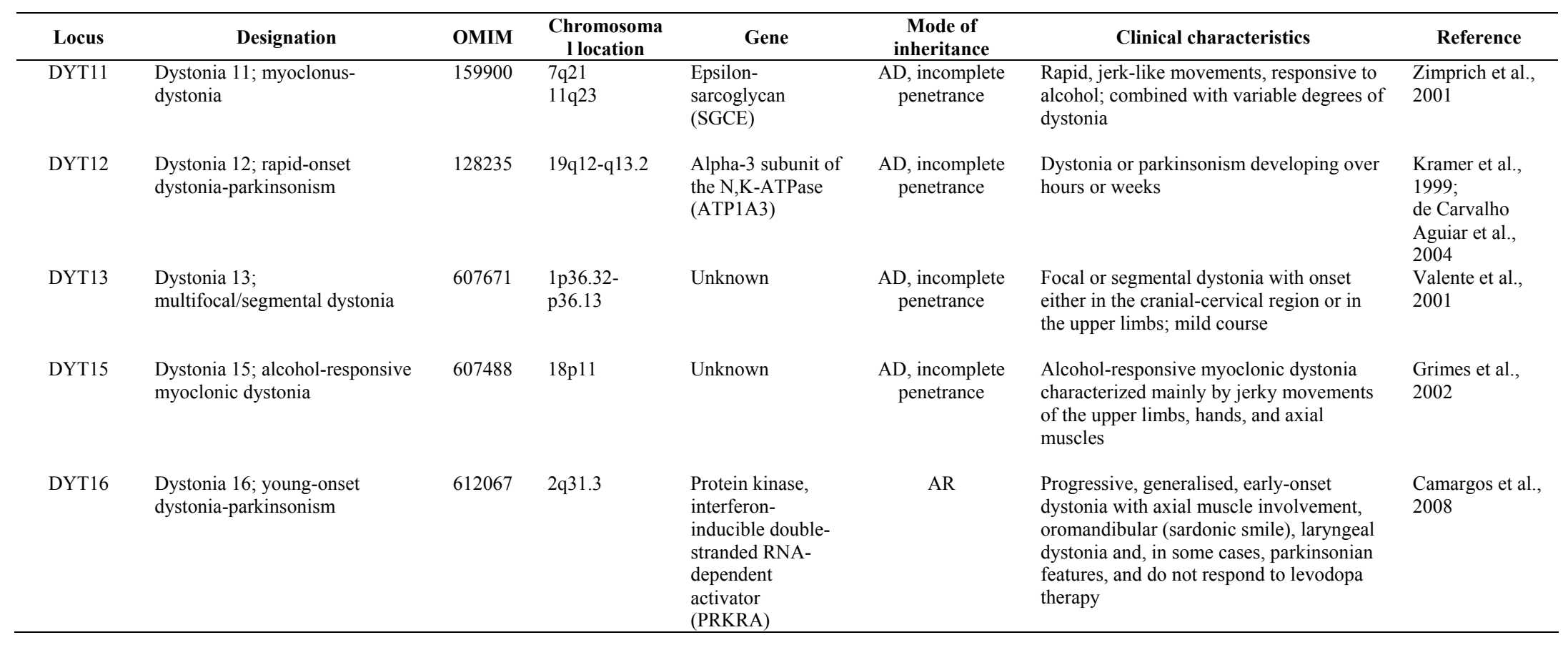

Notes: AD, autosomal dominant; AR, autosomal recessive; PTD, primary torsion dystonia; XR, X-linked recessive.

Modified with permission. Klein C, Ozelius LJ (2002) Dystonia: clinical features, genetics, and treatment. Curr Opin Neurol 15(4): 491-497. 
DYT3 is classified as a heredodegenerative dystonia, because post-mortem histological analysis has shown neuronal loss and astrocytosis in the striatum. DYT8, DYT9, and DYT10 are paroxysmal dystonias that are triggered by stress, drugs, exercise, or sudden movements.

Most of the hereditary dystonias are inherited in the autosomal dominant (AD) mode with incomplete penetrance. The low penetrance of many of the hereditary dystonias suggests that other genetic traits or environment factors might play a role in their onset.

To date, eight genes, mutations of which are responsible for the onset of inherited form of dystonia, have been identified: (1) DYT1 (Oppenheim's dystonia, OMIM 128100) due to mutation in TOR $1 A$ that encodes torsinA (Ozelius et al., 1997); (2) DYT3 (Lubag, OMIM 314250) due to insertion mutations in TATA-binding protein-associated factor 1 (TAF1) located on chromosome Xq13.1 (Makino et al., 2007); (3) DYT5 (doparesponsive dystonia, OMIM 128230) autosomal dominant form caused by mutations in the gene for guanosine triphosphate cyclohydrolase I (GCH1)(Nygaard et al., 1993; Ichinose et al., 1994), (4) autosomal recessive form caused by a mutation in tyrosine hydroxylase (TH)(Lüdecke et al., 1995); (5) DYT8 (paroxysmal non-kinesigenic dyskinesia, OMIM 118800) secondary to missense mutations in the myofibrillogenesis regulator 1 (MR-1)(Rainier et al., 2004; Djarmati et al., 2005); (6) DYT11 (myoclonusdystonia syndrome, OMIM 159900) secondary to mutations that lead to a truncation of the membrane glycoprotein $\varepsilon$-sarcoglycan (SGCE)(Zimprich et al., 2001); (7) DYT12 (rapid-onset dystonia-parkinsonism, OMIM 128235) caused by mutations in the gene that encodes the $\alpha-3$ subunit of the $\mathrm{Na}^{+} / \mathrm{K}^{+}$ATPase (ATP1A3)(de Carvalho Aguiar et al., 2004); and (8) DYT16 (young-onset dystonia-parkinsonism, OMIM 612067) due to a mutation in the stress-response gene PRKRA, which encodes the protein kinase, interferon-inducible double-stranded RNA-dependent activator (Camargos et al., 2008).

\subsection{DYT1 DYSTONIA}

Ozelius and colleagues (1997) identified gene TORIA in chromosome 9q32-9q34. A 3-bp deletion (GAG) in Exon 5 of TOR1A is associated with the majority of the cases of early-onset primary generalized dystonia. Some cases are clearly familial, whereas others appear sporadic. TOR $1 A$ is expressed ubiquitously in human tissues, and encodes a protein named torsinA. The GAG deletion mutation results in the loss of a glutamic acid in the carboxy terminus of torsinA (Ozelius et al., 1997; 1999). DYT1 dystonia is an uncommon disorder. The prevalence of the DYT1 GAG deletion has been reported to be 0.3 to 0.5 per 100,000 in the general population of Europe. However, in Ashkenazi Jews, the frequency is much higher, around 1 per 2,000 to 6,000 (Kamm, 2006).

DYT1 dystonia is a severe hereditary form of early-onset primary generalized dystonia. It is an autosomal dominant disease with less than $40 \%$ penetrance. The onset of dystonia usually appears between 5 to 26 years of age. Onset before 4 years or after 28 years is rare. Generally, the symptoms usually develop first in the legs as focal limb 
dystonia, and typically generalize within 5 years (Bressman et al., 1998; 2000).

However, variable phenotypic expressions have also been reported. Grundmann and colleagues (2003) screened a moderately large cohort of German dystonia patients with a GAG deletion in TOR $1 A$ and evaluated the dystonic phenotypic expression in DYT1 carriers, and found that 6 out of 256 patients were DYT 1 haplotype carriers. Two of the patients expressed the classic phenotype of early-onset primary generalized dystonia, two expressed multifocal dystonia, and the remaining two subjects presented with writer's cramp, and showed only slight progression over several years.

The pathophysiology of DYT1 dystonia is not well understood. Postmortem neuropathological studies of brains from subjects with primary dystonia failed to reveal any consistent evidence of neuronal loss, inflammation, or neurodegeneration. These findings suggest that functional and/or ultrastructural abnormalities, rather than neurodegeneration, underlie dystonic symptoms (Rostasy et al., 2003).

\subsubsection{Neuropathology in DYT1 Dystonia}

Zweig (1988) have examined brain tissues from two cases of early-onset primary generalized dystonia. They found neurofibrillary tangles in several brainstem nuclei such as locus ceruleus (LC), substantia nigra pars compacta (SNpc), pedunculopontine nucleus (PPN), and dorsal raphe (RMg) nucleus, and a mild neuronal loss within the LC in one case. However, they did not reveal consistent findings in the other case. Hornykiewicz and colleagues (1986) also reported that they did not find important histological changes in the basal ganglia, cerebral cortex, and some of the tested brainstem nuclei in two cases of early-onset primary generalized dystonia. Rostasy and colleagues (2003) carefully examined striatum, cerebellum, hippocampal formation, and SN of post-mortem brain tissues from three manifesting DYT1 carriers, three non-DYT1 dystonic patients, and eleven controls. They did not reveal any disease-specific evidence of gliosis and apoptosis. They did not detect cytoplasmic inclusion bodies in neurons in all brain tissues tested from dystonia patients. However, they noticed larger nigral dopaminergic neurons in all dystonia brains, and more closely spaced neurons in SN in manifesting DYT1 carriers. McNaught and colleagues (2004) later reported evidence of perinuclear inclusion bodies in some of the neurons in PPN, the cuneiform nucleus and periaqueductal gray (PAG), but not in the SNpc, striatum, hippocampus, and neocortex in four manifesting DYT1 carriers tested. These multifarious findings suggest that functional and/or ultrastructural abnormalities rather than neurodegeneration underlie DYT1 dystonia.

\subsubsection{Neurochemical Studies in DYT1 Dystonia}

Several groups have studied the neurochemical changes in DYT1 dystonia and have generated diverse findings. Hornykiewicz and colleagues (1986) reported norepinephrine (NE) and serotonin (5-HT) level changes in several brain regions in two cases of early-onset primary generalized dystonia, with decreased dopamine (DA) levels 
in striatum in one case. Furukawa and colleagues (2000) noticed the attenuated striatal DA levels ( $50 \%$ to $54 \%$ of control means) in the rostral putamen and caudate nucleus in one case of DYT1 dystonia. Augood and colleagues (2002) reported significantly increased striatal 3,4-dihydroxyphenylacetic acid (DOPAC)/DA, and a trend towards reduced striatal D1 and D2 receptor binding in three cases of DYT1 dystonia compared to three controls. Asanuma and colleagues (2005) studied nine non-manifesting DYT1 carriers and found that attenuated D2 receptor binding ( $85 \%$ of control) was a trait of the DYT1 genotype. These various investigations indicate that imbalances in nigrostriatal neurochemical signaling may contribute to disease manifestations in DTY1 dystonia.

\subsubsection{Neuroimaging Studies in DYT1 Dystonia}

Neuroimaging studies of DYT1 dystonia include metabolic and structural approaches. In the metabolic studies, hyperactivity has been reported in several brain regions in DYT1 carriers. Eidelberg and colleagues (1998) identified brain metabolic activity changes in DYT1 carriers with [18F] fluorodeoxyglucose (FDG) and positron emission tomography (PET). Those changes include genotype-related hyperactivity in lentiform nuclei, cerebellum, and supplementary motor areas (SMA), and syndromerelated hyperactivity in the midbrain, cerebellum, and thalamus. Ghilardi and colleague (2003) reported brain functional abnormalities during task performance by using $\mathrm{H}_{2}{ }^{15} \mathrm{O}$ PET. They found an increased activation in the left premotor cortex and right SMA, and an attenuated activation in the posterior medial cerebellum in DYT1 carriers during motor performance as well as an increased activation in the left ventral prefrontal cortex and lateral cerebellum in DYT1 carriers during sequence learning. Carbon and colleagues (2004a) reported syndrome-related hyperactivity in the presupplementary motor area (Brodmann area [BA] 6) and parietal association cortices bilaterally (BA 40/7), and genotype-related hyperactivity in the putamen, anterior cingulate (BA 24/32), and cerebellar hemispheres in DYT1 carriers with [18F] FDG PET.

In neurostructural studies, Carbon and colleagues (2004b; 2008a) noticed decreased fractional anisotropy (FA) in several brain regions in DYT1 carriers with diffusion tensor magnetic resonance imaging (DTI), that is a marker of axonal disintegrity. Those decreased fractional anisotropy included syndrome-related decrease in the left dorsal pontine brainstem and in the white matter of the sensorimotor cortex bilaterally, and genotype-related decrease in the white matter of the sensorimotor cortex in DYT1 carriers.

In aggregate, work to date in humans indicates DYT1 dystonia is due to functional and/or ultrastructural abnormalities of the brain rather than neurodegeneration.. 


\subsection{TORSINA}

TorsinA is the protein encoded by TOR1A. The dystonia-related GAG deletion results in the loss of a glutamic acid in the carboxy terminal (Ozelius et al., 1997; 1999). The molecular and cellular functions of torsinA are essential but not well understood. From the amino acid sequence, torsinA belongs to ATPases associated with a variety of cellular activities (AAA+) superfamily (Ozelius et al., 1997; 1999). TorsinA possesses an $\mathrm{N}$-terminal signal sequence, a single AAA + module, and two biochemically-confirmed glycosylation sites (Figure 1-1). The AAA+ module contains four conserved motifs: a Walker A motif that regulates nucleotide binding; a Walker B motif that is crucial for ATPase activity; a sensor 1 that is critical for nucleotide hydrolysis; and sensor 2 that is essential for nucleotide binding and hydrolysis(Ozelius et al., 1997; Neuwald et al., 1999; Ozelius et al., 1999; Joshi et al., 2003; Kamm et al., 2004; Hanson and Whiteheart, 2005; Callan et al., 2007). Unlike the other three motifs, which are very conserved and play similar functions between AAA+ proteins, sensor 2 determines the specificity of the protein (Joshi et al., 2003). Sensor 2 is also a very important domain to regulate subunit and/or substrate conformational changes. It's a function-determined domain for AAA+ proteins because $\mathrm{AAA}+$ proteins assemble into hexamers to function, and the most essential function is to regulate conformational changes of the substrates (Neuwald et al., 1999; Joshi et al., 2003; Hanson and Whiteheart, 2005). Members of the AAA+ family function as molecular chaperones for protein quality control (protein complex assembly, operation, disassembly, protein folding, unfolding, and degradation), membrane fusion and vesicular transport, and cytoskeletal regulation (Neuwald et al., 1999; Vale, 2000; Ogura and Wilkinson, 2001), all of these activities might provide insight regarding the function of torsinA.

TorsinA is an endoplasmic reticulum (ER)-resident glycoprotein (Hewett et al., 2003; Kuner et al., 2003; Liu et al., 2003; Callan et al., 2007). Strong torsinAimmunoreactivity (IR) is located diffusely in the cytoplasm of neurons that extends throughout neurites to synapses (Konakova et al., 2001; Konakova and Pulst, 2001; Augood et al., 2003; Kuner et al., 2003; Kamm et al., 2004). When overexpressed in cultured cells, mutant torsinA is enriched at the nuclear envelope (Goodchild and Dauer, 2004; Naismith et al., 2004).

In normal brain, torsinA-IR is widely distributed in all anatomical structures with intense IR detected in pyramidal neurons in neocortex, cholinergic interneurons in striatum, pyramidal neurons in hippocampus, motor neurons in the trigeminal nuclei, and dopaminergic neurons in the SNpc (Shashidharan et al., 2000a; Konakova and Pulst, 2001; Xiao et al., 2004). In rat brain, torsinA-IR is present in the cytoplasm, dendrites and axons but not in nuclei (Xiao et al., 2004).

TorsinA might function as a chaperone for unfolded or degraded proteins, and might facilitate movement of polytopic proteins to the cell surface (Torres et al., 2004). TorsinA has been localized to protein aggregations such as Lewy bodies in Parkinson's disease brain and inclusion bodies in trinucleotide repeat diseases, and its overexpression 


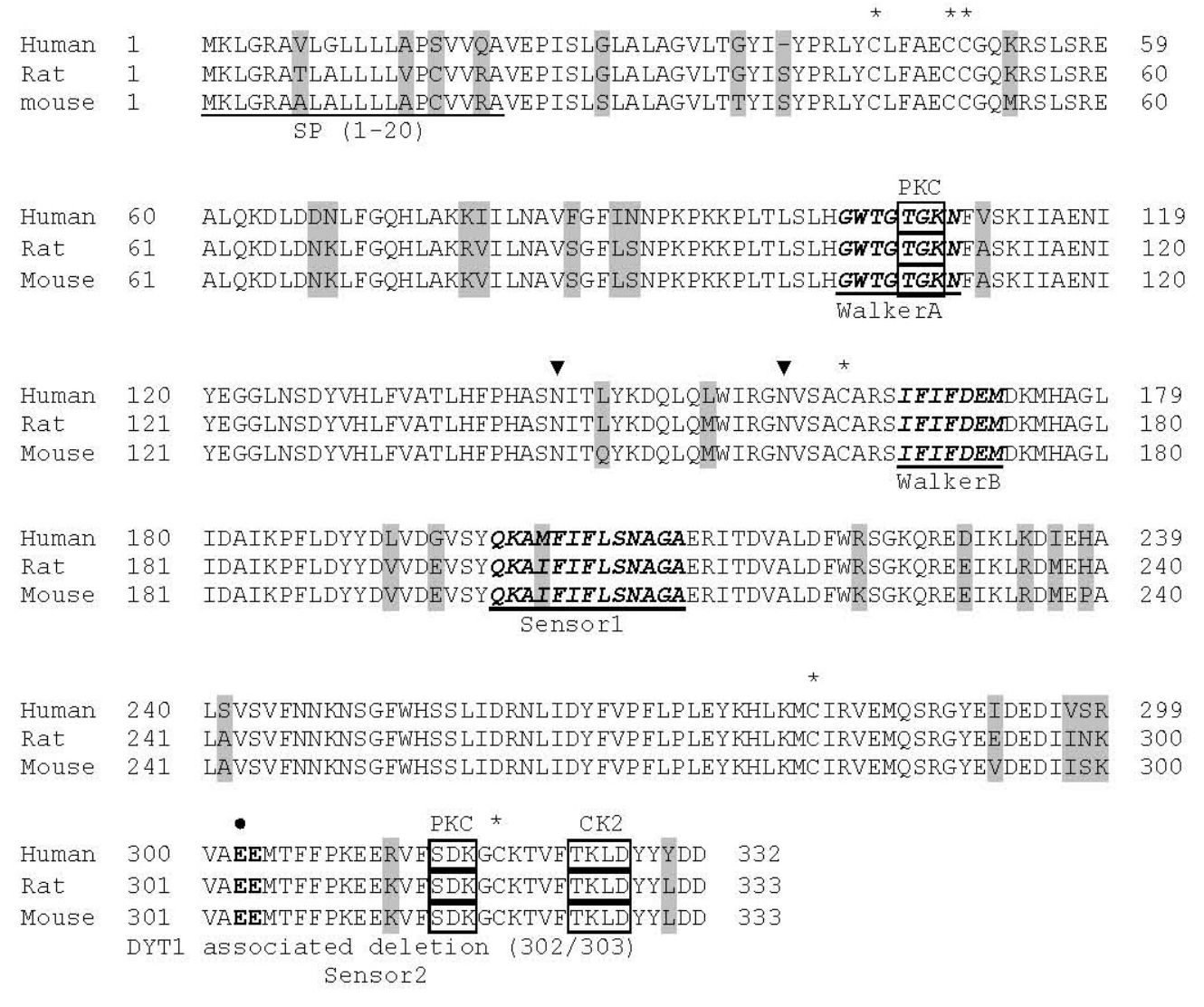

Figure 1-1. Alignment of human, rat, and mouse torsin $A$ amino-acid sequences.

Sequence disparities are shaded. The N-terminus of torsinA contains a 20-aa hydrophobic signal sequence (underlined), a AAA + module, two biochemically-confirmed glycosylation sites (N143, N158; solid triangle) and six conserved cysteine residues (C44, C49, C50, C162, C280, C319; asterisk). The AAA+ module includes four conserved motifs (walkerA, walkerB, sensor1, sensor2; bold italic and underlined). The site of GAG (E) deletion is presented bold and marked as solid circle. The possible phosphorylation sites for protein kinase $\mathrm{C}(\mathrm{PKC})$ and casein kinase 2(CK2) are boxed. 
facilitates the clearance of those protein aggregates (Shashidharan et al., 2000b; Sharma et al., 2001; McLean et al., 2002; Caldwell et al., 2003; Walker et al., 2003). TorsinA was found to interact with kinesin light chain 1 (KLC1) in a yeast two-hybrid study (Kamm et al., 2004). KLC1 is part of the heterotetrameric motor protein kinesin-I, and is thought to be involved in cargo binding and/or kinesin-I activity regulation (Kamal and Goldstein, 2002). TorsinA was also shown to modulate the cellular trafficking of the dopamine transporter (Torres et al., 2004; Cao et al., 2005), as well as other membranebound proteins, including $\mathrm{G}$ protein-coupled receptors, transporters, and ion channels (Torres et al., 2004). In addition, overexpression of torsinA facilitates the clearance of another dystonia-related protein, SGCE, by the ubiquitin proteosome system, and protects PC12 cells against a variety of cellular insults, including serum deprivation and oxidative stress (Kuner et al., 2003; Shashidharan et al., 2004; Esapa et al., 2007). Similarly, overexpression of torsinA protects dopamine neurons from oxidative stress in C. elegans (Cao et al., 2005). In a mammalian model, torsinA expression was up-regulated after oxidative stress in dopamine neurons in vivo (Kuner et al., 2004).

The chaperone function(s) of torsinA might include maintenance of cellular polarity and regulation of neurite extension by interactions with the cytoskeleton. Support for this hypothesis derives from several fronts. First, in vitro research has shown that torsinA-IR was localized to filopodia in cultured cells, whereas torsinA-IR has been detected in synapses in brain tissues (Konakova et al., 2001; Konakova and Pulst, 2001; Augood et al., 2003; Kamm et al., 2004). TorsinA was also confirmed to localize with microtubules and to co-immunoprecipitate with microtubule-associated protein tau (Ferrari-Toninelli et al., 2003; 2004; Hewett et al., 2006). Next, overexpression of mutant torsin A inhibited neurite extension; however, attenuation of wild-type torsinA facilitated neurite extension in SH-SY5Y cells (Ferrari-Toninelli et al., 2004; Hewett et al., 2006). TorsinA is critical for postnatal neurodevelopment. The expression of torsinA is striking in the prenatal and early postnatal period, with a most intense expression in cerebellum and cholinergic interneurons in striatum at postnatal day 14 (Xiao et al., 2004), which is a period of intense cellular migration, neurite extension, and synaptogenesis. TorsinA knock-out and homozygous $\triangle \mathrm{GAG}$ knock-in mice die shortly after birth (Goodchild et al., 2005). In aggregate, these studies suggest that torsinA might play an important role to regulate and maintain an anatomically or structurally precise neurite orientation.

TorsinA might also play a role to maintain nuclear envelope architecture and positioning. First of all, mutant torsinA tends to accumulate in the lumen of the nuclear envelope; however, wild-type torsinA is predisposed to stay in the lumen of ER (Goodchild and Dauer, 2005; Hewett et al., 2006; 2007; Nery et al., 2007). Next, torsinA interacts with lamin-associated polypeptide 1 (LAP1) in the nuclear envelope and lumenal domain-like LAP1 (LULL1) in the endoplasmic reticulum (Goodchild and Dauer, 2005). In a more recent work, torsinA was found to localize to a protein complex that contained several cytoskeletal complexes including motor protein kinesin light chain, LAP1, LULL1, plectin, and nesprin (Hewett et al., 2006; Nery et al., 2007). Plectin is an anchoring protein that associates with all three major components of the cytoskeleton for cross-linking (Liu et al., 1996). Nesprin is the outer nuclear membrane protein that 
interacts with cytoskeleton elements or the linker protein plectin (Wilhelmsen et al., 2005). The coordinated function of cytoskeletal and nuclear envelope proteins is very important for nuclear positioning and cell migration. TorsinA knock-out and homozygous $\triangle$ GAG knock-in mice develop blebs in the nuclear envelope, which protrude from the inner nuclear membrane (Goodchild et al., 2005). Furthermore, OOC5, a torsinA homologue in C. elegans, plays an essential role in PAR protein localization. The PAR family of proteins is essential for cellular polarity and partition establishment, and localization. Mutations of ooc-5 result in an abnormal nuclear rotation and polarity in C. elegans embryos (Basham and Rose, 1999; 2001).

Recent studies point out a critical role for torsin A in regulating protein secretion and synaptic vesicle recycling. Hewett and colleagues $(2007 ; 2008)$ reported that protein secretion processes were compromised in fibroblasts from DYT1 patients, and that attenuation of mutant torsinA expression restored protein secretion in DYT1 fibroblasts. In closely related work, Granata and colleagues (2008) found that an overexpression of wild-type torsinA attenuated synaptic vesicle recycling, whereas an overexpression of $\Delta \mathrm{E}$-torsin $\mathrm{A}$ intensified synaptic vesicle recycling at the expense of specificity.

TorsinA has a highly homologous family member torsinB, which is encoded by TOR1B located adjacent to TOR $1 A$ on human chromosome 9q34 (Hewett et al., 2004). TorsinB shares $61 \%$ amino acid identity with torsinA. Like torsinA, torsinB also harbors a AAA+ domain along with several glycosylation and phosphorylation sites (Hewett et al., 2004; O'Farrell et al., 2004). TorsinB is expressed in the neurons and is enriched at the nuclear envelope (Hewett et al., 2004; O'Farrell et al., 2004). In immunoprecipitation studies, torsinB was found to be associated with torsin A (Hewett et al., 2004), which suggested the possibility that torsinA and torsinB interact at a functional level. However, the developmental expression patterns of these two proteins are divergent with striking expression of torsinA during the prenatal and early postnatal periods, and prominent expression of torsinB during late the postnatal period and adulthood (Vasudevan et al., 2006). In summary, although torsinA and torsinB exhibit important structural similarities, torsinB can not completely compensate for the loss of torsinA since DYT1 knock-out mice die shortly after birth (Goodchild et al., 2005).

Although various studies have been done to disclose the function of torsinA, and a heterogeneous function of torsin $\mathrm{A}$ has been reported, the systems biology of torsin $\mathrm{A}$, and the causal effect of mutant torsinA to dystonia, are still unclear. Genetically modified animal models are useful tools to investigate the contributing effects of mutant torsinA to the onset of DYT1 dystonia and to open the door for future studies.

\section{$1.4 \quad$ ANIMAL MODELS OF DYT1 DYSTONIA}

Several murine models of DYT1 dystonia have been developed, and characterized to various degrees (Dang et al., 2005; Goodchild et al., 2005; Sharma et al., 2005; Shashidharan et al., 2005; Dang et al., 2006; Grundmann et al., 2007; Yokoi et al., 2008). These models include DYT1 knock-out (Goodchild et al., 2005), cortex-specific DYT1 
knock-out (Yokoi et al., 2008), torsinA knock-down (Dang et al., 2006), transgenic overexpression of mutant and wild-type torsinA (Sharma et al., 2005; Shashidharan et al., 2005; Grundmann et al., 2007), and DYT1 $\Delta$ GAG knock-in (Dang et al., 2005; Goodchild et al., 2005) mouse models. In the DYT1 $\triangle$ GAG knock-in mouse model, a GAA trinucleotide deletion was made to mimic the GAG deletion in human DYT1 mutation, which was supposed to encode one of the glutamic acids at the position corresponding to human E302/303. In addition, the expression of the DYT1 $\Delta$ GAG transcript was confirmed with RT-PCR and sequencing.

Whereas common features exist among some of these models, inconsistent findings have been noticed (Table 1-2). In addition, a comprehensive behavioral, neurochemical, and brain metabolical evaluation are needed for all the models. TOR $1 A$ knock-out and homozygous TORIA $\triangle$ GAG knock-in are embryonically or early postnatally lethal (Dang et al., 2005; Goodchild et al., 2005); morphological studies of these mice revealed neuronal-specific nuclear envelope vesicles, which appeared to derive from the inner nuclear membrane. Dang and colleagues (2005) evaluated the behavioral, morphological, and neurochemical features of heterozygous $\Delta$ GAG knock-in mice. They discovered abnormal motor behaviors in 6-month old male heterozygous $\triangle$ GAG knock-in mice, including horizontal hyperactivity in the open-field test, increased slips on the beam-walking test, and increased overlap in the foot-print analysis. They also noticed ubiquitin- and torsinA-positive aggregates in neurons of the pontine nuclei and attenuated striatal homovanillic acid (HVA) levels in male heterozygous $\triangle \mathrm{GAG}$ knock-in mice. In the DYT1 knock-down model, motor deficits such as horizontal hyperactivity and increased slips on the beam-walking test were also noticed with reduced striatal DOPAC in a neurochemical study (Dang et al., 2006). These findings suggest that torsin $\mathrm{A}$ is an essential protein for postnatal survival, and that $\Delta \mathrm{GAG}$ is a loss of function mutation. In a more recent study, similar motor deficits were reported in a cortex-specific DYT1 knock-out model (Yokoi et al., 2008). The authors suggest that loss of torsinA in the cerebral cortex alone is sufficient to mimic behavioral deficits noticed in heterozygous $\Delta$ GAG knock-in and DYT1 knock-down mice.

Transgenic models of DYT1 dystonia have been developed by Sharma et al. (2005), Shashidharan et al. (2005), and Grundmann et al. (2007). Shashidharan and colleagues (2005) reported that $40 \%$ of their $\triangle \mathrm{GAG}$ transgenic mice displayed dystonic movements of the limbs with self-clasping, circling behavior, and hyperactivity. They also found ubiquitin- and torsinA-positive inclusions in the PPN, pons, and PAG, and a decreased striatal DOPAC/DA ratio in $\triangle \mathrm{GAG}$ transgenic mice with a decreased striatal DA only in manifesting transgenic mice. The $\triangle \mathrm{GAG}$ transgenic mice developed by Sharma and colleagues (2005) showed a reduced ability to learn motor skills in an accelerating rotarod paradigm at six months of age, as well as abnormal dopaminergic D2 receptor responses in striatal cholinergic interneurons (Pisani et al., 2006) and an attenuated amphetamine-induced striatal DA release (Balcioglu et al., 2007). In a more recent study, Grundmann and colleagues (2007) generated another DYT1 transgenic model, in which torsin A expression was driven by a murine prion protein promoter. They found behavioral, morphological, and neurochemical abnormalities in $\triangle \mathrm{GAG}$ transgenic mice (GAG3, a $\mathrm{h} \Delta \mathrm{GAG}$ transgenic line) and wild-type transgenic mice 
Table 1-2. Murine DYT1 models.

\begin{tabular}{|c|c|c|c|c|}
\hline Model & Molecular construct & Morphology & Behavior & Neurochemistry \\
\hline $\begin{array}{l}\text { DYT1 transgenic } \\
\text { (Shashidharan et al., } \\
\text { 2005) }\end{array}$ & $\begin{array}{l}7.1 \mathrm{~kb} \text { fragment from the } \\
\text { pNSE-Ex } 4 \text { vector containing the } \\
\text { neuron specific enolase promoter, } \\
\text { human mutant ( } \triangle \text { GAG) torsinA- } \\
\text { cDNA and SV } 40 \text { polyA signal }\end{array}$ & $\begin{array}{l}\text { ubiquitin- and torsinA-IR } \\
\text { perinuclear aggregates } \\
\text { and/or inclusion in the } \\
\text { pedunculopontine nucleus, } \\
\text { pons \& periaqueductal } \\
\text { gray }\end{array}$ & $\begin{array}{l}40 \% \text { of transgenic mice from } \\
\text { each line displayed dystonic } \\
\text { movements of the limbs with } \\
\text { self-clasping, circling } \\
\text { behavior, \& } \\
\text { hyperactivity }\end{array}$ & $\begin{array}{l}\downarrow \text { striatal DA in } \\
\text { transgenic animals that } \\
\text { exhibited an abnormal } \\
\text { behavioral phenotype, } \downarrow \\
\text { striatal DOPAC/DA ratio } \\
\text { in all transgenic mice }\end{array}$ \\
\hline $\begin{array}{l}\text { DYT1 knock-in } \\
\text { (Dang et al., 2005) }\end{array}$ & $\begin{array}{l}\text { Exon } 5 \text { in the targeting vector } \\
\text { construct carries a GAA deletion at } \\
\text { codon } 302 \text {. The PGKNeoSTOP } \\
\text { cassette with a false translation } \\
\text { signal, splice donor site, and an } \\
\text { additional poly(A) tail was inserted } \\
\text { into intron } 4 \text {. }\end{array}$ & $\begin{array}{l}\text { ubiquitin- and torsinA- } \\
\text { containing aggregates in } \\
\text { pontine nuclei of male } \\
\text { DTY1 knock-in mice }\end{array}$ & $\begin{array}{l}\text { deficient performance on the } \\
\text { beam-walking test, open-field } \\
\text { hyperactivity }\end{array}$ & $\downarrow$ striatal HVA \\
\hline $\begin{array}{l}\text { DYT1 knock-out } \\
\text { (Goodchild et al., } \\
\text { 2005) }\end{array}$ & $\begin{array}{l}\text { Exons } 2-4 \text { of Torla were replaced } \\
\text { by a cassette containing Neo and } \\
\text { IRES-tau LacZ sequences }\end{array}$ & $\begin{array}{l}\text { vesicles within the } \\
\text { neuronal NE that appear to } \\
\text { derive from the inner } \\
\text { nuclear membrane }\end{array}$ & & \\
\hline $\begin{array}{l}\text { DYT1 knock-in } \\
\text { (Goodchild et al., } \\
\text { 2005) }\end{array}$ & $\begin{array}{l}\text { Exon } 5 \text { in the targeting construct } \\
\text { carries a GAG deletion. Neo } \\
\text { cassette was inserted into intron } 4 \\
\text { of Tor } 1 a \text {. }\end{array}$ & $\begin{array}{l}\text { homozygotes exhibit } \\
\text { vesicles within the } \\
\text { neuronal NE that appear to } \\
\text { derive from the inner } \\
\text { nuclear membrane }\end{array}$ & & \\
\hline
\end{tabular}


Table 1-2. (Continued).

\begin{tabular}{|c|c|c|c|c|}
\hline Model & Molecular construct & Morphology & Behavior & Neurochemistry \\
\hline $\begin{array}{l}\text { TOR1A knock-down } \\
\text { (Dang et al., 2006) }\end{array}$ & $\begin{array}{l}\text { PGKNeoSTOP cassette with a false } \\
\text { translation signal, splice donor site, } \\
\text { and an additional poly(A) tail was } \\
\text { inserted into intron } 4 \text { of Tor } 1 a \text { and } \\
\text { recombination occurred 5' to an } \\
\text { Exon } 5 \text { GAA deletion }\end{array}$ & & $\begin{array}{l}\text { horizontal hyperactivity, } \\
\uparrow \text { slips on a beam-walking } \\
\text { test }\end{array}$ & $\downarrow$ striatal DOPAC \\
\hline $\begin{array}{l}\text { DYT1 transgenic } \\
\text { (Grundmann et al., } \\
\text { 2007) }\end{array}$ & $\begin{array}{l}\text { human wild-type (hWT) and mutant } \\
\text { (h } \Delta \mathrm{GAG} \text { ) torsinA-cDNAs were } \\
\text { inserted into pBluescript II SK- } \\
\text { vector under the } 3.4 \mathrm{~kb} \text { fragment of } \\
\text { the murine prion protein promoter } \\
\text { and tagged C-terminally with V5- } \\
\text { His }\end{array}$ & $\begin{array}{l}\text { inclusion-like formation in } \\
\text { brainstem nuclei, torsinA- } \\
\text { IR localized to the NE, and } \\
\text { NE abnormalities in both } \\
\text { hWT and } \mathrm{h} \Delta \mathrm{GAG} \text { mice }\end{array}$ & $\begin{array}{l}\text { hWT mice: hypoactivity, } \\
\text { short stride length, prolonged } \\
\text { traversal times on beam } \\
\text { walking } \\
\mathrm{h} \Delta \mathrm{GAG} \text { mice: hyperactive, } \\
\text { defects on rotarod testing }\end{array}$ & $\begin{array}{l}\text { hWT mice: } \downarrow \text { striatal } \\
\text { DA, } 5 \text {-HT and 5-HIAA; } \\
\downarrow \text { brainstem HVA } \\
\text { h } \Delta \text { GAG mice: } \uparrow \\
\text { brainstem DOPAC, } 5 \text {-HT } \\
\text { and 5-HIAA }\end{array}$ \\
\hline $\begin{array}{l}\text { Cerebral Cortex- } \\
\text { specific DYT1 } \\
\text { Knock-out } \\
\text { (Yokoi et al., 2008) }\end{array}$ & $\begin{array}{l}\text { Exons 3-4 of Tor } 1 a \text { were deleted by } \\
\text { Emx1-cre in cerebral cortex }\end{array}$ & $\begin{array}{l}\text { reduction of torsinA-IR in } \\
\text { the cortical layers }\end{array}$ & $\begin{array}{l}\downarrow \text { hind base width in male } \\
\uparrow \text { slips on a beam-walking } \\
\text { open-field hyperactivity } \\
\text { more revolutions } \\
\text { or circling behaviors }\end{array}$ & No change \\
\hline
\end{tabular}


(WT24, a hWT transgenic line). The GAG3 mice showed deficient performance on rotarod testing and hyperactivity in open-field tests as well as inclusion bodies in brainstem nuclei and nuclear envelope vesicles in brainstem and striatum. Neurochemical analysis also revealed elevated levels of DOPAC, 5-HT, and 5hydroxyindoleacetic acid (5-HIAA) in the brainstem of GAG3 mice. The behavioral abnormalities noticed in WT24 mice included prolonged traversal times on beamwalking, shorter stride length on foot-print analysis, and hypoactivity on open-field tests. WT24 mice also exhibited inclusion bodies in brainstem nuclei and nuclear envelope vesicles in brainstem and striatum. In contrast to GAG3 mice, neurochemical studies revealed reductions in striatal DA, 5-HT, 5-HIAA, and brainstem HVA in WT24 mice.

\subsection{EXOGENOUS FACTORS}

\subsubsection{Perturbations and Secondary Dystonia}

Trauma to the central nervous system (CNS) and periphery are established causes of secondary dystonia (Schott, 1985; Lee et al., 1994; Hollinger and Burgunder, 2000; Hummel and Lucking, 2001; LeDoux and Brady, 2003). For example, Sankhla and colleagues (1998) reported that 27 out of 160 subjects with oromandibular dystonia had a history of facial trauma, oromandibular surgery, or a dental procedure. A previous history of head or face trauma with loss of consciousness occurred in $7.3 \%$ of cranial dystonia patients and $7.5 \%$ of extracranial dystonia patients in a case control study by Defazio et al. (1998). The study by Defazio and colleagues also revealed that $12 \%$ of cervical dystonia patients had a history of neck or trunk trauma, and $25 \%$ blepharospasm patients had anterior-segment ocular diseases.

Ischemic stroke is one of the more common causes of secondary dystonia (Jankovic and Van der Linden, 1988; Krystkowiak et al., 1998; Alarcon et al., 2004). Ischemic strokes that affected the striatum, globus pallidus, and thalamus have been clinically associated with the appearance of dystonic symptoms (Krystkowiak et al., 1998; LeDoux and Brady, 2003). Alarcon and colleagues (2004) did a cohort study on stroke and reported that 16 out of 1500 patients developed dystonia up to one year after either ischemic or hemorrhagic stroke.

Prescription drugs and neurotoxins are other well-known causes of secondary dystonia (Liu et al., 1992; He et al., 1995; van Harten et al., 1998; van Harten et al., 1999; Johnson et al., 2000). Neuroleptic drugs can precipitate acute dystonic reactions. The risk for neuroleptic-induced dystonia is modified by risk factors such as age, gender, and concomitant medications (Remington et al., 1990; Khanna et al., 1992; van Harten et al., 1999). In a study, cocaine was reported to be a risk factor for neuroleptic-induced dystonia (van Harten et al., 1998). A neurotoxin, 3-nitropropionic acid (3-NPA), produced by the fungus Arthrinium, often present in moldy sugarcane, was also noted to induce delayed dystonia (Liu et al., 1992; He et al., 1995; Johnson et al., 2000). Analyses of the secondary dystonias suggest that dopaminergic systems contribute to the 
pathophysiology of this movement disorder in a subset of cases. In many patients, lesions or insults involve widespread insults to the nervous system.

\subsubsection{Inciting Factors of Primary Dystonia}

Environmental factors are clearly associated with the development of primary adult-onset dystonias. Repetitive highly skilled tasks such as writing or playing a string instrument significantly increase the risk of developing task-specific focal hand dystonia (Chen and Hallett, 1998). Interestingly, scoliosis is a risk factor of cervical dystonia, possibly via compensatory alterations in head postures (Defazio et al., 2003).

Alternatively, scoliosis could simply be the manifestation of axial dystonia, which precedes the development of adult-onset cervical dystonia. Measles, mumps, or upper respiratory tract infections appear to be associated with the onset of spasmodic dysphonia (Schweinfurth et al., 2002). Defazio and colleagues (1999) also reported that prior head or face trauma with loss of consciousness was a risk factor for the spread of blepharospasm. Another group also reported that, in a cohort study of young onset primary cervical dystonia, $17.1 \%$ had been exposed to prior neck injury or surgery (Koukouni et al., 2007). Thus, acute trauma and chronic repetitive use strain might precipitate dystonia in genetically predisposed individuals.

\subsection{SIGNIFICANCE OF THE STUDY}

Although the association of the GAG deletion in TOR $1 A$ and mutant torsinA with generalized dystonia has been known for over a decade, most work with torsinA has been done in cultured cells. The systems biology of torsinA has been largely ignored. Because the DYT1 dystonia is penetrated in only 30-40\% of carriers (Ozelius et al., 1997), genetic modifiers and/or environmental factors might trigger the onset of DYT1 dystonia in genetically predisposed individuals. Relatively common perturbations (e.g., severe febrile illnesses, perinatal hypoxia, trauma, and intense sensorimotor training), which may affect either the CNS or PNS, occur with variable frequency and severity among DYT1 mutation carriers, and might trigger the onset of dystonic symptoms in perturbation-exposed DYT1 carriers. To understand the systems biology of torsinA after central and peripheral insults, we examined torsinA expression following transient forebrain ischemia and sciatic nerve transection, respectively. Our results, as described in Chapter 2, provide evidence that torsinA participates in the response of neural tissue to central and peripheral insults. By extrapolation, lower perturbation-induced expression of functional torsinA might possibly contribute to the appearance of DYT1 dystonia in mutation carriers.

The behavioral, pathological, and neurochemical consequences of mutant torsinA have not been vigorously explored in the CNS. For example, postmortem neuropathological and neurochemical studies have been limited to a few human DYT1 brains, and have not been confirmed in replicate studies (Augood et al., 2002; Rostasy et al., 2003). Due to a limited availability of human postmortem tissues, genetically 
modified animal models provide useful models to investigate and confirm findings in human patients and to open the door for future studies. In Chapter 3, transgenic mouse models that overexpress either human wild-type torsin A (hWT) or human mutant torsinA (hMT; two lines hMT1 and hMT2) were employed for behavioral, morphological, neurochemical, and metabolic examination of the DYT1 carrier state. This work is important because it identifies important regions and pathways that might be critical to the systems pathophysiology of DYT1 dystonia. On the other hand, some of the findings reported in Chapter 3 might simply be compensatory responses to the burden of mutant torsinA and the DYT1 genotype. In either case, the data presented in Chapter 3 might provide important insights into the underpinnings of DYT1 dystonia. 


\section{CHAPTER 2. TORSINA EXPRESSION AFTER NEURAL PERTURBATIONS TO THE CENTRAL AND PERIPHERAL NERVOUS SYSTEMS*}

\subsection{INTRODUCTION}

Torsin A is an ER-resident glycoprotein, in which a single glutamic acid deletion in amino acid 302/303 is associated with the development of early-onset primary generalized dystonia (Ozelius et al., 1997). The molecular and cellular functions of torsin A are essential for survial but are not well-understood. The primary amino acid sequence of torsinA placed it within the AAA + superfamily (Ozelius et al., 1997; 1999) and, as such, torsin A might function as a molecular chaperone.

A variety of studies have provided evidence that torsin $\mathrm{A}$ is a chaperone for protein quality control and protein degradation. TorsinA has been found localized with protein aggregations such as Lewy bodies and polyglutamine-containing neuronal inclusions in postmortem human brain (Shashidharan et al., 2000b; Sharma et al., 2001; Walker et al., 2003). Overexpression of torsinA suppressed the formation of protein aggregates in cellular and C. elegans models (McLean et al., 2002; Caldwell et al., 2003). Overexpression of torsinA was also found to facilitate clearance of another dystoniarelated protein, SGCE, by the ubiquitin-proteosome system (Esapa et al., 2007). Moreover, torsinA expression was up-regulated after oxidative stress in PC12 cells and dopaminergic neurons in the substantia nigra pars compacta (Hewett et al., 2003; Kuner et al., 2004). Overexpression of torsinA protects COS- 1 and PC12 cells against a variety of cellular insults (Kuner et al., 2003; Shashidharan et al., 2004). Similarly, overexpression of torsinA protects dopaminergic neurons from oxidative stress in $C$. elegans (Cao et al., 2005).

TorsinA might also modulate the cellular trafficking of polytopic proteins such as dopamine transporter (Torres et al., 2004; Cao et al., 2005), as well as other membranebound proteins, including $\mathrm{G}$ protein-coupled receptors, transporters, and ion channels (Torres et al., 2004). TorsinA might, however, play more than one role in cells. In particular, several lines of evidence suggest that torsinA might be part of the molecular machinery required to maintain nuclear envelope architecture and position, and to regulate neurite extension, protein secretion, and synaptic vesicle transport (FerrariToninelli et al., 2004; Goodchild and Dauer, 2005; Hewett et al., 2006; 2007; Granata et al., 2008; Hewett et al., 2008).

When overexpressed in cells, mutant torsinA is concentrated at the nuclear envelope and tends to form perinuclear inclusion bodies (Hewett et al., 2000; Bragg et al., 2004). Mutant torsinA has reduced ATPase activity (Konakova and Pulst, 2005; Pham et

\footnotetext{
* Permission to reproduce by International Brain Research Organization. Zhao Y, Xiao J, Ueda M, Wang Y, Hines M, Nowak TS Jr, LeDoux MS (2008) Glial elements contribute to stress-induced torsinA expression in the CNS and peripheral nervous system.

Neuroscience. 155: 439-453.
} 
al., 2006). Accordingly, loss of normal function might be one consequence of the missing glutamic acid residue in torsinA (McLean et al., 2002; Caldwell et al., 2003; Hewett et al., 2006; 2007; Granata et al., 2008; Hewett et al., 2008). However, the most deleterious result of mutant torsinA might be its dominant negative effects on wild-type torsinA (Torres et al., 2004; Cao et al., 2005; Hewett et al., 2008).

Because penetration of the DYT1 dystonia is only $30-40 \%$ (Ozelius et al., 1997), environmental factors might contribute to the onset of dystonia in genetically predisposed individuals. Trauma to the PNS and CNS (Schott, 1985; Lee et al., 1994; Sankhla et al., 1998; Hollinger and Burgunder, 2000; Hummel and Lucking, 2001), drugs (Remington et al., 1990; Khanna et al., 1992; van Harten et al., 1998; van Harten et al., 1999), neurotoxins (Liu et al., 1992; He et al., 1995; Johnson et al., 2000), and stroke (Krystkowiak et al., 1998; Alarcon et al., 2004) are known causes of secondary dystonia. Environmental factors also correlate with the onset of primary adult-onset dystonias (Chen and Hallett, 1998; Schweinfurth et al., 2002; Defazio et al., 2003). Because DYT1 mutation carriers demonstrate variable phenotypes from primary generalized dystonia to adult-onset focal dystonia, DYT1 dystonia and sporadic adult-onset dystonia may share common environmental risk factors (Leube et al., 1999; Grundmann et al., 2003). Based on this information, subclinical perturbations (e.g., fever, hypoxia, trauma, and intense sensorimotor training) to the CNS or PNS, which often occur in variable combinations and severity in DYT1 mutation carriers, might trigger the onset of early-onset generalized dystonia in perturbation-exposed carriers (Treves and Korczyn, 1986). Despite these important clinical associations, little is known about the expression and localization of torsinA after neural perturbations in vivo. Our study evaluated the temporal and spatial expression of torsinA in response to central and peripheral nervous system insults in models of transient forebrain ischemia and sciatic nerve transection, respectively. Insufficient response of functional torsinA to environment insults might contribute to the onset of DYT1 dystonia in DYT1 mutation carriers.

\subsection{METHODS}

\subsubsection{Animals}

All experiments were performed in accordance with the National Institutes of Health's Guide for the Care and Use of Laboratory Animals and with approval of the Institutional Animal Care and Use Committee. Wistar rats (Hilltop Lab Animals, Inc., Scottdale, PA, USA) were used for transient forebrain ischemia because the effects of 4vessel occlusion (4-VO) have been well characterized in animals of this source and strain (Pulsinelli and Brierley, 1979; Ueda and Nowak, 2005). The sciatic nerve transections were performed in Sprague-Dawley rats (Harlan, Indianapolis, IN, USA). 


\subsubsection{Transient Forebrain Ischemia}

Adult male Wistar rats (250 - $300 \mathrm{~g})$ were subjected to transient 4-VO ischemia (Pulsinelli and Brierley, 1979) with direct current (DC) potential monitoring as previously described (Ueda and Nowak, 2005). In brief, surgical procedures were carried out under general inhalational anesthesia with $1-2 \%$ halothane in $70 \% \mathrm{~N}_{2}$ and $30 \% \mathrm{O}_{2}$. The vertebral arteries were electrocauterized at the first cervical segment, and Silastic occluding devices were placed around the common carotid arteries. On the following day, rats were re-anesthetized and placed in a stereotaxic frame. Epidural and rectal temperatures were monitored and maintained at $37^{\circ} \mathrm{C}$. Hippocampal DC potentials were recorded with glass microelectrodes. The carotid occluding devices were tightened to produce cerebral ischemia, as verified by $10-20 \mathrm{mV}$ shifts in DC potential. All hemispheres included in these studies exhibited ischemic depolarizations of 7 - 9 min duration in hippocampus, previously shown to produce consistent loss of CA1 neurons (Ueda and Nowak, 2005). After release of occlusions, scalp incisions were closed, and rats were allowed to recover from anesthesia. Control rats underwent sham surgical procedures that included vertebral artery cauterization and electrode placement without carotid occlusion.

Brain tissues for RNA extraction and in situ hybridization were obtained at five post-ischemic survival intervals $(6 \mathrm{hr}, 24 \mathrm{hr}, 7 \mathrm{~d}, 14 \mathrm{~d}$, and $21 \mathrm{~d})$, whereas tissues for immunocytochemistry were collected at three post-ischemic survival intervals $(24 \mathrm{hr}, 7 \mathrm{~d}$, and $14 \mathrm{~d}$ ). Preparations from three ischemic and three sham control rats were obtained at each survival interval.

For RNA extraction and in situ hybridization, rats were anesthetized with 5\% halothane prior to decapitation. Brains were rapidly removed from the cranial vault and were sectioned in the mid-sagittal plane. For in situ hybridization, hemispheres were frozen in isopentane $\left(-40^{\circ} \mathrm{C}\right)$, sectioned parasagittally at $16 \mu \mathrm{m}$, and stored at $-80{ }^{\circ} \mathrm{C}$ in sealed slide boxes with desiccant capsules. For RNA extraction, cerebellum, striatum, thalamus, hippocampus, and cerebral cortex were dissected from the hemisphere, and were homogenized in RNAwiz ${ }^{\mathrm{TM}}$ (Ambion, Austin, TX, USA) on ice within 2 - 3 min after decapitation.

For immunocytochemistry, rats were overdosed with pentobarbital $(100 \mathrm{mg} / \mathrm{kg}$, intraperitoneally [IP]) prior to transcardiac perfusion with heparinized saline, and $4 \%$ paraformaldehyde/0.1 M phosphate buffer (PB). Brains were post-fixed for $2 \mathrm{hrs,}$ blocked, and incubated in a cryoprotectant solution (30\% sucrose/0.1 M PB, pH 7.4) for at least 48 hrs. Blocks were sectioned at $20 \mu \mathrm{m}$, and were collected on SuperFrost ${ }^{\circledR}$-Plus glass slides (Fisher Scientific, Pittsburgh, PA, USA).

\subsubsection{Sciatic Nerve Transection}

Three-month old male Sprague-Dawley rats (250-300 g) were subjected to left sciatic nerve transection under ketamine/xylazine $(87 / 13 \mathrm{mg} / \mathrm{kg}, \mathrm{IP})$ anesthesia. The rat 
sciatic nerve was readily identified in the posterior thigh between the vastus lateralis and caput vertebralis muscles. In each rat, the left sciatic nerve was completely transected except for the medial epineurium, which was left intact to allow for apposition of the cut ends to facilitate axonal regeneration. Wounds were closed, and animals were allowed to recover from anesthesia in individual cages. Four age-, weight- and gender-matched nonsurgical control rats were only subjected to anesthesia. Four surgical rats were employed at each of five post-transection intervals ( $24 \mathrm{hr}, 3 \mathrm{~d}, 7 \mathrm{~d}, 14 \mathrm{~d}$, and $28 \mathrm{~d}$ ). Three rats in each group were utilized for RNA extraction, and one was used for immunocytochemical examination of the dorsal root ganglia (DRG).

For RNA extraction, rats were overdosed with pentobarbital $(100 \mathrm{mg} / \mathrm{kg}$, IP) prior to transcardiac perfusion with saline and RNAlater (Ambion) as described in LeDoux et al. (2006). The vertebral column was sharply dissected from the remainder of the carcass, and was placed in a $50 \mathrm{ml}$ conical tube that contained RNAlater. The vertebral column was kept moist with RNAlater, while the right and left lumbar (L3-L6) DRG were microsurgically isolated and collected into separate pools for subsequent RNA extraction.

For immunocytochemistry, rats were overdosed with pentobarbital $(100 \mathrm{mg} / \mathrm{kg}$, IP) prior to transcardiac perfusion with heparinized saline and $4 \%$ paraformaldehyde $/ 0.1$ M PB. The vertebral column was dissected and kept moist with fixative, while the right and left lumbar (L4-L5) DRG were isolated and collected into separate vials. DRG were post-fixed for an additional $2 \mathrm{hr}$, and transferred to a cryoprotectant solution for at least $48 \mathrm{hr}$. DRGs were sectioned at $15 \mu \mathrm{m}$ with a cryostat, and were collected on SuperFrost ${ }^{\circledR-P l u s ~ g l a s s ~ s l i d e s . ~}$

\subsubsection{Relative Quantitative Real-time RT-PCR (QRT-PCR)}

Relative levels of torsinA mRNA were established in all brain and DRG tissues collected for QRT-PCR. The QRT-PCR detection of torsinA mRNA levels in brain regions was performed by Dr. Jianfeng Xiao in Dr. LeDoux's lab. In brief, total RNA was extracted with RNAwiz ${ }^{\mathrm{TM}}$. RNA purity and concentration were analyzed with a NanoDrop ${ }^{\circledR}$ spectrophotometer (NanoDrop Technologies, Wilmington, DE, USA). DNA was removed with DNA-free ${ }^{\mathrm{TM}}$ (Ambion). Reverse transcription was performed with RETROscript ${ }^{\mathrm{TM}}$ (Ambion) kit with $200 \mathrm{ng}$ total RNA as template. The reaction mix was incubated at $44{ }^{\circ} \mathrm{C}$ for $1 \mathrm{hr}$, and at $92{ }^{\circ} \mathrm{C}$ for $10 \mathrm{~min}$. QRT-PCR was performed with Taqman ${ }^{\circledR}$ probes (Applied Biosystems, Foster City, CA, USA) for the target gene (torsinA) and endogenous controls (18S rRNA for brain tissues and GAPDH for DRG). Primer and probe sequences are described in Table 2-1. Of note, technical triplicates were performed on each sample, and median values were used for subsequent analyses.

Differential expression of torsinA was determined with the comparative threshold cycle $\left(\mathrm{C}_{\mathrm{T}}\right)$ method. In particular, the expression levels of torsinA transcript in the ischemic and sham brains at each post-ischemic interval were calculated relative to the mean $\mathrm{C}_{\mathrm{T}}$ value for the sham controls at the corresponding time points. A two-factor 
Table 2-1. Probe and primers used for QRT-PCR, and primers used to generate in situ hybridization probes.

\begin{tabular}{|c|c|c|c|c|}
\hline Name & Sequence $\left(5^{\prime} \rightarrow 3^{\prime}\right)$ & Locus & Usage & $\begin{array}{l}\text { Product } \\
\text { (bp) }\end{array}$ \\
\hline QF1 & ggccgtgtcggtcttcaata & $\begin{array}{l}\text { NM_153303 } \\
743-762 \mathrm{nt}\end{array}$ & RT-PCR & \\
\hline QR1 & atagccacgggactgcatct & $\begin{array}{l}\text { NM_153303 } \\
893-874 \mathrm{nt}\end{array}$ & RT-PCR & $\begin{array}{l}151 \text { (with } \\
\text { QF1) }\end{array}$ \\
\hline QPro & $\begin{array}{l}\text { 6-FAM- } \\
\text { caagaacagtggcttctggcacagc } \\
\text { a-TAMRA }\end{array}$ & $\begin{array}{l}\text { NM_153303 } \\
764-789 \mathrm{nt}\end{array}$ & RT-PCR probe & \\
\hline TOR1AF & aagcggagcctcagccgtga & $\begin{array}{l}\text { NM_153303 } \\
180-199 \mathrm{nt}\end{array}$ & antisense probe 1 & \\
\hline TOR1AR & $\begin{array}{l}\text { gataatacgactcactatagggccac } \\
\text { aaacaggtgtacata }\end{array}$ & $\begin{array}{l}\text { NM_153303 } \\
423-405 \mathrm{nt}\end{array}$ & antisense probe 1 & $\begin{array}{l}244 \text { (with } \\
1 \mathrm{AF})\end{array}$ \\
\hline TOR1SF & $\begin{array}{l}\text { gataatacgactcactatagggaagc } \\
\text { ggagcctcagccgtga }\end{array}$ & $\begin{array}{l}\text { NM_153303 } \\
180-199 \mathrm{nt}\end{array}$ & sense probe 1 & \\
\hline TOR1SR & ccacaaacaggtgtacata & $\begin{array}{l}\text { NM_153303 } \\
423-405 \mathrm{nt}\end{array}$ & sense probe 1 & $\begin{array}{l}244 \text { (with } \\
1 \mathrm{SF})\end{array}$ \\
\hline TOR2AF & aaggaccaattacagatgtggat & $\begin{array}{l}\text { NM_153303 } \\
465-487 \mathrm{nt}\end{array}$ & antisense probe 2 & \\
\hline TOR2AR & $\begin{array}{l}\text { gataatacgactcactatagggccag } \\
\text { ggcgtgctccatgtct }\end{array}$ & $\begin{array}{l}\text { NM_153303 } \\
744-725 \mathrm{nt}\end{array}$ & antisense probe 2 & $\begin{array}{l}280 \text { (with } \\
2 \mathrm{AF})\end{array}$ \\
\hline TOR2SF & $\begin{array}{l}\text { gataatacgactcactatagggaag } \\
\text { gaccaattacagatgtggat }\end{array}$ & $\begin{array}{l}\text { NM_153303 } \\
465-487 \mathrm{nt}\end{array}$ & sense probe 2 & \\
\hline TOR2SR & ccagggcgtgctccatgtct & $\begin{array}{l}\text { NM_153303 } \\
744-725 \mathrm{nt}\end{array}$ & sense probe 2 & $\begin{array}{l}280 \text { (with } \\
\text { 2SF) }\end{array}$ \\
\hline TOR3AF & acaagaacagtggcttctggca & $\begin{array}{l}\text { NM_153303 } \\
763-784 \mathrm{nt}\end{array}$ & antisense probe 3 & \\
\hline TOR3AR & $\begin{array}{l}\text { gataatacgactcactatagggaaca } \\
\text { cagtcttgcagccett }\end{array}$ & $\begin{array}{l}\text { NM_153303 } \\
991-972 \mathrm{nt}\end{array}$ & antisense probe 3 & $\begin{array}{l}229 \text { (with } \\
2 \mathrm{AF})\end{array}$ \\
\hline TOR3SF & $\begin{array}{l}\text { gataatacgactcactatagggacaa } \\
\text { gaacagtggcttctggca }\end{array}$ & $\begin{array}{l}\text { NM_153303 } \\
763-784 \mathrm{nt}\end{array}$ & sense probe 3 & \\
\hline TOR3SR & aacacagtcttgcagccctt & $\begin{array}{l}\text { NM_153303 } \\
991-972 \mathrm{nt}\end{array}$ & sense probe 3 & $\begin{array}{l}229 \text { (with } \\
2 \mathrm{SF})\end{array}$ \\
\hline ActinAF & agcaagagaggcatcctga & $\begin{array}{l}\text { NM_031144 } \\
178-196 \mathrm{nt}\end{array}$ & $\begin{array}{l}\beta \text {-actin antisense } \\
\text { probe }\end{array}$ & \\
\hline ActinAR & $\begin{array}{l}\text { gataatacgactcactatagggacaa } \\
\text { cacagcctggatggcta }\end{array}$ & $\begin{array}{l}\text { NM_031144 } \\
421-401 \mathrm{nt}\end{array}$ & $\begin{array}{l}\beta \text {-actin antisense } \\
\text { probe }\end{array}$ & $\begin{array}{l}244 \text { (with } \\
\text { ActinAF) }\end{array}$ \\
\hline ActinSF & $\begin{array}{l}\text { gataatacgactcactatagggagca } \\
\text { agagaggcatcctga }\end{array}$ & $\begin{array}{l}\text { NM_031144 } \\
178-196 \mathrm{nt}\end{array}$ & $\begin{array}{l}\beta \text {-actin sense } \\
\text { probe }\end{array}$ & \\
\hline ActinSR & acaacacagcctggatggcta & $\begin{array}{l}\text { NM_031144 } \\
421-401 \mathrm{nt}\end{array}$ & $\begin{array}{l}\beta \text {-actin sense } \\
\text { probe }\end{array}$ & $\begin{array}{l}244 \text { (with } \\
\text { ActinSF) }\end{array}$ \\
\hline
\end{tabular}


(treatment and post-ischemic interval) analysis of variance (ANOVA) was used for statistical analysis with SAS (SAS Institute, Cary, NC, USA).

For relative quantitative analysis of torsinA mRNA in the DRG, expression levels were calculated in reference to the mean $C_{T}$ value for all right and left (L3-L6) DRG from the three non-surgical control rats. One-factor ANOVAs were used for independent analysis of data from the right and left DRG. Single degree-of-freedom post-hoc contrasts were limited to comparisons between individual post-surgical time points and ipsilateral control DRG. Analysis of the ipsilateral (left) DRG at $28 \mathrm{~d}$ was limited to two rats bscause poor-quality RNA was obtained from the third animal in this group.

\subsubsection{In situ Hybridization}

Radiolabeled ( ${ }^{35} \mathrm{~S}-\mathrm{UTP}$ ) complementary RNA (cRNA) probes were used to localize torsinA transcript in cryostat sections of rat brain. Primer pair sequences to make the radioactive probes are described in Table 2-1. The detailed protocol is provided in Xiao et al. (2004). In brief, probes were made by in vitro transcription with T7 RNA polymerase (Ambion). After fixation, acetylation, and dehydration through a graded series of ethanol, slides were incubated overnight in the hybridization buffer with radioactive probes (final concentration $-3 \times 10^{4} \mathrm{cpm} / \mu \mathrm{l}$ ). After treatment with RNase A (Sigma-Aldrich, St. Louis, MO, USA) at $37^{\circ} \mathrm{C}$ for $30 \mathrm{~min}$ followed by a high stringency wash at $60^{\circ} \mathrm{C}$ for $1 \mathrm{~h}$, slides were dehydrated and exposed to Kodak Biomax MR Film along with ${ }^{14} \mathrm{C}$ Microscale ${ }^{\mathrm{TM}}$ autoradiography standards (RPA504, Amersham Biosciences, Piscataway, NJ, USA) for 5 days. Each sheet of film was exposed to paired ischemia and sham microscopic slides. Autoradiographic images were acquired in the transmission mode (ScanMaker 9800 XL, Microtek, Carson, CA, USA), and were imported into ImageJ (Java version of NIH Image, http://rsb.info.nih.gov/ij/) for region of interest (ROI) quantification of radioactivity. Optical density (O.D.) was calibrated to the set of autoradiography standards to generate measures of radioactivity ( $\mathrm{nCi} / \mathrm{g}$ tissue) for each ROI. Hippocampal ROIs include internal and external blades of the dentate granule cell layer (iDG, eDG), four regions of stratum pyramidale that encompassed CA1 (Z1C, $\mathrm{Z} 2 \mathrm{C}$ ) and $\mathrm{CA} 3$ (Z3C, Z4C), and stratum oriens (SO), stratum radiatum (SR) and stratum lacunosum-moleculare (SLM) of the CA1 region. Signal was acquired from 15 pixels (3 $x 5$ rectangle) in the center of each ROI, from seven sections per animal, and the average was expressed relative to the mean obtained from sham sections hybridized in each of the experimental runs. Two-factor (treatment and post-ischemic interval) ANOVA was used for statistical analysis of relative radioactivity within each ROI.

\subsubsection{Immunocytochemistry}

The primary and secondary antibodies used for immunocytochemical studies are listed in Table 2-2. Cryostat brain and DRG sections were collected in eight and six series, respectively. One series of slides was air-dried overnight, and was stained with cresyl violet (brain) or hematoxylin and eosin (DRG). The other series were processed 
Table 2-2. Primary and secondary antibodies.

\begin{tabular}{|c|c|c|c|c|}
\hline Antibody name & Type & Target & Concentration & Source \\
\hline TA1 & $\begin{array}{l}\text { rabbit } \\
\text { polyclonal }\end{array}$ & torsin $\mathrm{A}$ & $1: 500$ & $\begin{array}{l}\text { Dr. Vijaya } \\
\text { Ramesh, Harvard } \\
\text { Medical School }\end{array}$ \\
\hline D-M2A8 & $\begin{array}{l}\text { mouse } \\
\text { monoclonal }\end{array}$ & torsin $\mathrm{A}$ & $1: 300$ & $\begin{array}{l}\text { Dr. Vijaya } \\
\text { Ramesh, Harvard } \\
\text { Medical School }\end{array}$ \\
\hline $\begin{array}{l}\text { Anti- } \\
\text { somatostatin }\end{array}$ & $\begin{array}{l}\text { rabbit } \\
\text { polyclonal }\end{array}$ & somatostatin & $1: 250$ & $\begin{array}{l}\text { Chemicon } \\
\text { International, } \\
\text { Temecula, CA, } \\
\text { USA }\end{array}$ \\
\hline Parv-19 & $\begin{array}{l}\text { mouse } \\
\text { monoclonal }\end{array}$ & parvalbumin & $1: 1000$ & $\begin{array}{l}\text { Sigma, St. Louis, } \\
\text { MO, USA }\end{array}$ \\
\hline GA5 & $\begin{array}{l}\text { mouse } \\
\text { monoclonal }\end{array}$ & GFAP & $1: 500$ & Chemicon \\
\hline OX -42 & $\begin{array}{l}\text { mouse } \\
\text { monoclonal }\end{array}$ & microglia & $1: 500$ & Chemicon \\
\hline V9 & $\begin{array}{l}\text { mouse } \\
\text { monoclonal }\end{array}$ & vimentin & $1: 10$ & $\begin{array}{l}\text { Abcam, } \\
\text { Cambridge, MA, } \\
\text { USA }\end{array}$ \\
\hline SY38 & $\begin{array}{l}\text { mouse } \\
\text { monoclonal }\end{array}$ & synaptophysin & $1: 100$ & Abcam \\
\hline $\begin{array}{l}\text { biotinylated } \\
\text { horse anti- } \\
\text { mouse }\end{array}$ & $\begin{array}{l}\text { horse } \\
\text { polyclonal }\end{array}$ & $\begin{array}{l}\text { mouse IgG } \\
(\mathrm{H}+\mathrm{L})\end{array}$ & $1: 500$ & $\begin{array}{l}\text { Vector, } \\
\text { Burlingame, CA, } \\
\text { USA }\end{array}$ \\
\hline $\begin{array}{l}\text { biotinylated goat } \\
\text { anti-rabbit }\end{array}$ & $\begin{array}{l}\text { goat } \\
\text { polyclonal }\end{array}$ & $\begin{array}{l}\text { rabbit IgG } \\
(\mathrm{H}+\mathrm{L})\end{array}$ & $1: 500$ & Vector \\
\hline $\begin{array}{l}\text { Cy2-tagged } \\
\text { donkey anti- } \\
\text { mouse }\end{array}$ & $\begin{array}{l}\text { donkey } \\
\text { polyclonal }\end{array}$ & $\begin{array}{l}\text { mouse IgG } \\
(\mathrm{H}+\mathrm{L})\end{array}$ & $1: 250$ & $\begin{array}{l}\text { Jackson } \\
\text { ImmunoResearch } \\
\text { Laboratories }\end{array}$ \\
\hline $\begin{array}{l}\text { Cy2-tagged } \\
\text { donkey anti- } \\
\text { rabbit }\end{array}$ & $\begin{array}{l}\text { donkey } \\
\text { polyclonal }\end{array}$ & $\begin{array}{l}\text { rabbit IgG } \\
(\mathrm{H}+\mathrm{L})\end{array}$ & $1: 250$ & $\begin{array}{l}\text { Jackson } \\
\text { ImmunoResearch } \\
\text { Laboratories }\end{array}$ \\
\hline $\begin{array}{l}\text { rhodamine red- } \\
\text { X-tagged } \\
\text { donkey anti- } \\
\text { mouse }\end{array}$ & $\begin{array}{l}\text { donkey } \\
\text { polyclonal }\end{array}$ & $\begin{array}{l}\text { mouse IgG } \\
(\mathrm{H}+\mathrm{L})\end{array}$ & $1: 250$ & $\begin{array}{l}\text { Jackson } \\
\text { ImmunoResearch } \\
\text { Laboratories }\end{array}$ \\
\hline $\begin{array}{l}\text { rhodamine red- } \\
\text { X-tagged } \\
\text { donkey anti- } \\
\text { rabbit }\end{array}$ & $\begin{array}{l}\text { donkey } \\
\text { polyclonal }\end{array}$ & $\begin{array}{l}\text { rabbit IgG } \\
(\mathrm{H}+\mathrm{L})\end{array}$ & $1: 250$ & $\begin{array}{l}\text { Jackson } \\
\text { ImmunoResearch } \\
\text { Laboratories }\end{array}$ \\
\hline
\end{tabular}


for immunohistochemical detection of torsinA and biomarkers for hippocampal interneurons (somatostatin and parvalbumin), astrocytes (glial fibrillary acidic protein [GFAP]) microglia (OX-42), intermediate filaments (vimentin), and synaptic vesicles (synaptophysin). Anatomically equivalent sections from animals that represented each of the three post-ischemic survival intervals and corresponding sham controls were processed simultaneously. Ipsilateral and contralateral DRG sections from all postsurgical intervals were processed as a group.

For peroxidase-based detection of torsinA, sections were first incubated in the quenching buffer $\left(10 \%\right.$ methanol and $3 \% \mathrm{H}_{2} \mathrm{O}_{2}$ in $0.02 \mathrm{M}$ phosphate-buffered saline [PBS]) for $5 \mathrm{~min}$. Sections were blocked and permeabilized in PBS that contained 2\% nonfat dry milk and $0.3 \%$ Triton X-100 (Sigma). Sections were incubated overnight with primary antibody diluted in PBS with 3\% normal serum (Jackson ImmunoResearch Laboratories, West Grove, PA, USA) and $0.1 \%$ Triton X-100. Sections were incubated with biotinylated secondary antibody diluted in PBS with $2 \%$ normal serum and $0.1 \%$ Triton X-100 for 4 hrs, peroxidase-labeled streptavidin (Vector Laboratories, Burlingame, CA, USA) for $1 \mathrm{hr}$, and nickel-intensified diaminobenzidine (Vector Laboratories) for visualization. Between each step, slides were thoroughly rinsed with PBS. After the final rinse, slides were air-dried overnight, dehydrated, cleared, and coverslipped with Permount (Fisher Scientific).

Double-label fluorescent immunocytochemistry was used to examine the relationships between torsinA and cell-type specific biomarkers (Table 2-2). Two primary antibodies that recognized torsin A were used in these studies: a rabbit polyclonal, TA1, and a mouse monoclonal, D-M2AB. When TA1 was employed, Cy2or rhodamine red-X (RRX)-tagged donkey anti-rabbit secondary antibodies (Jackson ImmunoResearch Laboratories) were used to visualize torsinA-IR. With D-M2A8, biotinylated horse anti-mouse was used as a secondary antibody followed by Cy2-tagged streptavidin (Jackson ImmunoResearch Laboratories). Slides were thoroughly rinsed, dehydrated, cleared, and coverslipped with 1,3-diethyl-8-phenylxanthine (DPX; SigmaAldrich) mounting medium. Sections were visualized with epifluorescence (Leica DM6000, Leica Microsystems Inc, Bannockburn, IL, USA) and confocal laser-scanning (Bio-Rad Laboratories, Hercules, CA, USA) microscopes. For consistency of illustration, all torsinA-IR was transferred to the RGB green channel, and other biomarker-IR to the RGB red channel within Adobe Photoshop (San Jose, CA, USA).

\subsection{RESULTS}

\subsubsection{TorsinA Transcript Was Up-regulated after Transient Forebrain Ischemia}

QRT-PCR was performed to evaluate the spatial and temporal expression of torsinA mRNA after transient forebrain ischemia, with 18S rRNA as an endogenous control. The efficiencies of torsinA (1.74) and 18S rRNA (1.75) amplification were practically identical; the slope of $\Delta \mathrm{C}_{\mathrm{T}}$ versus $\log _{10} \mathrm{ng}$ total $\mathrm{RNA}$ was 0.054 . The $\mathrm{C}_{\mathrm{T}}$ 
values associated with torsinA and $18 \mathrm{~S}$ rRNA amplification showed strong linear relationships with $\log _{10}$ ng total RNA (torsinA: $R^{2}=0.978$; 18 S rRNA: $R^{2}=0.990$ ).

Up-regulation of torsinA mRNA was not detected at the $6 \mathrm{hr}$ post-ischemic interval. However, torsinA mRNA levels were significantly elevated within $24 \mathrm{hr}$ after ischemia in all regions tested (Figure 2-1). Transcript levels remained elevated at 7 days in all regions, and declined toward sham values by $14 \mathrm{~d}$ in striatum, thalamus, and cortex, and by $21 \mathrm{~d}$ in cerebellum and hippocampus. In hippocampus and cerebellum, there were strong overall effects of ischemia (hippocampus $\left[F_{1,20}=21.63, P=0.0002\right]$, cerebellum $\left.\left[F_{1,20}=13.12, P=0.0017\right]\right)$, post-ischemic interval (hippocampus $\left[F_{4,20}=5.24, P=\right.$ $0.0047]$, cerebellum $\left[F_{4,20}=4.17, P=0.0129\right]$ ), and their interaction (hippocampus $\left[F_{4,20}\right.$ $=5.34, P=0.0043]$, cerebellum $\left.\left[F_{4,20}=4.48, P=0.0095\right]\right)$ on torsinA mRNA levels (Figure 2-1). In these two regions, increased expression of torsinA transcript was present at $24 \mathrm{hr}, 7 \mathrm{~d}$, and $14 \mathrm{~d}$ but not at $6 \mathrm{hr}$ or $21 \mathrm{~d}$. In the other three regions examined, the effects of ischemia were also considerable (striatum $\left[F_{1,20}=13.96, P=\right.$ $0.0013]$, thalamus $\left[F_{1,20}=8.43, P=0.0088\right]$, and cerebral cortex $\left[F_{1,20}=17.72, P=\right.$ $0.0004]$ ), although there were no significant effects of post-ischemic interval and the ischemia x post-ischemic interval interaction on the relative levels of torsinA transcript. As seen in Figure 2-1, individual contrasts between the ischemia and sham groups were significant $(P<0.05)$ in all regions tested at the $24 \mathrm{hr}$ and $7 \mathrm{~d}$ post-ischemic intervals and, additionally, in cerebellum and hippocampus at the $14 \mathrm{~d}$ post-ischemic interval. The degree of torsinA mRNA up-regulation was greatest in ischemic cerebral cortex and hippocampus ( $>$ 3-fold). TorsinA mRNA up-regulation in thalamus and striatum was also substantial ( $>$ 2-fold compared to control).

The distribution of torsinA mRNA expression determined by in situ hybridization was consistent with its generalized expression in major neuron populations. And the torsinA hybridization signal was not grossly impacted following ischemia (Figure 2-2). The decline in signal, evident in the hippocampal CA1 pyramidal layer at longer postischemic intervals, was consistent with the loss of these neurons. In addition, a more diffuse increase in torsinA hybridization was apparent in hippocampal neuropil at 7 and 14 days, as further supported by quantitative analyses. Among the nine hippocampal ROIs analyzed, $\operatorname{SLM}\left(F_{1,16}=18.13, P=0.0006\right)$ and $\mathrm{iDG}\left(F_{1,16}=6.88, P=0.0185\right)$ showed the largest overall effects of ischemia on relative torsin A radioactivity (Figure 2-3). The ischemia $x$ post-ischemic interval interaction was also significant in $\mathrm{iDG}\left(F_{3,16}\right.$ $=4.89, P=0.0134)$ and $\operatorname{SLM}\left(F_{3,16}=5.71, P=0.0074\right)$. In SLM, for example, relative torsin A radioactivity was only increased at the $7 \mathrm{~d}$ post-ischemic interval. In $\mathrm{Z} 1 \mathrm{C}$ and $\mathrm{Z} 2 \mathrm{C}$, the effects of post-ischemic interval $\left(F_{1,16}=13.03, P=0.0001\right.$ and $F_{1,16}=16.86, P$ $=0.0001$, respectively $)$ and the ischemia x post-ischemic interval interaction $\left(F_{3,16}=\right.$ $\left.10.32, P=0.0005 ; F_{3,16}=17.33, P=0.0001\right)$ were highly significant due to the increased signal in post-ischemic tissue at $24 \mathrm{hr}$ and decreased signal at $7 \mathrm{~d}$. Other noteworthy findings were the effects of ischemia in SR $\left(F_{1,16}=9.26, P=0.0077\right)$ and the ischemia $\mathrm{x}$ post-ischemic interval interaction in $\operatorname{eDG}\left(F_{1,16}=8.37, P=0.0014\right)$. Individual contrasts between the ischemia and sham groups showed that relative torsinA radioactivity first became elevated at the $24 \mathrm{hr}$ post-ischemic interval in iDG, eDG, Z2C, and $\mathrm{Z1C}(P<$ 0.05 , for all). At the $7 \mathrm{~d}$ post-ischemic interval, relative torsinA radioactivity was 

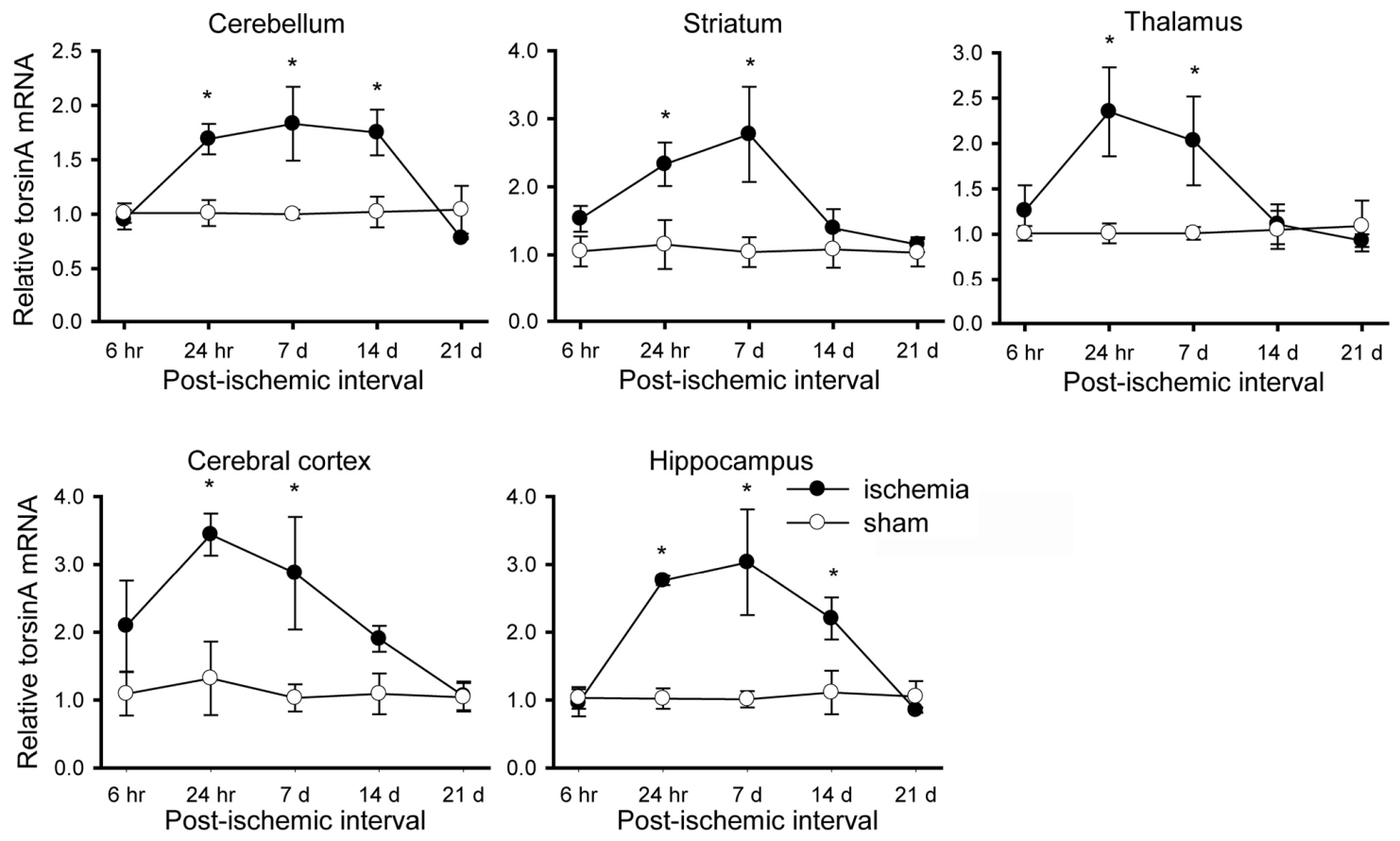

Figure 2-1. QRT-PCR analysis of regional torsinA expression after transient forebrain ischemia.

Torsin A transcript levels in each brain region are expressed relative to the mean CT value for the sham controls at each time point. A significant increase in torsinA transcript was observed in all regions at $24 \mathrm{hr}$ and $7 \mathrm{~d}$ post-ischemic intervals, and persisted in cerebellum and hippocampus at $14 \mathrm{~d}$. Results are expressed as the mean \pm SEM (*, P $<$ 0.05 for the difference between ischemic and sham groups at each interval). 


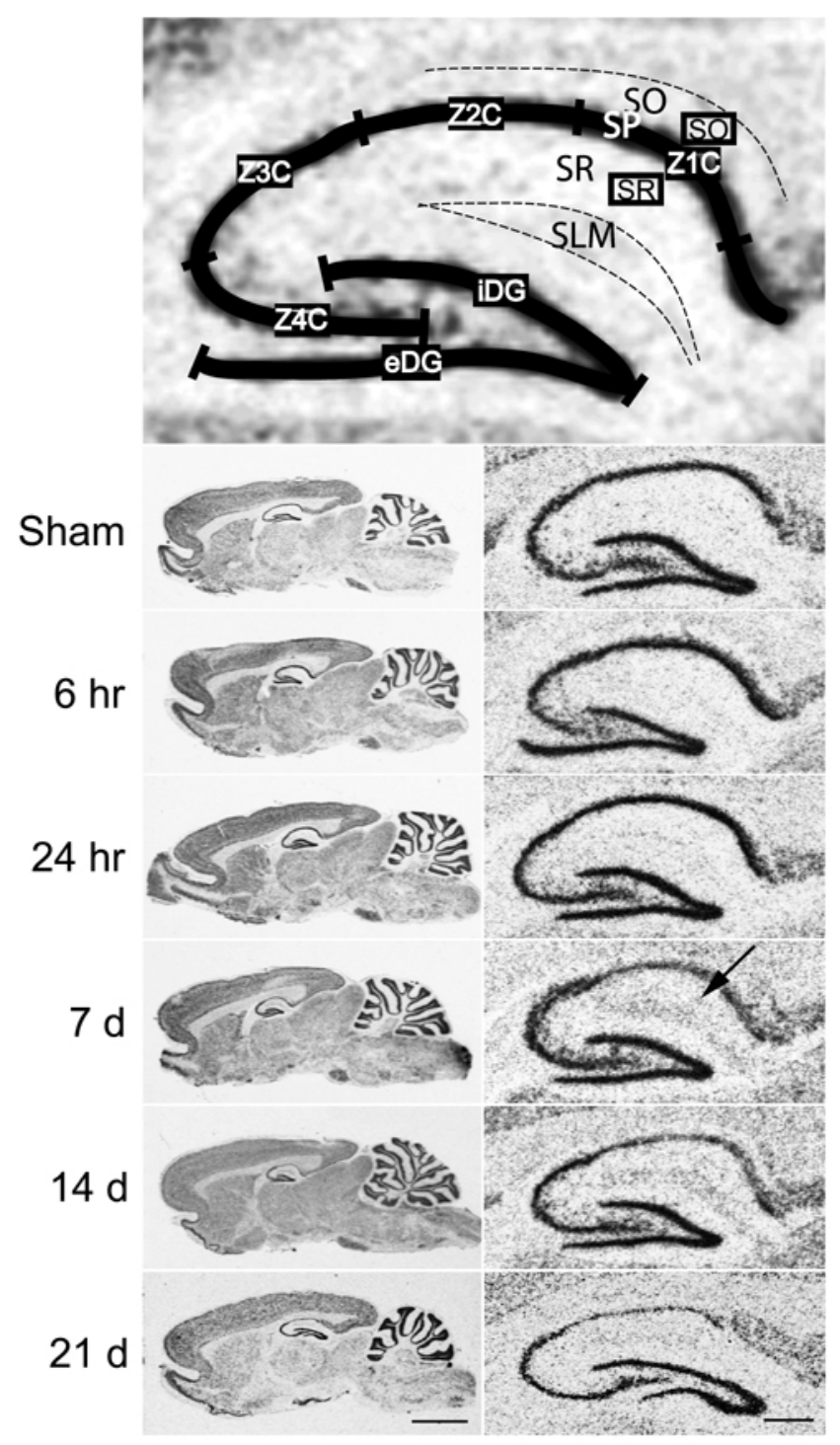

Figure 2-2. In situ hybridization of torsinA.

Representative parasagittal sections are illustrated for a sham control and at indicated post-ischemic intervals, together with higher-magnification images of the corresponding hippocampus. Evident changes included a decrease in torsinA expression in the CA1 pyramidal cell layer at late post-ischemic intervals, accompanied by elevated signal in neighboring neuropil (arrow). Scale bars indicate $5 \mathrm{~mm}$ for whole-brain images and 500 $\mu \mathrm{m}$ for hippocampal images. The upper panel identifies ROIs subjected to further quantitative analysis (see Figure 2-3) including the internal and external blades of the dentate granule cell layer (iDG, eDG); four regions of stratum pyramidale that encompass CA1 (Z1C, Z2C) and CA3 (Z3C, Z4C); and stratum oriens (SO), stratum radiatum (SR) and stratum lacunosum-moleculare (SLM) of the CA1 region. 

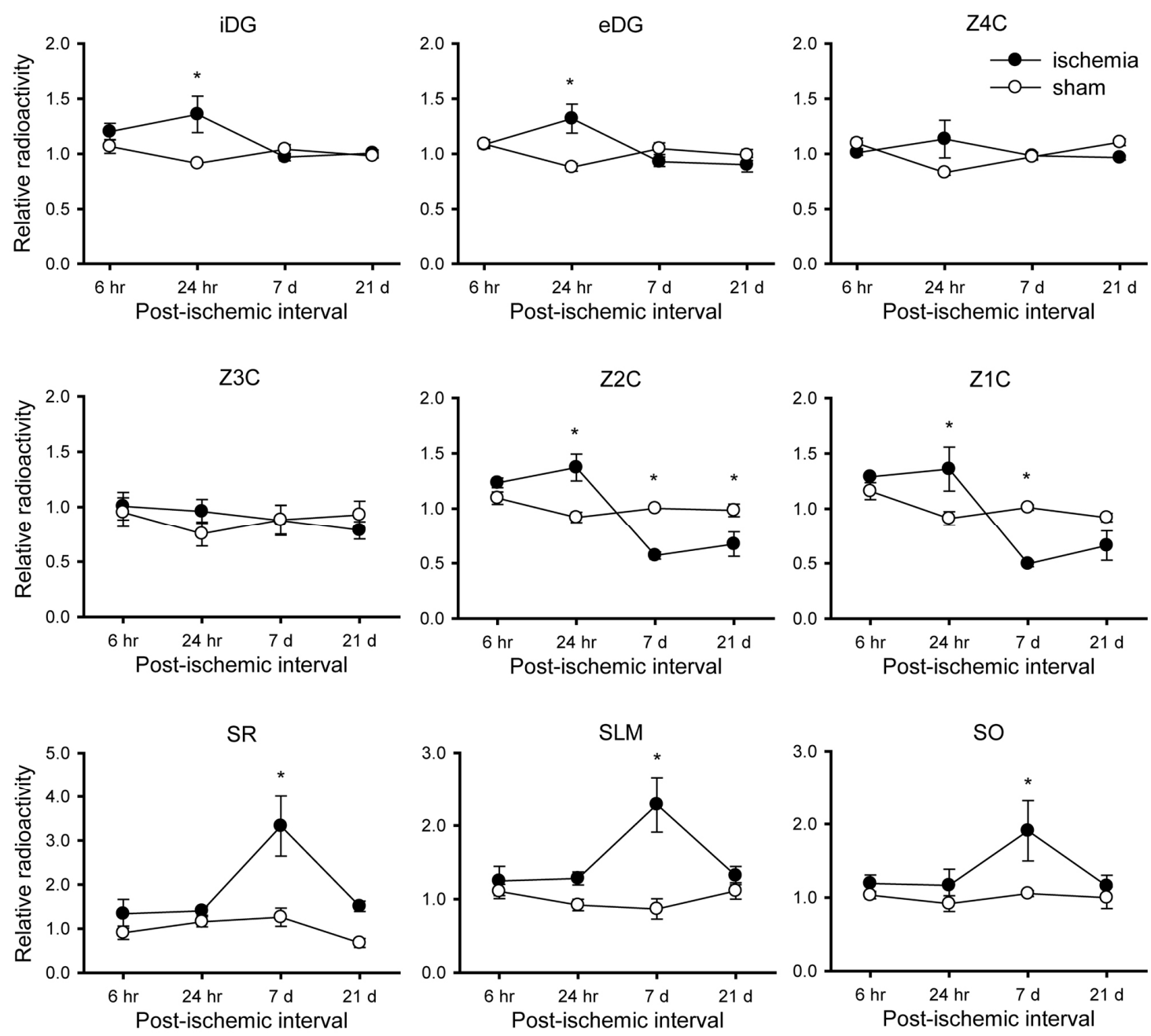

Figure 2-3. Quantitative in situ hybridization analysis of hippocampal torsin A transcript levels.

TorsinA hybridization was determined in the ROIs indicated in Figure 2-3, and were expressed relative to the mean value for sham sections hybridized in each experimental run. A slight but significant increase in torsinA transcript was observed in dentate granule cells (iDG and eDG) and CA1 neurons (Z1C and Z2C) at $24 \mathrm{hr}$ after ischemia. Expression in the CA1 pyramidal layer decreased at later intervals, accompanied by increased expression in SR, SLM, and SO at $7 \mathrm{~d}$. Results are expressed as the mean \pm SEM $(*, P<0.05$ for the difference between ischemic and sham groups at each postischemic interval) 
significantly up-regulated in SO, SR and $\operatorname{SLM}(P<0.05$, for all), and down-regulated in $\mathrm{Z} 2 \mathrm{C}$ and $\mathrm{Z} 1 \mathrm{C}(P<0.05$, for both). By $21 \mathrm{~d}$ post-ischemia, torsinA hybridization returned toward sham values in all regions except $\mathrm{Z} 2 \mathrm{C}$.

Given the possible relationship of SNpc functional abnormalities to the pathophysiology of DYT1 dystonia, SNpc torsinA transcript levels were evaluated with quantitative in situ hybridization. As seen in Figure 2-4, there was a significant effect of ischemia, post-ischemic interval, and ischemia x post-ischemic interval $\left(F_{1,16}=9.07, P=\right.$ $0.0083 ; F_{3,16}=3.73, P=0.0332 ; F_{3,16}=4.55, P=0.0173$, respectively) on relative torsinA radioactivity in the SNpc. In addition, individual contrasts between the ischemia and sham groups were significant $(P<0.05)$ at the $24 \mathrm{hr}$ post-ischemic interval.

\subsubsection{TorsinA Was Up-regulated in Hippocampal Astrocytes and Interneurons}

Changes in torsinA immunocytochemistry were consistent with the hybridization results, and permitted signal localization to specific cell types. The initial increase in torsinA-IR at $24 \mathrm{hr}$ occurred in the major hippocampal neuron populations that exhibited endogenous expression, whereas later diffuse increases overlapped the distributions of glial activation and synaptophysin up-regulation that took place in regions of CA1 neuron loss (Figure 2-5).

Double labeling (Figure 2-6) identified torsinA co-localization in GFAP-positive astrocytes but not OX-42-labeled microglia. Additional cells strongly-IR for torsinA included parvalbumin and somatostatin-IR interneurons. As seen in Figure 2-7, hippocampal somatostatin and parvalbumin interneurons were torsinA-IR in postischemic and sham tissues. However, after ischemia, the relative intensity of torsinA-IR was higher in these cell types than in adjacent neurons. Many of the parvalbumin-IR interneurons were scattered among pyramidal cells in the hippocampal pyramidal cell layer and granule cells in the dentate gyrus whereas others were localized to the dentate hilus and near the edge of the SO. Most of the somatostatin-IR interneurons were found in the dentate subgranular proliferative zone, dentate hilus, $\mathrm{SO}$ and the boundary region between the SR and SLM.

As seen in Figure 2-8, torsinA-IR was increased in neurons in the subgranular proliferative zone and hilus of the dentate gyrus, and pyramidal cells of the CA2 and CA1 regions at $24 \mathrm{hr}$ post-ischemia. At $7 \mathrm{~d}$ post-ischemia, torsinA-IR was mildly decreased in CA1 pyramidal cells, and increased in neurons in the subgranular proliferative zone and hilus of the dentate gyrus, CA3/CA2 pyramidal cells, and the cells in the SR. In the $14 \mathrm{~d}$ post-ischemic hippocampus, robust torsinA-IR was apparent in cells scattered within the SR and hilus of the dentate gyrus, and moderately-IR cells were sparsely distributed within the SO. 


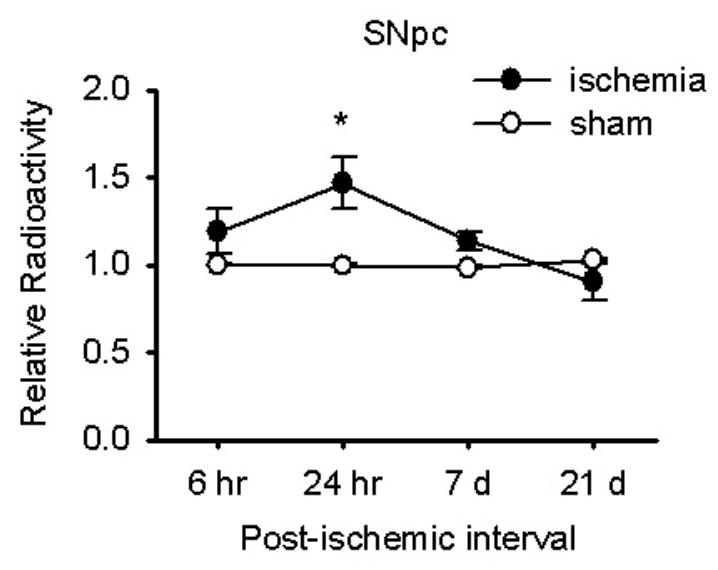

Figure 2-4. Quantitative in situ hybridization analysis of torsinA transcript levels in SNpc.

TorsinA hybridization signal was expressed relative to the mean value for sham sections hybridized in each experimental run. A small but significant increase in torsinA transcript was observed at $24 \mathrm{hr}$ after ischemia. Results are expressed as the mean \pm SEM ${ }^{*}, P<0.05$ for the difference between ischemic and sham groups at each post-ischemic interval). 


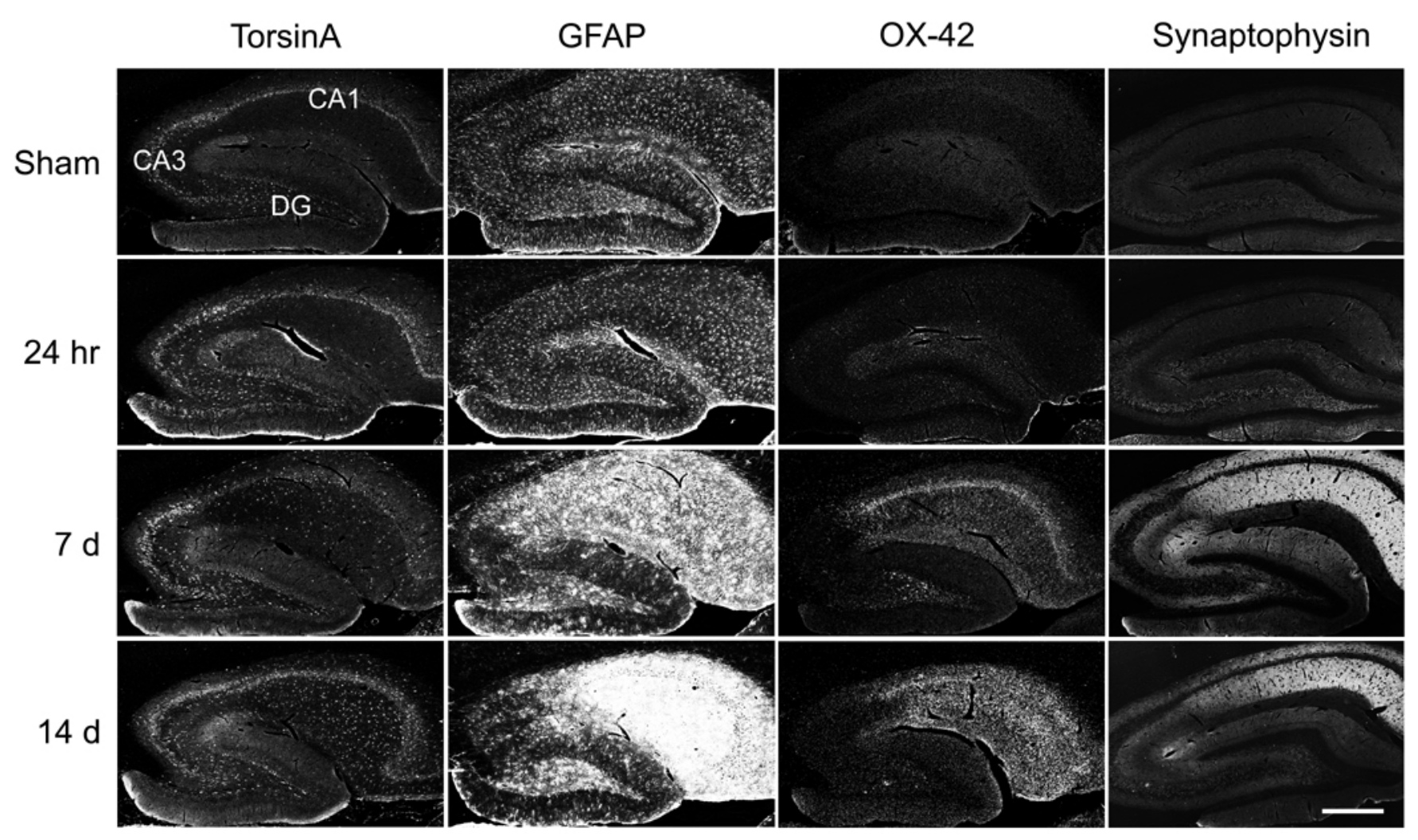

Figure 2-5. Distribution of torsin A immunoreactivity and comparison with other markers.

Torsin A-IR was moderately increased in the major hippocampal neuron populations at the $24 \mathrm{hr}$ post-ischemic interval, and overlapped the distributions of astrocyte (GFAP) and microglial (OX-42) activation and synaptophysin upregulation at later intervals. Confocal gray scale images of fluorescent immunocytochemistry are shown for torsinA (antibody TA1), GFAP, and $\mathrm{OX}-42$, and inverted gray-scale images of peroxidase detection are shown for synaptophysin. Scale bar, $500 \mu \mathrm{m}$ 


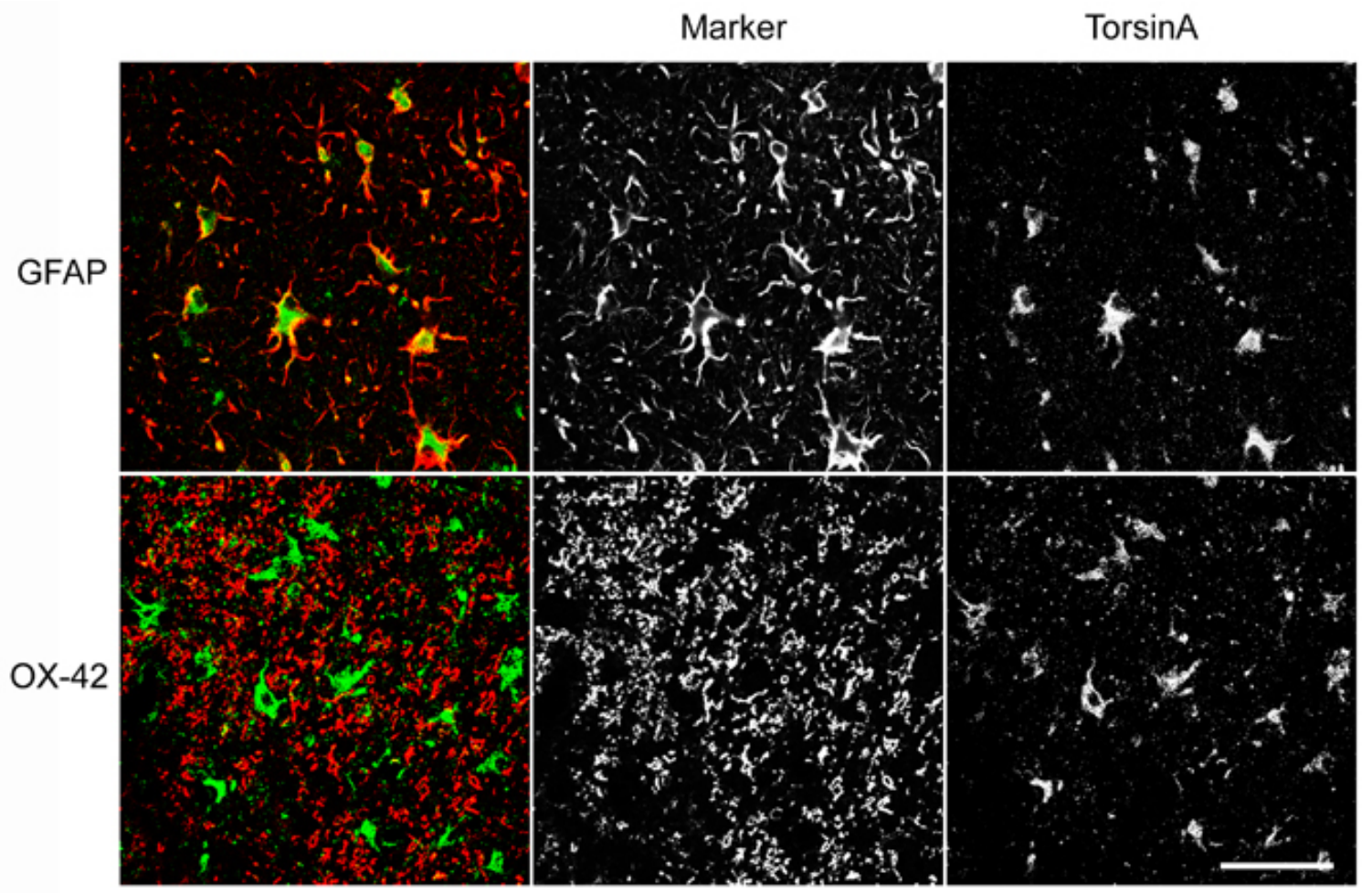

Figure 2-6. Cellular localization of torsinA immunoreactivity in glia.

High-magnification confocal images of double-label fluorescent immunocytochemistry for simultaneous detection of torsinA (green, right column gray scale) and cell markers GFAP, OX-42 (red, middle column gray scale) in post-ischemic (7 d) hippocampus. TorsinA co-localizes with GFAP-positive astrocytes but not OX-42-labeled microglia. Double-labeled cells appear yellow in the merged images. Scale bar, $50 \mu \mathrm{m}$. 
Figure 2-7. Cellular localization of torsinA immunoreactivity in interneurons.

High-magnification confocal images of double-label fluorescent immunocytochemistry for simultaneous detection of torsinA (green, right column gray scale) and cell markers parvalbumin and somatostatin (red, middle column gray scale) in sham and post-ischemic (7 d) hippocampus. TorsinA-IR is prominent in neurons that express parvalbumin and somatostatin (arrows). Double-labeled cells appear yellow in the merged images. Scale bar $=50 \mu \mathrm{m}$. 


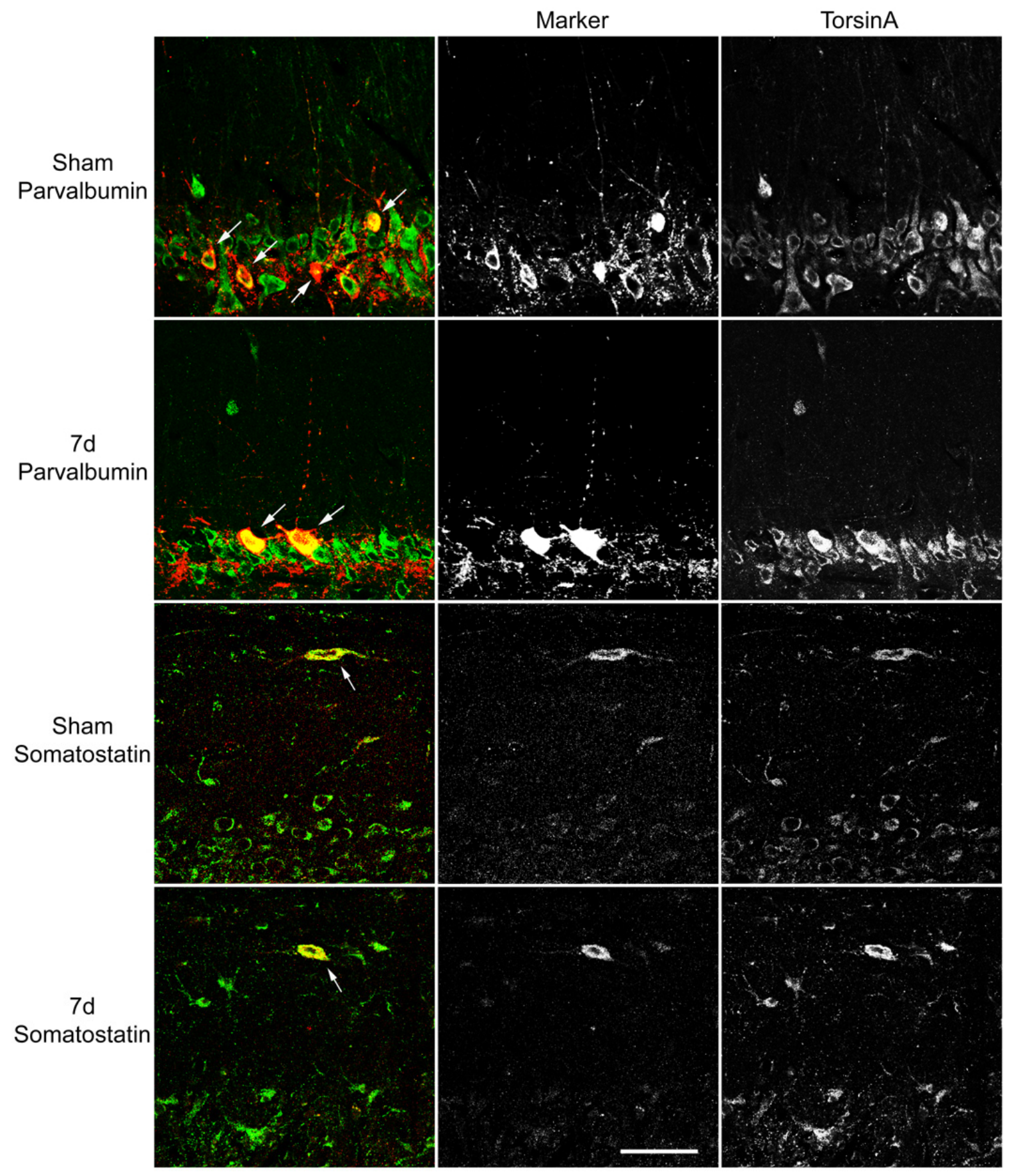


Figure 2-8. Immunoperoxidase detection of torsin $A$ in post-ischemic hippocampus. Using the TA1 polyclonal antibody, increased torsinA-IR was detected in the cells in the subgranular proliferative zone (arrow) and hilus of the dentate gyrus, and in the pyramidal cells in CA3 and CA2 region at all time points after ischemia, and in cells scattered within the SR and SO of CA1 at $14 \mathrm{~d}$ after ischemia. M, molecular layer; G, granule cell layer; and H, hilus of the dentate gyrus. Scale bar, $200 \mu \mathrm{m}$. 


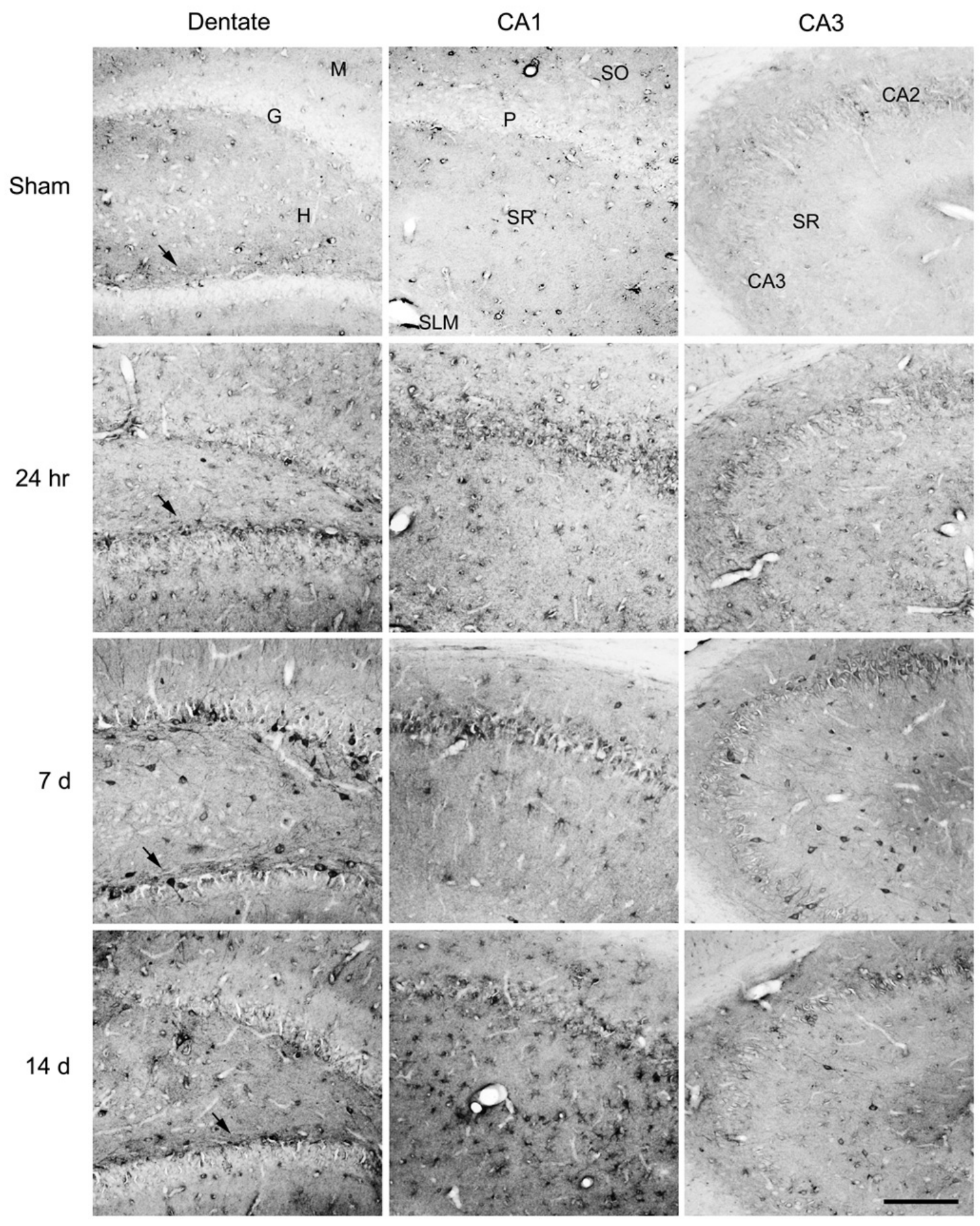




\subsubsection{TorsinA Transcript and Protein Were Up-regulated in Bilateral DRG after Unilateral Sciatic Nerve Transection}

TorsinA mRNA expression was increased after sciatic nerve transection (Figure 2-9), as assessed by QRT-PCR. The amplification efficiencies for torsinA and GAPDH were 0.95 and 1.01 , respectively, and the slope of $\Delta \mathrm{C}_{\mathrm{T}}$ versus $\log _{10} \mathrm{ng}$ total RNA was -0.043 . The $\mathrm{C}_{\mathrm{T}}$ values associated with torsin $\mathrm{A}$ and GAPDH amplification showed strong linear relationships with $\log _{10}$ ng total RNA (torsinA: $R^{2}=0.94$; GAPDH: $R^{2}=0.99$ ). The overall effect of sciatic nerve transection was robust in contralateral DRG $\left(F_{5,12}=\right.$ $8.31, P=0.0015)$, but did not reach statistical significance in ipsilateral $\mathrm{DRG}\left(F_{5,11}=\right.$ $2.47, P=0.098)$. Post-hoc contrasts showed that torsinA expression differed between the control and surgical groups in ipsilateral and contralateral DRG at $24 \mathrm{hr}$ and $3 \mathrm{~d}(P<$ 0.05 , for all), with a significant increase that persisted in the contralateral DRG at $7 \mathrm{~d}(P$ $<0.05)$.

In control DRG, torsinA-IR was detected in satellite cells, the somas of ganglion cells, and axons (Figure 2-10). After sciatic nerve transection, torsinA-IR increased in ganglion and satellite cells ipsilateral to the lesion, but only in satellite cells contralaterally. In ipsilateral ganglion cells, torsinA-IR was most prominent at 3 and $7 \mathrm{~d}$ after sciatic nerve transection. GFAP-IR co-labeled torsinA-positive satellite cells (Figure 2-11).

\subsubsection{TorsinA and Vimentin Co-localize in Neuronal and Glial Elements in the CNS and PNS}

Given the apparent up-regulation of GFAP after CNS and PNS insults and prominent expression of torsinA in GFAP-IR reactive astrocytes and satellite cells, we elected to localize a closely related intermediate filament protein, vimentin, in hippocampus and DRG (Figure 2-12). Vimentin-IR interneurons and reactive astrocytes were readily apparent in post-ischemic hippocampus. In interneurons, vimentin-IR was diffuse and co-localized with torsinA-IR. Although many reactive astrocytes expressed vimentin and torsinA, co-localization of vimentin- and torsinA-IR was weak in these cells. After sciatic nerve transection, vimentin-IR was readily visualized in satellite cells of the ipsilateral and contralateral DRG.

\subsection{DISCUSSION}

In normal brain, expression of torsin A is high in neurons and low in glia, and its developmental regulation indicates that torsinA might play a role in postnatal maturational events in the CNS (Xiao et al., 2004). The present results indicate an altered pattern of torsinA expression, which notably involved astroglial cell types, after challenges to the central and peripheral nervous systems. The similar quantitative and temporal features of torsinA up-regulation after sciatic nerve transection and 4-VO suggest the presence of common transcriptional control mechanisms, as well as a 

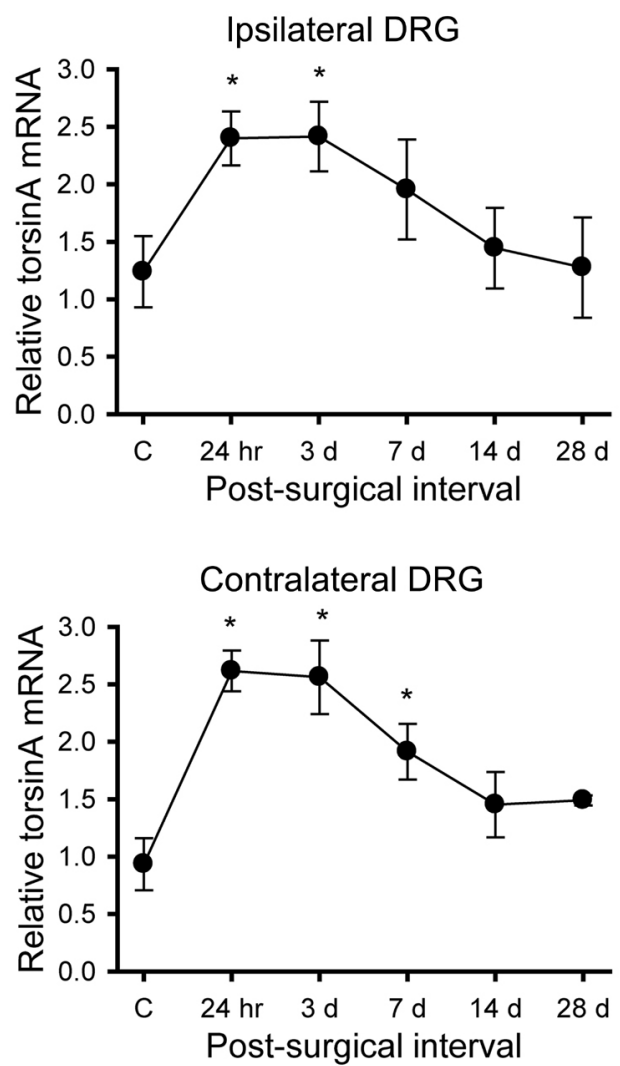

Figure 2-9. Temporal profiles of torsin A mRNA expression in DRG after unilateral sciatic nerve transection.

TorsinA mRNA expression levels in ipsilateral and contralateral DRGs were calculated in reference to the mean CT value for all DRG from control rats (C). Prominent bilateral increases in torsin A transcript were observed bilaterally at 1 and 3 days. Symbols indicate the mean $\pm \operatorname{SEM}(*, \mathrm{P}<0.05$ for the difference between lesioned and control animals). 
Figure 2-10. Immunocytochemical localization of torsinA expression in DRG after unilateral sciatic nerve transection.

TorsinA-IR increases were detected ipsilaterally in both ganglion cells $(\mathrm{G})$ and satellite cells (arrow), but only in satellite cells contralaterally. C, non-surgical control. Scale bar, $100 \mu \mathrm{m}$. 


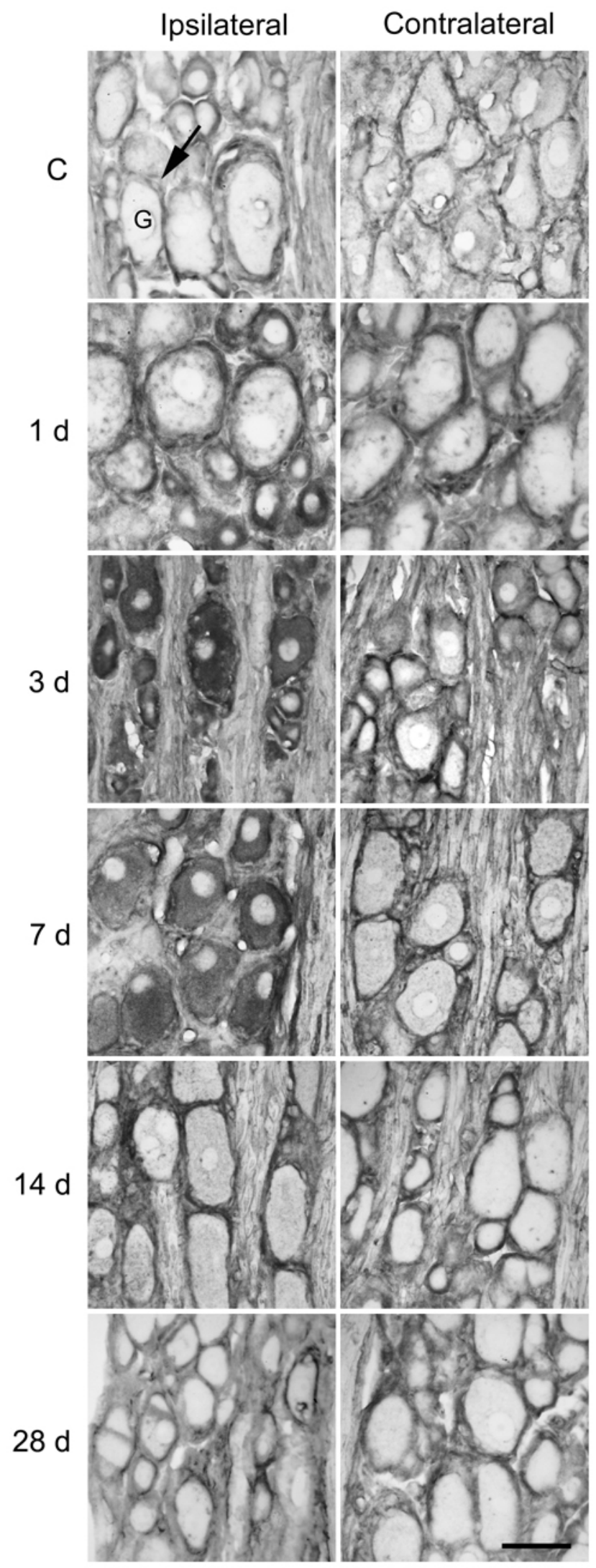



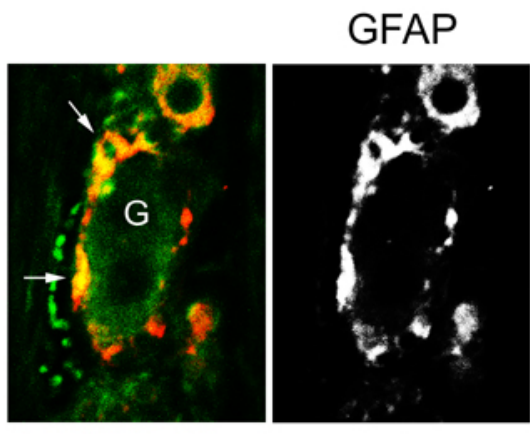

\section{Torsin A}

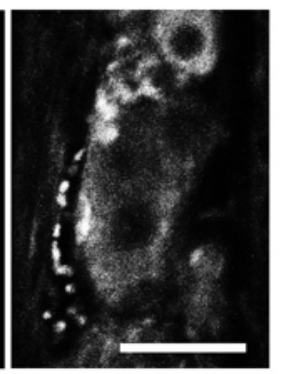

Figure 2-11. Co-localization of torsinA and GFAP in satellite cells.

Confocal images of fluorescent immunocytochemistry illustrate co-localization in satellite cells (arrow) of ipsilateral DRG $14 \mathrm{~d}$ after sciatic nerve transaction. Colocalization appears yellow in the merged images. G, ganglion cell. Scale bar, $50 \mu \mathrm{m}$. 


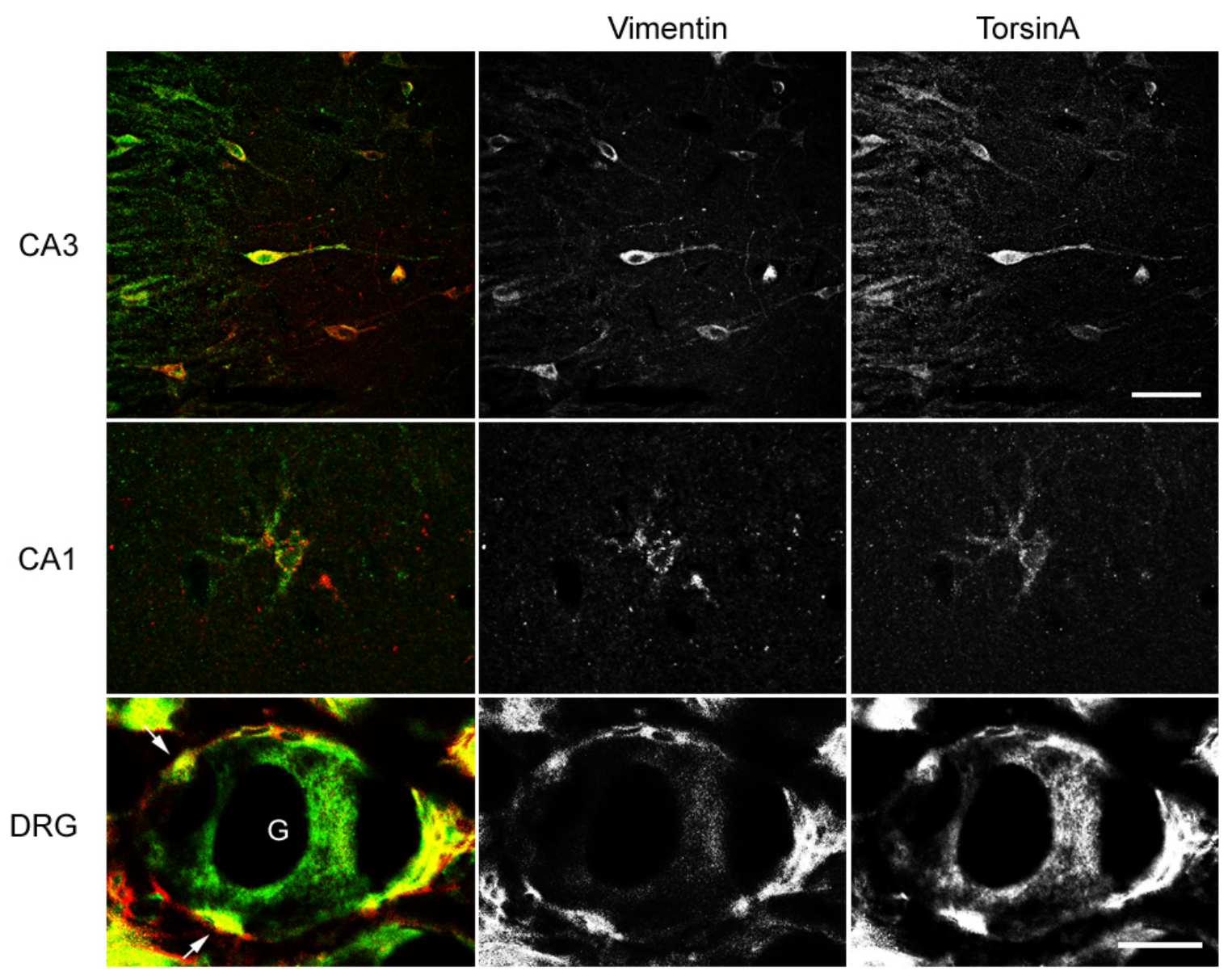

Figure 2-12. Co-localization of torsin $A$ and vimentin after ischemia and sciatic nerve transection.

Confocal images of fluorescent immunocytochemistry illustrate co-localization in a subset of CA3 interneurons and CA1 astrocytes in $7 \mathrm{~d}$ post-ischemic hippocampus. Vimentin also co-localizes with the component of torsinA expression in satellite cells (arrow) of ipsilateral DRG $14 \mathrm{~d}$ after sciatic nerve transection. Co-localization appears yellow in the merged images. G, ganglion cell. Scale bars, $50 \mu \mathrm{m}$ (top three panels) and $25 \mu \mathrm{m}$ (other panels). 
common role for this protein in the reparative and/or adaptive responses to such perturbations.

\subsubsection{Post-ischemic Torsin A Expression in the CNS}

Brief durations of global ischemia such as those used in these studies resulted in a selective loss of hippocampal CA1 pyramidal cells and interneurons of dentate hilus (Pulsinelli et al., 1982a; Nishino and Nowak, 2004; Ueda and Nowak, 2005). However, $4-\mathrm{VO}$ produces severe reductions in blood flow throughout forebrain structures, as wellas appreciable perfusion deficits in cerebellum and brainstem (Pulsinelli et al., 1982b). The rapid, generalized increase in torsinA transcript levels throughout the brain (Figure 2-1) that maintain the distribution in major neuron populations seen in control brain (Figure 2-2) appears to reflect a relatively homogeneous response to this initial ischemic insult. This parallels, in many respects, the acute post-ischemic induction of many ischemiaresponsive genes, including many heat shock proteins (Nowak, 1991; Kawagoe et al., 1992; Xue et al., 1998; Nowak and Kiessling, 1999; Yagita et al., 2001; Tanaka et al., 2002). Studies in other in vivo and in vitro models also suggest a role for torsinA in response to oxidative stress (Hewett et al., 2003; Kuner et al., 2004; Cao et al., 2005).

In contrast, the delayed component of torsin A increase includes prominent expression in reactive astrocytes in regions of hippocampus (e.g., CA1) known to undergo neuron loss and synaptic reorganization after ischemia (Arabadzisz and Freund, 1999; Briones et al., 2004). In agreement with previous work, astrocytic and microglial markers showed the most prominent post-ischemic response in the CA1 region (SchmidtKastner et al., 1990; Morioka et al., 1991; Gottlieb and Matute, 1999). Although not specifically evaluated in this study, the persistent modest increase in torsinA expression noted in cerebellum (Figure 2-1) might be a correlate of glial activation in response to Purkinje cell vulnerability that also has been described after global ischemia (Diemer and Siemkovicz, 1981).

Astrocytes are believed to carry out protective functions such as maintenance of ionic homeostasis, prevention of excitotoxicity (via glutamate uptake), scavenging free radicals, provision of nutrients and growth factors, and support of synaptogenesis and neurogenesis (Panickar and Norenberg, 2005). Astrocytes are associated with the synapses, enwrap many pre- and post-synaptic terminals, and facilitate synaptic formation and synaptic neurotransmitter release (Araque et al., 1999; Grosche et al., 1999; Ventura and Harris, 1999; Riquelme et al., 2002; Liu et al., 2004; Sobkowicz et al., 2006). The up-regulation of torsin $A$ in reactive astrocytes might facilitate one or more protective functions of astrocytes such as glutamate uptake via movement of the polytopic glutamate transporter to the cell surface. Alternatively, torsinA might contribute to the morphological and topological changes that reactive astrocytes must undergo in order to facilitate synaptogenesis and network reorganization (Lepekhin et al., 2001; Witcher et al., 2007). 
These results also demonstrate an up-regulation of torsinA expression in surviving somatostatin- and parvalbumin-IR interneurons (Figure 2-7), which likely contribute to the partial maintenance of torsinA transcript levels in the CA1 stratum pyramidale at late post-ischemic intervals despite the death of most pyramidal neurons (Figure 2-3). It is well established that parvalbumin-IR interneurons in the hippocampus are resistant to ischemic stress (Nitsch et al., 1989; Ferrer et al., 1995). Similarly, somatostatin-IR interneurons in the CA1 region are also relatively resistant to ischemia (Bering and Johansen, 1993; Bering et al., 1997). Surviving interneurons in the CA1 region undergo significant morphological changes, and may serve as substitute targets for Schaffer collateral and other excitatory synaptic input after hippocampal ischemia (Arabadzisz and Freund, 1999). Accordingly, it is rational to postulate that torsinA might participate in structural changes and/or transport of cell surface receptors in these hippocampal interneurons.

Transient global ischemia is followed by neurogenesis in the subgranular proliferative zone (Sharp et al., 2002; Kokaia and Lindvall, 2003), and there is some evidence to suggest a parallel response in the posterior periventricular zone adjacent to the hippocampus (Nakatomi et al., 2002). Neuroblasts that originate from the subgranular proliferative zone give rise to neurons within the granule cell layer and GFAP-IR astrocytes in the dentate hilus. Although BrdU labeling was not examined in this study, the numerous cells robustly-IR for torsin A in the subgranular proliferative zone (Figure 2-8) might be such neuroblasts. Developmental profiles of torsinA transcript and protein expression are also consistent with a role for torsinA during neurogenesis in brain (Xiao et al., 2004).

\subsubsection{TorsinA in the Injured PNS}

TorsinA is constitutively expressed in the PNS, where it is present in neuronal and glia elements (ganglion and satellite cells, respectively) in the DRG. After unilateral sciatic nerve transection, torsinA transcript increased bilaterally (Figure 2-9). TorsinA immmunoreactivity was detected in both cell types in the DRG ipsilateral to the lesion, but was more prominently increased in satellite cells contralaterally (Figure 2-10). Bilateral effects of sciatic nerve transection are consistent with work from other laboratories. Ryoke and colleagues (2000) reported that a conditioning lesion (i.e., left sciatic nerve transection) enhanced expression of IL-1 $\beta$ and TGF- $\beta$ in the contralateral DRG and promoted nerve regeneration. Similarly, increased expression of four cytokines (IL-1 $\beta$, TGF- $\beta 1$, TNF- $\alpha$, and IL-10) was apparent in contralateral DRG for up to 35 days after sciatic nerve transection (Ruohonen et al., 2002). Up-regulation of torsinA in ipsilateral ganglion cells is consistent with its potential role in the response to cellular stress as noted above in the context of cerebral ischemia. However, the mechanism for up-regulation of torsinA in contralateral satellite cells is less obvious. Satellite cells appear to play important roles in the physiology of their contiguous ganglion cells (Dublin and Hanani, 2007; Kuo et al., 2007). Satellite cells exhibit increased gapjunction coupling in response to the ipsilateral application of noxious stimuli (Dublin and Hanani, 2007). Up-regulation of p75 in satellite cells appears to be responsible for 
sympathetic sprouting in the DRG after peripheral nerve lesions (Hu and McLachlan, 2000). Because unilateral sciatic nerve transection is associated with compensatory changes in gait and appendicular loads, up-regulation of torsinA in contralateral satellite cells could be related to the increased signaling demands on the adjacent ganglion cells. Alternatively, up-regulation of torsinA in satellite cells could be part of a generalized response to the surgical intervention, possibly due to plasma TGF- $\beta$. Interestingly, work in Drosophila suggested that TGF- $\beta$ signaling might be defective in DYT1 dystonia (Koh et al., 2004). Over-expression of Smad2, a downstream effector of TGF- $\beta$, suppressed ultrastructural defects at the neuromuscular junction in $\triangle \mathrm{GAG}$ human torsinA flies.

\subsubsection{TorsinA Function}

TorsinA protein is structurally related to the $\mathrm{ClpB} / \mathrm{Hsp} 100$ family of proteins, which have been shown to have unfoldase activities (Hong and Vierling, 2000; Weibezahn et al., 2004; Ung et al., 2007). According to the evidence that torsinA was found localized to protein aggregations such as Lewy bodies in Parkinson's disease brain and inclusion bodies in trinucleotide repeat diseases, and its overexpression facilitated clearance of the aggregates (Shashidharan et al., 2000b; Sharma et al., 2001; McLean et al., 2002; Walker et al., 2003; Caldwell et al., 2003) and overexpression of torsinA facilitated clearance of another dystonia-related protein, SGCE, by the ubiquitin proteosome system (Esapa et al., 2007), torsinA is hypothesized to play a similar role as an unfoldase in mammalian systems (McLean et al., 2002; Kuner et al., 2003).

Several largely-independent lines of evidence indicate that torsinA contributes to the brain development and might regulate neurite extension and synaptic functioning. TorsinA was strikingly expressed in prenatal and early postnatal period, with the most intense expression in cerebellar Purkinje cells, striatal cholinergic interneurons, and SNpc dopaminergic neurons at postnatal day 14 (Xiao et al., 2004), a period of intense cellular migration, neurite extension, and synaptogenesis. TorsinA knock-out and homozygous $\triangle$ GAG knock-in mice die shortly after birth (Goodchild et al., 2005). TorsinA was found localized to the neurites and synapses (Augood et al., 2003; Konakova et al. 2001; Konakova and Pulst, 2001; Kuner et al., 2003; Kamm et al., 2004). Overexpression of mutant torsin A inhibited neurite extension; however, attenuation of wild-type torsinA facilitated neurite extension (Ferrari-Toninelli et al., 2004; Hewett et al., 2006). In addition, torsinA was found to interact with snapin, a SNARE-associated protein, and to control synaptic-vesicle recycling (Ilardi et al., 1999; Granata et al., 2008). TorsinA was also interacted with kinesin light chain, a motor protein to transport cargos from cell body to synapses along microtubules (Kamm et al., 2004).

Other evidence suggests that torsinA might maintain the structure of the nuclear envelope and endoplasmic reticulum by interacting with cytoskeletal proteins. TorsinA knock-out, homozygous $\triangle \mathrm{GAG}$ knock-in, and $\triangle \mathrm{GAG}$ transgenic mice showed morphological abnormalities of the nuclear envelope (Goodchild et al., 2005; Grundmann et al., 2007). TorsinA co-immunoprecipitates with a multi-molecular complex that includes cytoskeleton proteins (vimentin, tubulin, and actin), a motor protein (KLC1), 
nuclear envelope proteins (LAP1 and nesprin), an endoplasmic reticulum protein (LULL1), and a linker protein (plectin) (Goodchild and Dauer, 2005; Hewett et al., 2006; Nery et al., 2007). The linker protein plectin links the nuclear envelope to the cytoskeleton by an interaction with nesprin, an outer nuclear membrane protein (Wilhelmsen et al., 2005). In vitro studies have shown that mutant torsinA interferes with cytoskeletal events that involve vimentin (Hewett et al., 2006). Vimentin, a member of the intermediate filament family of proteins, is expressed in the developing brain (Sancho-Tello et al., 1995; Hutchins and Casagrande, 1989), and is also induced in reactive glia (Kindy et al., 1992; Braun et al., 1998). Vimentin plays an important role in cellular morphology and organelle positioning (Goldman et al., 1996).

\subsection{CONCLUSIONS}

Neurodevelopmental abnormalities might be central to the pathobiology of DYT1 dystonia, given that generalized dystonia rarely develops during adulthood in $\triangle \mathrm{GAG}-$ mutation carriers (Bressman et al., 2000; Carbon et al., 2008b). On the other hand, the reduced penetrance of the $\triangle \mathrm{GAG} T O R 1 A$ mutation suggests that a perturbation (e.g., trauma, hypoxia, severe febrile illness, intense sensorimotor training) to the CNS or PNS might be required for the appearance of a dystonic phenotype. Hypoxic-ischemic insults are believed to be pathogenic in cases of dystonic cerebral palsy (Kyllerman, 1982; Treves and Korcyzyn, 1986; Cerovac et al., 2007), an example of secondary dystonia, and it is conceivable that perinatal factors such as hypoxia-ischemia might increase expressivity of dystonia in carriers of the DYT1 mutation. Its well-demarcated gross anatomy and precise intrinsic connections make the post-ischemic rat hippocampus an ideal model system in which to study the reactive synaptogenesis, astrocytosis, and neurogenesis that follows the loss of CNS neurons, and sciatic nerve transection offers comparable advantages in the PNS. The induction of torsinA in glia suggests a novel avenue through which to explore the cellular and systems pathopathophysiology of DYT1 dystonia. 


\section{CHAPTER 3. BEHAVIOR, MORPHOLOGICAL, NEUROCHEMICAL, AND METABOLIC FEATURES OF DYT1 $\triangle$ GAG TRANSGENIC MICE*}

\subsection{INTRODUCTION}

Although the cellular function of mutant torsinA has been explored with a variety of in vivo approaches, the data generated in these studies do not provide a clear link between the molecular biology of torsin A and the development of dystonia. However, post-mortem studies have provided evidence that functional abnormalities and/or ultrastructural abnormalities rather than neurodegeneration underlie DYT1 dystonia and pointed to the nigrostriatal pathway as a potential site of neuropathological significance in human DYT1 dystonia. Rostasy and colleagues (2003) failed to disclose any consistent evidence of neuronal loss, inflammation, or neurodegeneration in DTY1 dystonia, but they did detect an increased nigral cell density along with somatic enlargement of nigral dopaminergic neurons in the brains of DYT1 dystonia patients. A significant increase in DA turnover and a decline in dopamine D1 and D2 receptor binding have also been established in DYT1 dystonic striatum (Augood et al., 2002). In addition, functional neuroimaging studies have identified an increased metabolic activity in the putamen, cerebellum, and SMA in carriers of the DYT1 mutation (Eidelberg, 1998; Carbon et al., 2004a). Together with evidence of high-level expression of torsinA transcript and protein within dopaminergic neurons of the SNpc during brain development (Konakova et al., 2001; Konakova and Pulst, 2001; Augood et al., 2003; Oberlin et al., 2004; Xiao et al., 2004; Vasudevan et al., 2006), these findings suggest that torsinA might be important for nigrostriatal development and function, whereby a mutant and non-functional protein could lead to aberrant nigrostriatal function and the subsequent development of dystonia.

Unfortunately, the above-noted dopaminergic aberrations in human DYT1 dystonia have not been replicated in independent studies. Furthermore, the available data are limited by the number of brains examined in each study (Augood et al., 2002; Rostasy et al., 2003; Asanuma et al., 2005). Genetically modified animal models are useful tools to investigate the contributing effects of mutant torsinA to the onset of DYT1 dystonia, investigate and confirm findings in human patients, and open the door for future studies.

Current thinking related to AAA+ proteins suggests that a single mutant torsin A molecule could disrupt assembly of functional torsinA homohexamers. Accordingly, intense transgenic expression of mutant torsinA should interrupt the function of endogenous torsinA by interfering with formation of intact homohexamer. On this background, Sharma and colleagues (2005) developed the hMT1, hMT2, and hWT lines of mice. In these transgenic mice, either human wild-type or mutant torsin A are driven by the human cytomegalovirus (CMV) immediate early promoter. Because there is no

\footnotetext{
* Permission to reproduce by Elsevier Inc. Zhao Y, DeCuypere M, LeDoux MS (2008) Abnormal motor function and dopamine neurotransmission in DYT1 DeltaGAG transgenic mice. Exp Neurol. 210: 719-730.
} 
tag added to the human torsinA cDNA in the expression vector, the expression of the exogenous gene cannot be evaluated in the transgenic mice. However, previous studies have reported that CMV promoters drive widespread expression of exogenous genes in the neurons and astrocytes, (Fritschy et al., 1996; van den Pol and Ghosh, 1998). Furthermore, under the CMV promoter the cellular pattern of expression involves entire neuronal arbors, transcripts and their protein products are not restricted to aberrant cellular compartments (van den Pol and Ghosh, 1998). Therefore, the models developed by Sharma colleagues are suitable for the study of DYT1 dystonia. In previous work, transgenic mice that express mutant torsinA show reduced ability to learn motor skills in an accelerating rotarod paradigm at six months of age, as well as abnormal dopaminergic D2 receptor responses in striatal cholinergic interneurons (Pisani et al., 2006).

Furthermore, amphetamine-induced DA release is attenuated in the hMT1 mice (Balcioglu et al., 2007). Of note, the hMT1 and hMT2 mice do not exhibit dystonia. Moreover, no other murine model of DYT1 dystonia actually manifests dystonia. These results are not entirely unexpected, because the penetrance of the human DYT1 $\triangle \mathrm{GAG}$ mutation is less than $40 \%$. In conclusion, hMT mice can be viewed as models of the DYT1 carrier state.

In the work described herein, we rigorously characterized the behavioral, morphological, neurochemical, and brain metabolical features of the hMT1 transgenic model of the DYT1 carrier state. As shown below, the hMT1 line exhibits robust transgene expression. Specifically, a comprehensive battery of behavorial tests was used to identify motor abnormalities in hMT1 mice. Electron and confocal microscopy were employed to evaluate previous reports of neuronal nuclear bleb formation and ubiquitinpositive cytoplasmic inclusions, respectively, in human DYT1 dystonia and other murine models of DYT1 dystonia (McNaught et al., 2004; Dang et al., 2005; Goodchild et al., 2005; Shashidharan et al., 2005; Grundmann et al., 2007). High-performance liquid chromatography with electrochemical detection (HPLC-EC) was carried out to comprehensively quantify monoaminergic neurotransmitters and their metabolites in multiple neural structures. Finally, 2-deoxy-D-glucose (2-DG) utilization, as well as cytochrome oxidase (CO) histochemistry, was performed to evaluate short- and longterm brain metabolic demands.

\subsection{METHODS}

\subsubsection{DYT1 Transgenic Mouse Model and Genotyping}

Breeding colonies of hWT, hMT1, and hMT2 mice were established at the University of Tennessee Health Science Center by matings with wild-type (WT) C57BL/6J mice. All mice used in experiments were C57BL/6J backcrossed at least 8X. Tail DNA from the breeders and their offspring were isolated with the AquaPure Genomic DNA Tissue Kit (Bio-Rad Laboratories, Hercules, CA, USA) for genotyping. The primer pair used for genotyping analysis is detailed in Table 3-1. The primers amplified a 560-bp segment $\left(35\right.$ cycles; annealing temperature $-60^{\circ} \mathrm{C}$ ) within the human 
Table 3-1. Probe and primers used for QRT-PCR, and primers used for generation of Northern blot probes.

\begin{tabular}{|c|c|c|c|c|}
\hline Name & Sequence $\left(5^{\prime} \rightarrow 3^{\prime}\right)$ & Locus & Usage & Product (bp) \\
\hline GF1 & cacattgcactttccacatgct & $\begin{array}{l}\text { NM_000113 } \\
479-500 \mathrm{nt}\end{array}$ & Genotyping & \\
\hline GR1 & cgttttgcagcctttatctga & $\begin{array}{l}\text { NM_000113 } \\
1040-1020 \mathrm{nt}\end{array}$ & Genotyping & $\begin{array}{l}560 \text { (with } \\
\text { GF1) }\end{array}$ \\
\hline TOR1AF & gcgtctctactgcctcttcg & $\begin{array}{l}\text { NM_000113 } \\
197-216 \mathrm{nt}\end{array}$ & $\begin{array}{l}\text { antisense probe } \\
1\end{array}$ & \\
\hline TOR1AR & $\begin{array}{l}\text { gataatacgactcactatagggt } \\
\text { ggacatagtcactgttcag }\end{array}$ & $\begin{array}{l}\text { NM_000113 } \\
466-447 \mathrm{nt}\end{array}$ & $\begin{array}{l}\text { antisense probe } \\
1\end{array}$ & $\begin{array}{l}270 \text { (with } \\
1 \mathrm{AF})\end{array}$ \\
\hline TOR1SF & $\begin{array}{l}\text { gataatacgactcactataggg } \\
\text { gcgtctctactgcctcttcg }\end{array}$ & $\begin{array}{l}\text { NM_000113 } \\
197-216 \mathrm{nt}\end{array}$ & sense probe 1 & \\
\hline TOR1SR & tggacatagtcactgttcag & $\begin{array}{l}\text { NM_000113 } \\
466-447 \mathrm{nt}\end{array}$ & sense probe 1 & $\begin{array}{l}270 \text { (with } \\
1 \mathrm{AF})\end{array}$ \\
\hline TOR2AF & acaagaacagtggcttctggca & $\begin{array}{l}\text { NM_000113 } \\
817-838 \mathrm{nt}\end{array}$ & $\begin{array}{l}\text { antisense probe } \\
2\end{array}$ & \\
\hline TOR2AR & $\begin{array}{l}\text { gataatacgactcactataggg } \\
\text { ggtgaacaccgttttgcagc }\end{array}$ & $\begin{array}{l}\text { NM_000113 } \\
104 \overline{9}-1030 \mathrm{nt}\end{array}$ & $\begin{array}{l}\text { antisense probe } \\
2\end{array}$ & $\begin{array}{l}233 \text { (with } \\
2 \mathrm{AF})\end{array}$ \\
\hline TOR2SF & $\begin{array}{l}\text { gataatacgactcactataggg } \\
\text { acaagaacagtggcttctggca }\end{array}$ & $\begin{array}{l}\text { NM_000113 } \\
817-838 \mathrm{nt}\end{array}$ & sense probe 2 & \\
\hline TOR2SR & ggtgaacaccgttttgcagc & $\begin{array}{l}\text { NM_000113 } \\
1049-1030 \mathrm{nt}\end{array}$ & sense probe 2 & $\begin{array}{l}233 \text { (with } \\
2 \mathrm{SF})\end{array}$ \\
\hline Actb1AF & agcaagagaggtatcctga & $\begin{array}{l}\text { NM_144884 } \\
257-275 \mathrm{nt}\end{array}$ & $\begin{array}{l}\beta \text {-actin } \\
\text { antisense probe }\end{array}$ & \\
\hline Actb1AR & $\begin{array}{l}\text { gataatacgactcactataggg } \\
\text { acagcacagcctggatggcta }\end{array}$ & $\begin{array}{l}\text { NM_144884 } \\
500-480 \mathrm{nt}\end{array}$ & $\begin{array}{l}\beta \text {-actin } \\
\text { antisense probe }\end{array}$ & $\begin{array}{l}244 \text { (with } \\
\text { Actb1AF) }\end{array}$ \\
\hline Actb1SF & $\begin{array}{l}\text { gataatacgactcactataggg } \\
\text { agcaagagaggtatcctga }\end{array}$ & $\begin{array}{l}\text { NM_144884 } \\
257-275 \mathrm{nt}\end{array}$ & $\begin{array}{l}\beta \text {-actin sense } \\
\text { probe }\end{array}$ & \\
\hline Actb1SR & acagcacagcctggatggcta & $\begin{array}{l}\text { NM_144884 } \\
500-480 \mathrm{nt}\end{array}$ & $\begin{array}{l}\beta \text {-actin sense } \\
\text { probe }\end{array}$ & $\begin{array}{l}244 \text { (with } \\
\text { Actb1SF) }\end{array}$ \\
\hline QF1-h & gcgtctctactgectcttcg & $\begin{array}{l}\text { NM_000113 } \\
197-216 \mathrm{nt}\end{array}$ & RT-PCR & \\
\hline QR1-h & ggttgtcgtccagatccttc & $\begin{array}{l}\text { NM_000113 } \\
282-263 \mathrm{nt}\end{array}$ & RT-PCR & $\begin{array}{l}86 \text { (with } \\
\text { QF1-h) }\end{array}$ \\
\hline QP1-h & gggcagaag & $\begin{array}{l}\text { NM_000113 } \\
229-236 \mathrm{nt}\end{array}$ & RT-PCR & \\
\hline QF1-m & ccgtgtcggtcttcaataaca & $\begin{array}{l}\text { NM_144884 } \\
769-789 \mathrm{nt}\end{array}$ & RT-PCR & \\
\hline QR1-m & $\begin{array}{l}\text { aataatctatgaggttccggtca } \\
\text { a }\end{array}$ & $\begin{array}{l}\text { NM_144884 } \\
843-820 \mathrm{nt}\end{array}$ & RT-PCR & $\begin{array}{l}75 \text { (with } \\
\text { QF1-m) }\end{array}$ \\
\hline QP1-m & cagcagcc & $\begin{array}{l}\text { NM_144884 } \\
809-816 n t\end{array}$ & RT-PCR & \\
\hline
\end{tabular}


torsin A coding sequence that was identified via 1\% agarose gel electrophoresis (Figure 3-1A). The genotype of the breeders was confirmed by restriction digestion with BseRI (New England BioLabs, Ipswich, MA, USA). The human WT torsinA PCR product was digested with BseRI into four fragments (279 bp, $238 \mathrm{bp}, 24 \mathrm{bp}$, and $22 \mathrm{bp}$ ). The human mutant torsin A PCR product was digested with BseRI into three fragments (279 bp, 259 bp, and 22 bp). Fragment profiles were identified with $2 \%$ agarose gel electrophoresis

(Figure 3-1B).

\subsubsection{Northern Blot Hybridization}

Whole-brain RNA from WT $(\mathrm{n}=4)$, hWT $(\mathrm{n}=4)$, hMT1 $(\mathrm{n}=3)$, and hMT2 $(\mathrm{n}=$ 4) mice were extracted with TRI reagent ${ }^{\circledR}$ (Ambion, Austin, TX, USA) and DNA was removed with DNA-free ${ }^{\mathrm{TM}}$. Total RNA quality was examined with agarose gel electrophoresis and a NanoDrop ${ }^{\circledR}$ ND-1000 spectrophotometer. Pooled human whole brain RNA was obtained from Ambion (Human Brain Reference RNA, $n=23$ brains). The MicroPoly(A)Purist (Ambion) kit was used to extract mRNA from total RNA. The mRNA was electrophoretically resolved on denaturing gels and transferred to positively charged nylon membranes. Radiolabeled $\left({ }^{32} \mathrm{P}-\mathrm{UTP}\right)$ cRNA probes were generated by in vitro transcription with T7 RNA polymerase. Primer pair sequences to make the radioactive probes are described in Table 3-1. After ultraviolet crosslinking, blots were prehybridized and hybridized overnight with TOR1A and Actb ( $\beta$-actin) cRNA probes. The TOR1A probe was generated from human cDNA template, whereas the Actb probe was generated from mouse cDNA template. After washing, blots were exposed to Kodak Biomax MR radiographic film prior to development.

\subsubsection{QRT-PCR}

Reverse transcription was performed with Ambion's RETROscript ${ }^{\mathrm{TM}}$ kit with 500 ng total RNA as template. The reaction mixture was incubated at $44{ }^{\circ} \mathrm{C}$ for $1 \mathrm{hr}$ and at 92 ${ }^{\circ} \mathrm{C}$ for 10 min. QRT-PCR was performed with the Roche LightCycler 480 with genespecific primers and Universal Taqman ${ }^{\circledR}$ probes (Table 3-1; Roche Applied Science, Indianapolis, IN, USA) for the target genes (human torsin A and mouse torsinA) and endogenous control (Cyclophilin D). Relative levels of human torsinA transcript in mouse brain were calculated relative to Human Brain Reference RNA and total RNA from normal human striatum (Stratagene, La Jolla, CA, USA; $\mathrm{n}=1$ brain), whereas levels of mouse torsinA mRNA (hWT [n=4], hMT1 [n=3], and hMT2 [n=4]) and striatal $(\mathrm{hWT}[\mathrm{n}=6], \mathrm{hMT} 1[\mathrm{n}=8]$, and hMT2 $[\mathrm{n}=4]$ ) were calculated relative to WT littermates (whole brain $[n=4]$ and striatum $[n=6]$ ).

\subsubsection{Behavioral Assessment}

Adult (3-4 month) male hWT $(\mathrm{n}=24)$ and hMT1 $(\mathrm{n}=35)$ mice, along with WT $(n=20)$ age- and gender-matched littermate controls, were used for quantitative analyses 


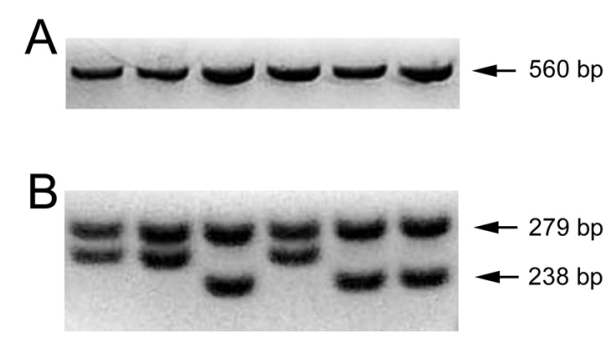

C WT hWT hMT2 hMT1 Hum

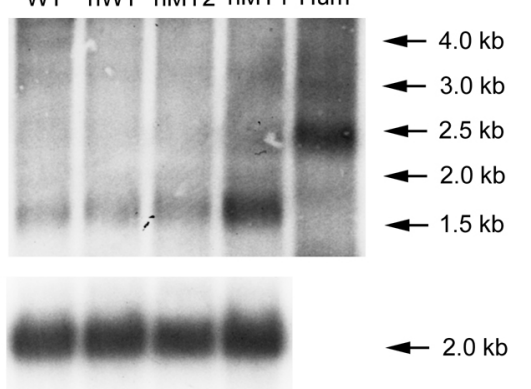

Figure 3-1. Genotyping and Northern blot analysis of hWT, hMT1, and hMT2 transgenic mice.

Gel images of PCR products before (A) and after (B) digestion are shown. Products from hMT1 or hMT2 mice appear in lanes 1, 2, and 4, whereas products from hWT mice appear in lanes 3, 5, and 6. (C) Northern blot analysis of equal amount of poly-A RNA obtained from brain tissues of human, WT, hWT, hMT1, and hMT2 mice. Human torsin A probes recognized a $1.5 \mathrm{~kb}$ band in transgenic mice, and a $2.5 \mathrm{~kb}$ band in human brain. Mouse $\beta$-actin (loading control) appeared as a $2.0 \mathrm{~kb}$ band below each lane. 
of motor functions (Jiao et al., 2005). In addition, hMT1, hMT2, and hWT mice, including animals over one year of age, were routinely observed for evidence of dystonia during open-field behavior.

\subsubsection{Rotarod Performance}

Mice were acclimated to a Rotamex-5 rotarod (Columbus Instruments, Columbus, $\mathrm{OH}, \mathrm{USA}$ ) that rotated at $5 \mathrm{rpm}$ for $5 \mathrm{~min}$ one day prior to data acquisition. Two motor assessments were performed. The first assessment began with a $30 \mathrm{~s}$ acclimation period at $4 \mathrm{rpm}$, followed by an acceleration of $4 \mathrm{rpm}$ every $30 \mathrm{~s}$ to a maximum of $5 \mathrm{~min}$ at 40 $\mathrm{rpm}$. Mice were given three trials at the same time each day for 5 consecutive days. The second assessment began with an initial speed of $4 \mathrm{rpm}$, which gradually accelerated at a rate of $1 \mathrm{rpm}$ every $5 \mathrm{~s}$ to an incremented target speed for 5 consecutive days $(5,10,20$, 30, and $40 \mathrm{rpm}$, respectively). Transgenic and WT littermate mice were randomly selected for one of these two trials. All tests were performed in technical triplicate, and median values were used for statistical comparison.

\subsubsection{Footprint Analysis}

Mouse forepaws (green) and hindpaws (red) were dipped in nontoxic water-based paints. Mice were allowed to walk down an enclosed runway lined with white paper. Three trials were performed on three separate days within one week. Two to four steps from the middle portion of each run were measured for (1) stride length, (2) hind-base width (the distance between the right and left hindlimb strides), and (3) front-base width (the distance between the right and left forelimb strides). At least seven steps were measured for each mouse. Mean values were used for statistical analysis.

\subsubsection{Tail Suspension}

This test involved the response of each mouse to $1 \mathrm{~min}$ of vertical suspension from the tail. Neurological dysfunction is exhibited as hindlimb and/or forelimb clasping during this maneuver.

\subsubsection{Vertical Rope Climb}

Mice were acclimated to a vertical, 40-cm long, 10-mm thick nylon rope prior to testing. The bottom of the rope was suspended $15 \mathrm{~cm}$ above a padded base, and the top entered into a darkened escape box. Three trials with a 5-min intertrial interval were completed for each mouse. Median times were used for statistical analysis. 


\subsubsection{Raised-beam Task}

Mice were acclimated to an $80-\mathrm{cm}$ long, 20-mm wide beam elevated $50 \mathrm{~cm}$ above a padded base. A $60 \mathrm{~W}$ lamp at the start served as an aversive stimulus, whereas the opposite end of the beam entered a darkened escape box. Transversal time and number of slips were measured as mice traversed the beam. After initial testing with a $20-\mathrm{mm}$ diameter square beam, mice were given follow-up tests using supplementary round (8$\mathrm{mm}$ and $12-\mathrm{mm}$ diameter) and square (12-mm diameter) beams. All testing was performed in triplicate, and median values were used for subsequent statistical analyses.

\subsubsection{Confocal Microscopy}

Adult (3-4 month) male WT $(\mathrm{n}=3)$, hWT $(\mathrm{n}=3)$, and hMT1 $(\mathrm{n}=3)$ mice were overdosed with pentobarbital (100 $\mathrm{mg} / \mathrm{kg}$, IP) prior to transcardiac perfusion with heparinized saline and $4 \%$ paraformaldehyde/ $0.1 \mathrm{M} \mathrm{PB}$. Brains were dissected, postfixed in 4\% paraformaldehyde for another $2 \mathrm{hrs}$, and incubated in a cryoprotectant solution ( $30 \%$ sucrose $/ 0.1 \mathrm{M} \mathrm{PB}, \mathrm{pH} 7.4$ ) for at least $48 \mathrm{hrs}$. Brains were sectioned at 20 $\mu \mathrm{m}$ on a cryostat, collected onto SuperFrost ${ }^{\circledR}$-Plus glass slides, circled with a PAP pen, and allowed to dry on a slide warmer for 10 min. Sections were blocked in $2 \%$ nonfat dry milk and $0.3 \%$ Triton X-100 in $0.02 \mathrm{M}$ PBS, and incubated overnight with mouse monoclonal anti-torsinA antibody D-M2A8 (1:300 diluted in PBS with 3\% normal donkey serum and $0.1 \%$ Triton X-100) and rabbit polyclonal anti-ubiquitin antibody (1:1000; Dakocytomation, Carpinteria, CA, USA). Sections were incubated for $4 \mathrm{hr}$ with biotinylated horse anti-mouse (1:500) and RRX- tagged donkey anti-rabbit secondary antibodies (1:250) diluted in PBS with 2\% normal donkey serum and $0.1 \%$ Triton X-100. After rinsing with PBS, sections were incubated for $1 \mathrm{hr}$ with Cy2-tagged streptavidin (1:500) diluted in PBS with $0.1 \%$ Triton X-100. Sections were rinsed, air-dried, dehydrated, cleared, and coverslipped with DPX mounting compound. Sections were visualized with epifluorescence (Leica DM6000) and confocal laser-scanning microscopy.

\subsubsection{Electron Microscopy}

Adult (3-4 month) male WT $(\mathrm{n}=3)$, hWT $(\mathrm{n}=3)$, and hMT1 $(\mathrm{n}=3)$ mice were overdosed with pentobarbital (100 $\mathrm{mg} / \mathrm{kg}$, IP) prior to transcardiac perfusion with heparinized saline and $4 \%$ paraformaldehyde $/ 2.5 \%$ glutaraldehyde $/ 15 \%$ picric acid in 0.1 $\mathrm{M} P \mathrm{~PB}$. The brains and cervical spinal cords were dissected from surrounding tissue. Regions of interest (striatum, pons, cerebellar cortex, and spinal cord) were cut into $3 \times 3$ x $3 \mathrm{~mm}$ blocks that were post-fixed overnight. Tissue blocks were post-fixed in 1\% osmium tetroxide (Electron Microscopy Sciences, Hatfield, PA, USA) in PBS for $4 \mathrm{hrs,}$ and were rinsed briefly in deionized water. After ascending dehydration in $30 \%, 50 \%$, $70 \%, 85 \%, 95 \%$, and $3 \times 100 \%$ ethanol (each for $30 \mathrm{~min}$ ), tissue blocks were infiltrated with 50\% Spurr (Electron Microscopy Sciences) in 100\% ethanol overnight at room temperature, and $100 \%$ Spurr over 8 hrs. Blocks were cured at $70{ }^{\circ} \mathrm{C}$ for 2 days. One- 
micrometer sections were cut on a Reichert Ultracut E microtome (Reichert Instruments, Depew, NY, USA), and were stained with toluidine blue. Areas of interest were selected, sectioned at $75 \mathrm{~nm}$, mounted onto 150 -mesh grids, and post-stained with $4 \%$ uranyl acetate in methanol and Venable lead citrate. Sections were visualized, and were photographed with a JEOL 2000EX transmission electron microscope (JOEL USA Inc., Peabody, MA, USA) at $60 \mathrm{kV}$ with 30,000X magnification.

\subsubsection{HPLC-EC Analysis of Monoamines and Their Metabolites}

All standards, including 5-HIAA, 5-HT hydrochloride, DA hydrochloride, DOPAC, epinephrine hydrochloride (EPI), HVA, and NE hydrochloride, were of analytical grade, and were purchased from Sigma-Aldrich. Sodium octylsulphonate (SOS) and monobasic anhydrous sodium dihydrogen phosphate used in mobile-phase preparation were purchased from Fluka Chemie (Buchs, Switzerland). HPLC-grade water and acetonitrile were obtained from Fisher Scientific.

Tissues from adult (3-4 month) male hWT $(n=10)$ and hMT1 $(n=11)$ mice, along with WT $(\mathrm{n}=10)$ age- and gender-matched littermate controls were analyzed with HPLC-EC to quantify cerebral cortical, striatal, and cerebellar levels of DA, NE, EPI, 5HT, DOPAC, HVA, and 5-HIAA.

Fresh samples of striatum, cerebellar cortex, and cerebral cortex were weighed and homogenized in $100 \mu \mathrm{l}$ of an ice-cold solution of $0.1 \mathrm{M}$ perchloric acid, $0.1 \mathrm{mM}$ sodium metabisulfite, and $0.1 \mathrm{mM}$ EDTA per $10 \mathrm{mg}$ wet weight. Homogenates were centrifuged at $20,000 \mathrm{~g}$ for $25 \mathrm{~min}$ at $4{ }^{\circ} \mathrm{C}$. Supernatants were filtered through $0.22 \mu \mathrm{m}$ pore size polyvinylidene fluoride syringe-driven membrane filters (Millipore Corp., Bedford, MA, USA), and the filtrate was immediately frozen and stored at $-80{ }^{\circ} \mathrm{C}$ until the time of analysis.

HPLC analysis was performed with an ESA Model 5600A CoulArray® system (ESA Inc., Chemlsford, MA, USA), equipped with Shimadzu Model DGU-14A on-line degassing unit (Shimadzu Scientific Instruments, Columbia, MD, USA), an ESA Model 582 pump, and an ESA Model 542 refrigerated autosampler. The detection system consisted of three coulometric array modules, and each contained four electrochemical detector cells. Electrode potentials were selected over the range of +50 to $+600 \mathrm{mV}$, with a $50 \mathrm{mV}$ increment against palladium electrodes. Chromatographic separation was achieved by auto-injecting $20 \mu \mathrm{l}$ sample aliquots at $5^{\circ} \mathrm{C}$ onto a MetaChem Intersil (MetaChem Technologies, Torrance, CA, USA) reversed-phase $\mathrm{C}_{18}$ column $(5 \mu \mathrm{m}$ particle size, $250 \times 4.6 \mathrm{~mm}$ I.D.) with an ESA Hypersil $\mathrm{C}_{18}$ guard column $(5 \mu \mathrm{m}$ particle size, $7.5 \times 4.6 \mathrm{~mm}$ I.D.). The mobile phase used for compound separation consisted of 75 $\mathrm{mM}$ monobasic sodium dihydrogen phosphate, $2.0 \mathrm{mM}$ SOS, $25 \mu \mathrm{M}$ EDTA, $0.005 \%$ triethylamine, and 10\% acetonitrile, $\mathrm{pH} 3.0$. A flow rate of $1.5 \mathrm{ml} / \mathrm{min}$ and analysis time of $45 \mathrm{~min}$ were used for all experiments. System control and data acquisition/processing were performed with ESA CoulArray software (version 1.02). All samples were processed in technical triplicate, and median values used for statistical analysis. 


\subsubsection{2-DG Autoradiography and CO Histochemistry}

\subsubsection{Tissue Collection}

Adult (3-4 month) male hMT1 $(\mathrm{N}=9)$ and hWT $(\mathrm{N}=8)$ mice, along with WT $(\mathrm{N}$ $=9$ ) age- and gender-matched littermate controls, were used for quantitative analyses of brain metabolism with 2-DG uptake and CO histochemistry.

After a single dose of $2-\mathrm{DG}(0.165 \mu \mathrm{Ci} / \mathrm{g})$ given by intraperitoneal injection, mice were placed in individual cages with free movement for 45 min to allow for 2-DG absorption, overdosed with pentobarbital, and perfused with heparinized saline followed by a mixture of $2.5 \%$ paraformaldehyde $/ 1.5 \%$ glutaraldehyde $/ 4 \%$ sucrose in $0.1 \mathrm{M} \mathrm{PB}$. Brains were rapidly removed from the skull, blocked, rapidly frozen in isopentane $(-40$ ${ }^{\circ} \mathrm{C}$ ), and stored at $-80{ }^{\circ} \mathrm{C}$.

Brains were sectioned in five series on a cryostat at $20 \mu \mathrm{m}$ in the coronal plane. Sections were collected onto SuperFrost ${ }^{\circledR}$-Plus glass slides and stored at $-80{ }^{\circ} \mathrm{C}$ in vacuum-sealed slide containers. One series of sections was air-dried overnight and stained with cresyl violet. Separate adjacent series were processed for 2-DG autoradiography imaging and CO histochemistry.

\subsubsection{Image Acquisition and Glucose Utilization (GU) Densitometric Analysis}

Brain sections were exposed to Kodak Biomax MR Film together with ${ }^{14} \mathrm{C}$ Microscale $^{\mathrm{TM}}$ autoradiography standards for 7 days. Autoradiographic images were acquired in the transmission mode and were imported into ImageJ for ROI quantification of radioactivity. Optical density (O.D.) was calibrated to the set of autoradiography standards to generate measures of radioactivity for each ROI. ROIs were defined according to a widely-employed mouse brain atlas (Franklin and Paxinos, 1997). Due to potential confounding variables such as peritoneal absorption, blood-brain permeability, and global utilization, ROI GU data from each mouse was converted to Z-scores.

\subsubsection{CO Histochemistry}

Our CO histochemistry protocol was modified from the protocol of GonzalezLima and Jones (1994). The reaction solution was freshly made in $0.1 \mathrm{M} \mathrm{PB} \mathrm{(pH.} \mathrm{7.4)}$ that contained $0.06 \%$ diaminobenzidine, $0.02 \%$ cytochrome c, and $4.5 \%$ sucrose. Brain slides, together with brain-homogenate standards, were incubated in the reaction solution for $1.5 \mathrm{~h}$ in the dark at $37^{\circ} \mathrm{C}$ in a shaking water bath. The reaction was stopped by washing the slides with $0.1 \mathrm{M} \mathrm{PB}$ with $4 \%$ sucrose for $3 \times 5 \mathrm{~min}$. After dehydration in ascending concentrations of ethanol $(30 \%, 50 \%, 75 \%, 95 \%$, and 2 X 100\%), the slides were cleared with xylene and were coversliped with Permount. 


\subsubsection{Preparation of CO Standards and Biochemical Assay of CO Activity}

Fresh whole brains from five wild-type C57BL/6J mice were homogenized with a manual Dounce-glass homogenizer without buffer. The brain pastes were transferred to 2 $\mathrm{ml}$ microcentrifuge tubes. After centrifugation at $1000 \mathrm{rpm}$ for $2 \mathrm{~min}$ at $4{ }^{\circ} \mathrm{C}$, the tubes were rapidly frozen in prechilled isopentane $\left(-40^{\circ} \mathrm{C}\right)$ and were stored at $-80{ }^{\circ} \mathrm{C}$.

Brain pastes were sectioned on a cryostat in series of variable thickness that covered the entire range of $\mathrm{CO}$ activities measured in different brain structures $(5 \mu \mathrm{m}, 10$ $\mu \mathrm{m}, 20 \mu \mathrm{m}, 30 \mu \mathrm{m}, 40 \mu \mathrm{m}, 50 \mu \mathrm{m}$, and $60 \mu \mathrm{m}$ ), collected onto SuperFrost ${ }^{\circledR}$-Plus glass slides, and stored at $-80^{\circ} \mathrm{C}$ in a vacuum-sealed slide container for further usage as $\mathrm{CO}$ activity standards.

The $\mathrm{CO}$ activity of the brain pastes was determined with a spectrophotometric method modified from Hess and Pope (1953) by Gonzalez-Lima and Jones (1994). First, the sample solution was generated by mixing the brain homogenate in $0.75 \%$ deoxycholate solution at ratio of $0.01 \mathrm{~g}$ per $5 \mathrm{ml}$. Next, $0.1 \mathrm{ml}$ of the sample solution was added to $0.9 \mathrm{ml}$ of $30 \mu \mathrm{M}$ reduced cytochrome c solution and mixed well. The O.D. was measured with a SmartSpec3000 spectrophotometer (Bio-Rad Laboratories, Hercules, CA, USA) at $550 \mathrm{~nm}$ with a kinetic program with $15 \mathrm{~s}$ intervals over a 3 min period. The $\Delta$ O.D. was used for CO activity calculation with an extinction coefficient of $19000 / \mathrm{M}-$ $\mathrm{cm}$. Each sample solution was read in triplicate and each homogenate was reacted 5 times. A measured mean activity of $30.02 \mathrm{mmol} / \mathrm{min} / \mathrm{g}$ of tissue was used for subsequent densitometric analyses.

\subsubsection{CO Densitometric Analysis}

Microscope slides were scanned with a Polaroid SprintScan 4000 (Polaroid Corporation, Waltham, MA, USA) and PathScan Enabler (Meyer Instrument, Houston, TX, USA) at a resolution of 2000 dpi along with brain-paste standards. The digital images were imported into ImageJ for densitometry analysis, and the standards were used to convert O.D. levels into enzyme activity values, reported as $\mu \mathrm{mol} / \mathrm{min} / \mathrm{g}$ of tissue for each ROI. Due to considerable variations in raw ROI CO activity, $\mathrm{CO}$ activity within each ROI was converted to Z-scores for subsequent statistical analysis.

\subsubsection{Statistical Analyses}

The results of all locomotor and biochemical experiments were analyzed by means of one-way ANOVA using SAS. An alpha $(\alpha)$ of 0.05 was chosen for statistical significance.

The results of 2-DG and $\mathrm{CO}$ histochemistry were analyzed with unpaired t-tests. Data from hMT1 mice were compared to pooled data from $\mathrm{hWT}$ and WT mice, given that (1) hWT mice express very low levels of human wild-type torsinA (data shown below), 
and (2) the high correlation of the data generated from hWT and WT mice (Pearson $r=$ 0.98 for $\mathrm{GU}$; Pearson $\mathrm{r}=0.96$ for $\mathrm{CO}$ activity). Because of the large number of comparisons used in these experiments, the level of significance was set at 0.01 instead of 0.05 . To evaluate networks altered by mutant torsinA, Pearson correlations were calcuated for GU and $\mathrm{CO}$ activity in neuroanatomically-connected brain regions. The ratios of $\mathrm{CO}$ activities and 2-DG signal densities were analyzed with unpaired t-tests.

\subsection{RESULTS}

\subsubsection{TorsinA Expression in DYT1 Transgenic Mice}

The transgenic expression of human torsinA was confirmed with Northern blot analyses. As shown above in Figure 3-1C, human torsin A transcript appears as a $1.5 \mathrm{~kb}$ band in transgenic mice and a $2.5 \mathrm{~kb}$ fragment in human brain. The expression of human torsinA was robust in hMT1 mice, but was weak in hWT and hMT2 mice.

To extend the Northern blot results, QRT-PCR was performed with total RNA from whole brain and striatum, along with species-specific primers and probes. Cyclophilin D was used as an endogenous control. The amplification efficiencies of human torsinA (1.99), mouse torsinA (1.98), human cyclophilin D (1.98) and mouse cyclophilin D (1.97) were nearly identical.

The whole brain expression of human torsinA was measured in all three transgenic lines relative to pooled human whole brain reference RNA, whereas expression of human torsinA in the mouse striatum was referenced to RNA obtained from a single human striatum. As shown in Table 3-2, hMT1 mice showed robust whole-brain and striatal expression of human torsinA transcript (3.90X or $390 \%$ in the whole brain and $4.95 \mathrm{X}$ or $495 \%$ in striatum). In contrast, hWT and hMT 2 mice expressed relatively low levels of human torsinA transcript. Due to the high level of human mutant torsinA expression in hMT1 transgenic mice and the low level of mutant torsinA expression in hMT2 mice, behavioral, morphological, neurochemical, and metabolic studies were limited to the hMT1 transgenic line.

The relative expression of endogenous mouse torsinA transcript was calculated for the three transgenic lines. Analysis of Table 3-2 indicated that the directions of change in relative expression were the same for whole brain and striatum. In whole brain, there were neither overall nor individual effects of genotype on relative levels of mouse torsin A transcript. In striatum, although the effect of genotype on endogenous torsinA expression was not significant $\left(F_{3,27}=2.09, P=0.130\right)$, individual comparisons revealed a significant difference between endogenous torsinA expression in hWT and hMT1 mice $\left(F_{1,27}=6.21, P=0.05\right)$. 
Table 3-2. Relative levels of human and mouse torsinA transcripts in DYT1 transgenic mice.

\begin{tabular}{ccccc}
\hline \multirow{2}{*}{ Line } & \multicolumn{2}{c}{ Whole Brain RNA } & \multicolumn{2}{c}{ Striatal RNA } \\
\cline { 2 - 5 } & $\begin{array}{c}\text { Human } \\
\text { torsinA } \\
\text { transcript* }\end{array}$ & $\begin{array}{c}\text { Mouse torsinA } \\
\text { transcript }\end{array}$ & $\begin{array}{c}\text { Human } \\
\text { torsinA } \\
\text { transcript** }\end{array}$ & $\begin{array}{c}\text { Mouse torsinA } \\
\text { transcript }\end{array}$ \\
\hline hMT1 & $3.90 \pm 0.451$ & $1.14 \pm 0.14$ & $4.95 \pm 0.34$ & $1.33 \pm 0.22$ \\
hMT2 & $0.07 \pm 0.002$ & $1.01 \pm 0.02$ & $0.07 \pm 0.02$ & $1.04 \pm 0.06$ \\
hWT & $0.04 \pm 0.001$ & $0.95 \pm 0.07$ & $0.05 \pm 0.03$ & $0.90 \pm 0.05$ \\
& & & & \\
WT littermates & -- & $1.01 \pm 0.02$ & -- & $1.07 \pm 0.04$ \\
\hline
\end{tabular}

Notes: *Relative to pooled RNA from 23 human brains. **Relative to striatal RNA from a single human brain. 


\subsubsection{Motor Dysfunction in DYT1 Transgenic Mice}

The motoric abilities of transgenic mice were evaluated with a battery of tests that included the raised-beam task, vertical-rope climbing, footprint analysis, and an accelerating rotarod. In addition, we examined the response of transgenic mice to tail suspension. In aggregate, these tests assessed several overlapping aspects of sensorimotor function such as motor power, coordination, and postural stability.

There was no clear-cut evidence of dystonia in any of the mice. WT, hWT, and hMT1 mice did not differ in their response to tail suspension. In particular, no mice exhibited forepaw or hindpaw clasping within the 1-min period of observation. There were no effects of genotype on either the accelerating rotarod (Figure 3-2A and B) or vertical rope climbing (Figure 3-2C). However, there were significant effects of genotype on footprint analysis and the raised-beam task $(P<0.05$, for both). Compared to WT and hWT mice, hMT1 showed increased hind-base width on footprint analysis $\left(F_{1}\right.$, ${ }_{76}=5.21, P=0.025$, Figure 3-2D) and prolonged traversal times on the 12-mm square raised-beam task $\left(F_{1,53}=18.85, P<0.0001\right.$, Figure 3-2E). In follow-up raised-beam task experiments, the effect of genotype on the 12-mm and 8-mm round-beam tasks was significant for traversal times $\left(F_{2,37}=5.62, P=0.007\right.$; and $F_{2,37}=3.52, P=0.040$; respectively) and slip counts $\left(F_{2,37}=3.55, P=0.039\right.$; and $F_{2,37}=5.45, P=0.008$; respectively). Compared to WT mice, hMT1 mice demonstrated a $24 \%$ increase in traversal times and a $425 \%$ increase in slip counts on the $12-\mathrm{mm}$ round-beam task $(P<$ 0.05, for both). As shown in Figure 3-2E and 3-2F, a 29\% increase in traversal times along with a $650 \%$ increase in slip counts were noted on the 8 -mm round-beam task $(P<$ 0.05 , for both). The hWT mice also exhibited prolonged traversal times and more slips on the round-beam tasks $(P<0.05$, for all $)$.

\subsubsection{No Cytoplasmic Inclusion Bodies and Nuclear Envelope Vesicles Were Found in DYT1 Transgenic Mice}

Fluorescent immunocytochemistry was performed to search for ubiquitin- and/or torsinA-positive cytoplasmic inclusion bodies in hMT1 mice. Although all brain regions were surveyed, particular attention was focused on the pontine nuclei, cerebral cortex, striatum, SNpc, and midbrain. The relative distribution of torsinA- and ubiquitin-IR did not differ between hMT1 and WT mice (Figure 3-3). TorsinA- and ubiquitin-IR were localized to the cytoplasm of neurons, but did not co-localize to cytoplasmic inclusions. The subcellular localization pattern of torsinA-IR in hMT1 mice was similar to WT littermates with no evidence of increased torsinA-IR surrounding the nuclear envelope. Electron microscopy was used to search for ultrastructural abnormalities of the nuclear envelope. In contrast to several other mouse models of DYT1 dystonia, we were unable to identify bleb formation at the nuclear envelope in hMT1 mice (Figure 3-4). 

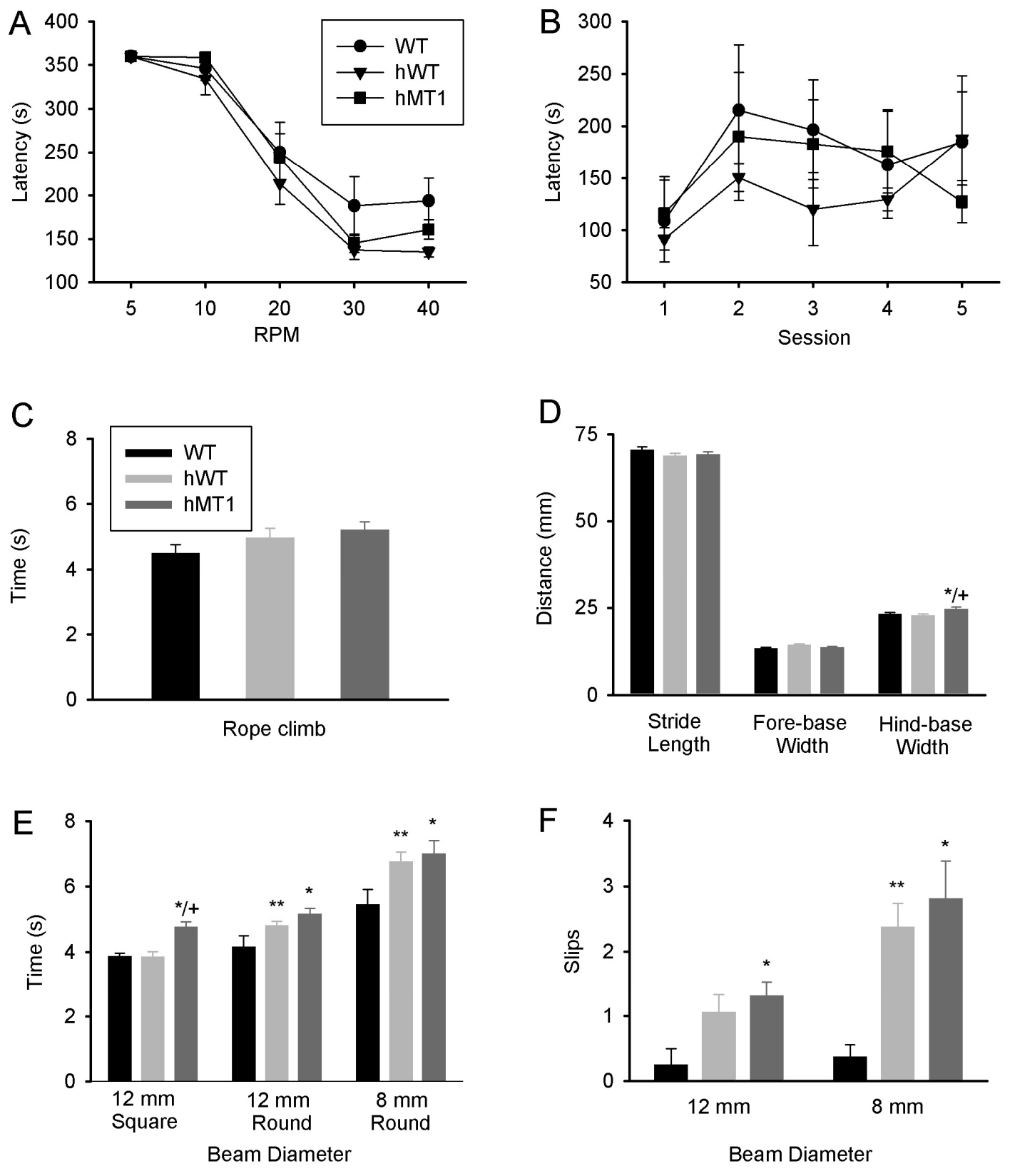

Figure 3-2. Behavioral analysis of motor functioning in DYT1 transgenic mice. Performance of WT (filled circles or black bars), hWT (filled inverted triangles or gray bars) and hMT1 (filled squares or dark gray bars) mice was quantitative analyzed in an accelerating rotarod with increasing destination speeds (A); in an accelerating rotarod with the same destination speed for five consecutive days (B); in vertical-rope climbing (C); footprint analysis (D); and the raised beam task with 12-mm square-beam, 12-mm round-beam, and 8-mm round-beam $(\mathrm{E}, \mathrm{F})$. Results are expressed as the mean $\pm \mathrm{SEM}$. * denotes a significant difference between hMT1 and WT littermates $(p<0.05)$. + denotes a significant difference between hMT1 and hWT littermates $(p<0.05)$. ** denotes a significant difference between hWT and WT littermates $(p<0.05)$. 


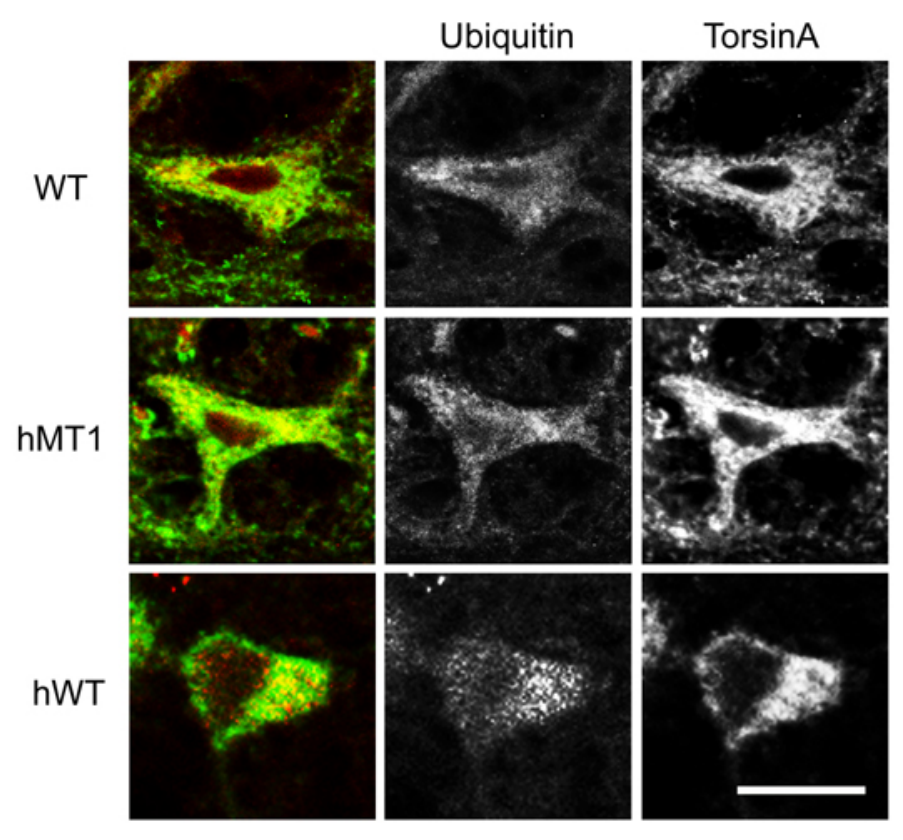

Figure 3-3. Cellular localization of torsin $A$ and ubiquitin immunoreactivity in neurons.

High-magnification confocal images of double-label fluorescent immunocytochemistry for simultaneous detection of torsin A (green, right column gray scale) and ubiquitin (red, middle column gray scale) in the pontine nuclei of hMT1, hWT and WT mice. No obvious torsinA and ubiquitin-IR cytoplasmic inclusions or increased torsinA-IR in nuclear envelope was found in hMT1. Double-label cells appear yellow in the merged images. Scale bar, $25 \mu \mathrm{m}$. 


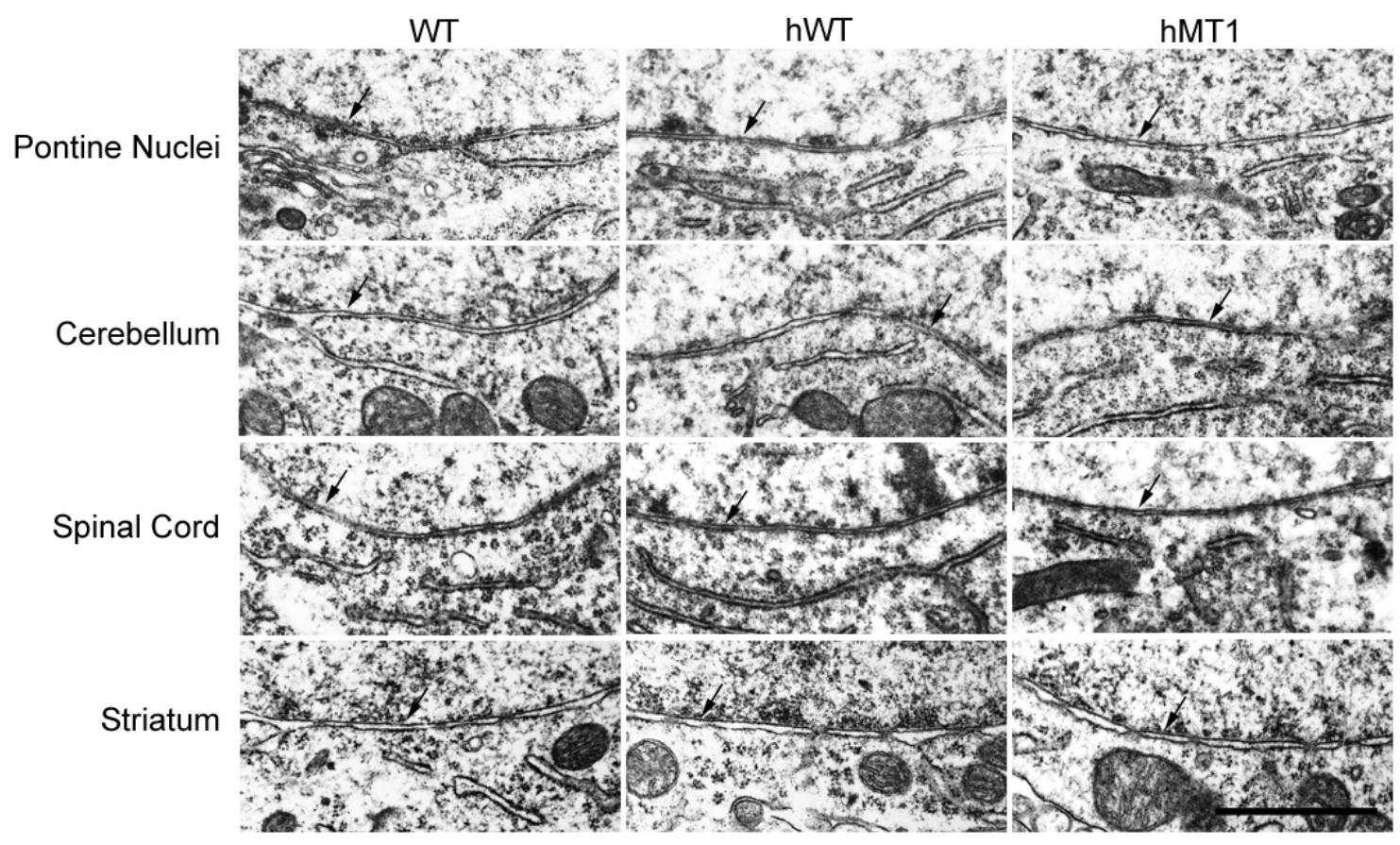

Figure 3-4. Electron microscopic images of the nuclear envelopes in DYT1 transgenic mice.

Electron microscopy was used to identify nuclear envelope blebs in the pontine nuclei, cerebellum, spinal cord, and striatum of hMT1, hWT, and WT mice. There was no nuclear envelope blebs (arrow) found in these regions. Scale bar, $1 \mu \mathrm{m}$. 


\subsubsection{Neurochemical Phenotype of DYT1 Transgenic Mice}

In order to examine the possibility of a neurochemical imbalance in $\triangle$ GAG DYT1 transgenic mice, HPLC-EC was performed to quantify levels of monoamines and their metabolites in striatum, cerebellum, and cerebral cortex. As seen in Figure 3-5, there was a noteworthy effect of genotype on the level of DOPAC (F2, $28=4.89, \mathrm{P}=0.015)$ in the cerebellum. Compared to WT mice, DOPAC was $59 \%$ higher $(\mathrm{P}=0.026)$ in hMT1 mice. In cerebral cortex, a significant effect of genotype was apparent with respect to 5HT (F2, $28=3.87, \mathrm{P}=0.033$ ). Compared to WT mice, 5 -HT content was $98 \%$ higher ( $\mathrm{P}$ $=0.012)$ in hWT mice. Similarly, 5 -HT content also tended to be higher in hMT1 than in WT mice $(76 \%, \mathrm{P}=0.054)$. In the striatum, significant effects of genotype were observed for EPI (F2, $28=3.45, \mathrm{P}=0.046)$, DOPAC (F2, $28=4.99, \mathrm{P}=0.014)$, and HVA (F2, $28=5.26, \mathrm{P}=0.012$ ) levels. In comparison to WT mice, EPI, DOPAC, and HVA levels were increased by $85 \%(\mathrm{P}=0.016), 58 \%(\mathrm{P}=0.004)$ and $76 \%(\mathrm{P}=0.007)$, respectively, in hMT1 mice. Although there was no significant difference in striatal DA content between hMT1 and WT mice, DA turnover (DOPAC/DA and HVA/DA) was significantly higher in the mutants $(\mathrm{P}=0.006$ or both; Figure 3-6). To note, a significant elevated level of DOPAC was also found in the cerebellum in hWT mice $(\mathrm{P}=0.006)$.

\subsubsection{Brain Metabolic Abnormalities in DYT1 Transgenic Mice}

2-DG autoradiography as well as $\mathrm{CO}$ histochemistry was used to map brain metabolic activity in hMT1, hWT, and WT mice. 2-DG autoradiography and CO histochemistry provide complementary information regarding the glycolytic and oxidative metabolism of the brain, in general. CO histochemistry is more specific for neuronal activity, and readily demarcates the boundaries of neural structures. Cytochrome c-oxidase (i.e., $\mathrm{CO}$ ) is the terminal enzyme complex in the electron transport chain of mitochondria. The regulation and assembly of $\mathrm{CO}$ requires a coordinated interaction of the nuclear and mitochondrial genomes (Fontanesi et al., 2006). CO is more specific for oxidative metabolism and more reflective of neuronal metabolic demands that occurr over days to weeks (Di Rocco et al., 1989; Wong-Riley, 1989; Gonzalez-Lima and Garrosa, 1991; Hevner et al., 1995). However, 2-DG is a glucose analogue that has the 2-hydroxyl group replaced by a hydrogen so that it cannot undergo glycolysis. Glucose hexokinase trapped 2-DG in most cells, which can be used as a good marker for immediate tissue demand for glucose and its signal reflects both synaptic.and neural activities (Wree and Schleicher, 1988; Wree, 1990; Duncan and Stumpf, 1991; McCasland and Graczyk, 2001). In addition, the spatial resolution of CO histochemistry is superior to 2-DG autoradiography.

\subsubsection{CO Activity in DYT1 Transgenic Mice}

The regional distribution of $\mathrm{CO}$ staining observed in WT mouse brain was similar to the pattern that described for rat brain (Hevner et al., 1995). The highest densities of 

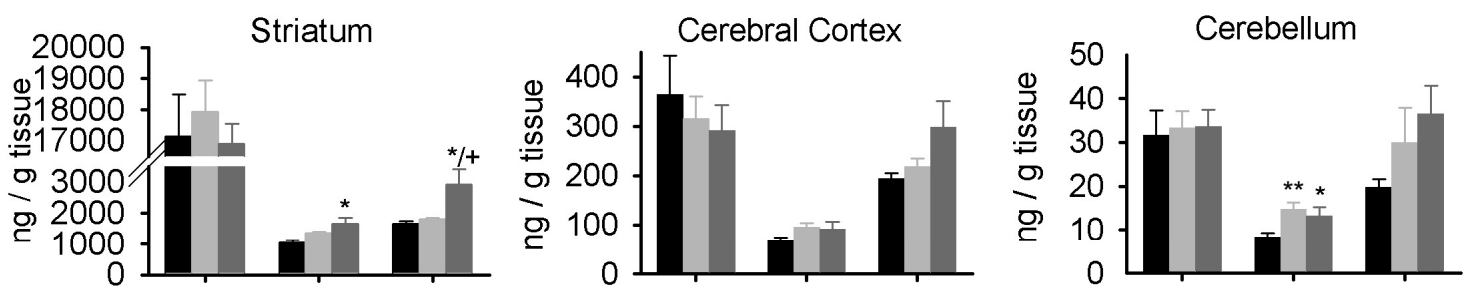

DA DOPAC HVA

DA DOPAC HVA

DA DOPAC HVA
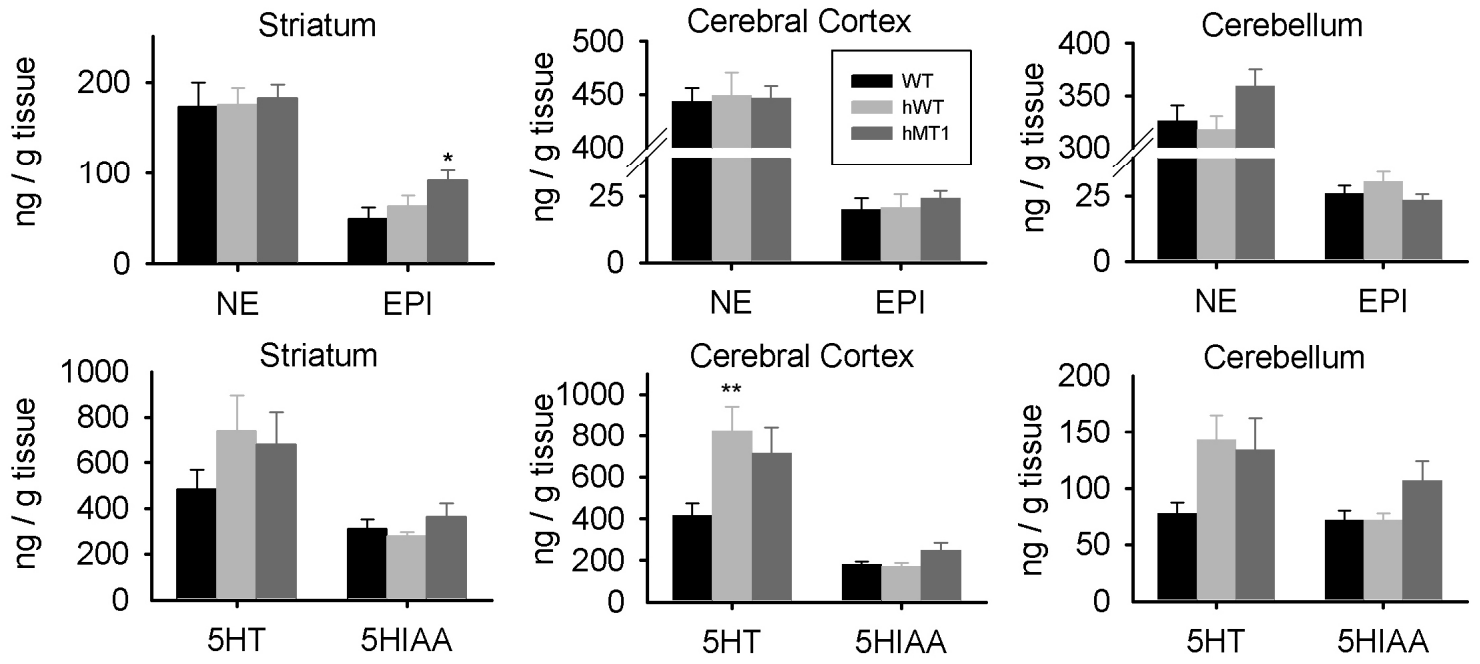

Figure 3-5. Quantitative HPLC-EC analysis of monoamines and their metabolites in DYT1 transgenic mice.

Striatal, cerebral cortical, and cerebellar monoamines and their metabolites were analysed in WT (black bars), hWT (gray bars), and hMT1 (dark gray bars) mice. DOPAC level increase was observed in striatum and cerebellum of hMT1. Similarlly, HVA and EPI level increases in hMT1 were observed in striatum. Results are expressed as the mean \pm SEM. * denotes a significant difference between hMT1 and WT littermates $(P<0.05)$. + denotes a significant difference between hMT1 and hWT littermates $(P<0.05)$. ${ }^{* *}$ denotes a significant difference between hWT and WT littermates $(P<0.05)$. 


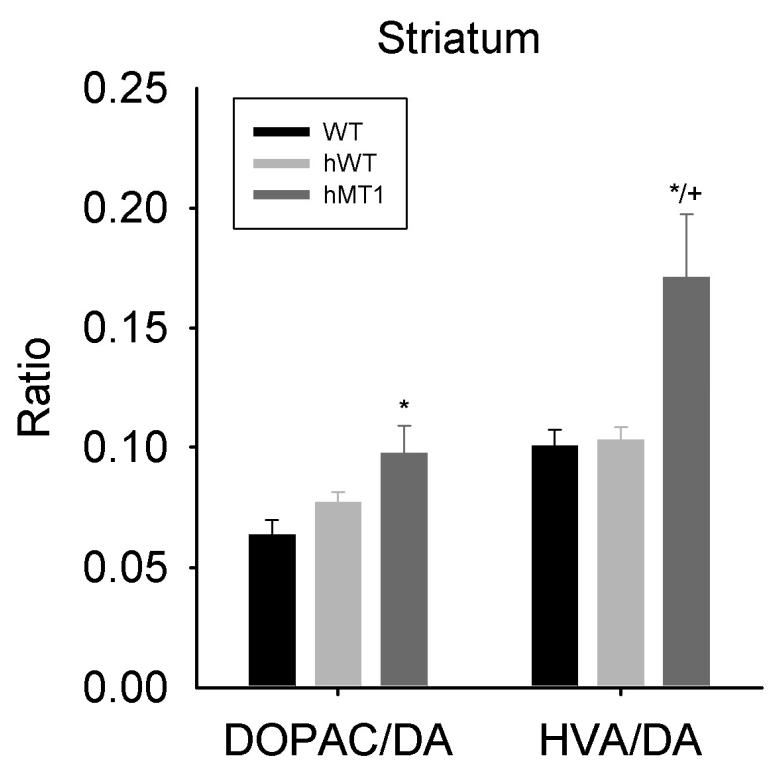

Figure 3-6. Dopamine turnover in the striatum of DYT1 transgenic mice.

Dopamine turnover of WT (black bars), hWT (gray bars), and hMT1 (dark gray bars) mice was expressed as DOPAC/DA and HVA/DA ratios. Striatal DOPAC/DA and HVA/DA were significantly increased in hMT1. Results are expressed as the mean \pm SEM. * denotes a significant difference between hMT1 and WT littermates $(P<0.05)$. + denotes a significant difference between hMT1 and hWT littermates $(P<0.05)$. 
CO histochemical staining was found in cerebellar cortex, deep cerebellar nuclei, red nucleus, caudate-putamen, subthalamic nucleus, and subregions of the cerebral cortex. The lowest levels of $\mathrm{CO}$ histochemical staining were found in white matter (e.g., corpus callosum) and neuronal populations with intermingled fiber pathways (e.g., globus pallidus). In gray matter, the density of CO staining was not correlated with neuronal density. For example, regions with dense neuronal packing such as the substantia nigra pars compacta and granule cell layer of the dentate gyrus were weakly visualized with $\mathrm{CO}$ histochemistry. Furthermore, compatible with the density of mitochondria at synapses, some regions with a relative paucity of neuronal soma such as the molecular layer in cerebellar cortex and stratum lacunosum-moleculare in hippocampus, showed a relatively high $\mathrm{CO}$ staining. In some regions, the cellular patterns of $\mathrm{CO}$ staining were quite distinctive. For example, in the red and vestibular nuclei, the majority of $\mathrm{CO}$ staining was noted in the somas, whereas in the caudate-putamen and deep cerebellar nuclei, neuronal soma and contiguous neuropil stained with similar intensity.

Densitometric analysis of $\mathrm{CO}$ activity in 55 neuroanatomical ROIs did not identify a difference in whole brain CO activity between hMT1 and control mice. However, after converting ROI CO activity to Z-scores, significant alterations in CO activity were noted in individual neural structures. As seen in Table 3-3, significant increases of $\mathrm{CO}$ activity were found in the inferior olive medial nucleus (IOM) and Purkinje cell layer of cerebellar cortex in hMT1 mice in comparison with controls , whereas significant decreases of CO activity were found in hMT1 caudal caudateputamen, substantia nigra pars reticulata and somatosensory 1 hindlimb in comparison with controls.

\subsubsection{GU in ROIs in DYT1 Transgenic Mice}

Aggregate densitometric analysis of the 40 neuroanatomical ROIs showed that whole-brain GU was similar between hMT1 and control mice. However, comparison of individual ROI GU Z-scores revealed a significantly altered GU in several motor regions of the brain. Z-scores of GU in the 40 ROIs and the respective statistical values are presented in Table 3-4. In comparison to controls, hMT1 mice showed a significantly increased GU in IOM, inferior olive dorsal accessory nucleus (IOD), and SNpc and a significant reduced GU in medial globus pallidus (MGP) and lateral globus pallidus (LGP).

\subsubsection{Correlation Analysis}

To provide additional interrogation of regional metabolic demand in the sensorimotor regions of the brain (e.g., basal ganglia, cerebellum, and their input and output nuclei), the correlation coefficients between anatomically-connected ROIs were analyzed with Z-scores derived from CO histochemistry. Significant positive correlations were noted between the interposed and red nuclei (0.54), medial cerebellar and red nuclei (0.67), rostral caudate-putamen and LGP (0.74), rostral caudate-putamen 
Table 3-3. CO activity distribution in ROIs in DYT1 transgenic mice.

\begin{tabular}{|c|c|c|c|c|c|}
\hline \multirow{2}{*}{ ROI } & \multirow{2}{*}{$\begin{array}{c}P \\
\text { (Z-score) }\end{array}$} & \multicolumn{2}{|c|}{ CO activity $(\mu \mathrm{mol} / \mathrm{min} / \mathrm{g})$} & \multicolumn{2}{|c|}{ Z-score } \\
\hline & & Control & hMT1 & Control & hMT1 \\
\hline $\mathrm{CPuC}$ & 0.0007 & $41.43 \pm 1.92$ & $39.98 \pm 2.64$ & $1.47 \pm 0.09$ & $0.93 \pm 0.1$ \\
\hline SNR & 0.0033 & $24.61 \pm 1.69$ & $25.86 \pm 2.06$ & $-0.63 \pm 0.05$ & $-0.85 \pm 0.05$ \\
\hline IOM & 0.0062 & $20.15 \pm 2.54$ & $28.85 \pm 2.17$ & $-1.14 \pm 0.18$ & $-0.45 \pm 0.15$ \\
\hline PCL & 0.0077 & $35.53 \pm 2.16$ & $44.04 \pm 2.94$ & $0.74 \pm 0.11$ & $1.45 \pm 0.2$ \\
\hline S1HL & 0.0099 & $35.19 \pm 1.96$ & $34.57 \pm 2.57$ & $0.67 \pm 0.08$ & $0.26 \pm 0.11$ \\
\hline GL & 0.0110 & $27.26 \pm 1.78$ & $33.32 \pm 2.49$ & $-0.28 \pm 0.09$ & $0.11 \pm 0.11$ \\
\hline VLG & 0.0125 & $28.7 \pm 2.16$ & $28.43 \pm 2.12$ & $-0.12 \pm 0.07$ & $-0.5 \pm 0.11$ \\
\hline MGP & 0.0141 & $15.83 \pm 1.07$ & $16.09 \pm 1.34$ & $-1.72 \pm 0.1$ & $-2.06 \pm 0.08$ \\
\hline ML & 0.0172 & $31.17 \pm 2.08$ & $38.71 \pm 2.67$ & $0.19 \pm 0.1$ & $0.77 \pm 0.19$ \\
\hline S1FL & 0.0234 & $34.94 \pm 1.81$ & $34.67 \pm 2.54$ & $0.66 \pm 0.07$ & $0.28 \pm 0.13$ \\
\hline IOD & 0.0299 & $19.77 \pm 1.74$ & $27.49 \pm 2.16$ & $-1.18 \pm 0.11$ & $-0.6 \pm 0.21$ \\
\hline Lat & 0.0385 & $35.38 \pm 2.96$ & $43.32 \pm 3.69$ & $0.73 \pm 0.19$ & $1.3 \pm 0.18$ \\
\hline Po & 0.0601 & $31.92 \pm 2.08$ & $32.45 \pm 3.1$ & $0.27 \pm 0.09$ & $-0.06 \pm 0.13$ \\
\hline CPuRV & 0.0765 & $41.33 \pm 1.94$ & $40.97 \pm 2.95$ & $1.45 \pm 0.15$ & $1.04 \pm 0.16$ \\
\hline $\mathbf{R t}$ & 0.0783 & $25.61 \pm 1.64$ & $26.05 \pm 2.35$ & $-0.51 \pm 0.07$ & $-0.83 \pm 0.15$ \\
\hline AInt & 0.0838 & $33.51 \pm 2.7$ & $40.4 \pm 3.86$ & $0.5 \pm 0.17$ & $0.92 \pm 0.16$ \\
\hline CPuRD & 0.0917 & $31.48 \pm 1.59$ & $31.85 \pm 2.42$ & $0.22 \pm 0.14$ & $-0.09 \pm 0.11$ \\
\hline Med & 0.0951 & $21.67 \pm 2.07$ & $27.99 \pm 2.8$ & $-0.95 \pm 0.12$ & $-0.62 \pm 0.14$ \\
\hline BLA & 0.1585 & $33.93 \pm 1.83$ & $34.67 \pm 3.08$ & $0.53 \pm 0.11$ & $0.25 \pm 0.15$ \\
\hline DC & 0.1633 & $26.33 \pm 3.05$ & $34.94 \pm 4.26$ & $-0.35 \pm 0.24$ & $0.25 \pm 0.33$ \\
\hline LGP & 0.1671 & $23.86 \pm 1.42$ & $25.14 \pm 2.09$ & $-0.72 \pm 0.09$ & $-0.94 \pm 0.12$ \\
\hline $\mathrm{Cg}$ & 0.1951 & $33.9 \pm 2.05$ & $34.32 \pm 2.64$ & $0.53 \pm 0.13$ & $0.24 \pm 0.17$ \\
\hline S1BF & 0.2564 & $33.93 \pm 1.82$ & $36.64 \pm 3.02$ & $0.64 \pm 0.11$ & $0.49 \pm 0.06$ \\
\hline CA3poly & 0.2760 & $29.13 \pm 1.93$ & $30.79 \pm 3.05$ & $-0.08 \pm 0.1$ & $-0.24 \pm 0.11$ \\
\hline IPC & 0.3013 & $28.46 \pm 2.33$ & $34.19 \pm 2.62$ & $-0.07 \pm 0.17$ & $0.21 \pm 0.2$ \\
\hline M2 & 0.3666 & $31.66 \pm 1.61$ & $32.39 \pm 2.4$ & $0.37 \pm 0.12$ & $0.17 \pm 0.17$ \\
\hline VP & 0.3696 & $34.64 \pm 1.98$ & $38.59 \pm 3.19$ & $0.63 \pm 0.08$ & $0.74 \pm 0.09$ \\
\hline LVe & 0.4113 & $20.38 \pm 2.33$ & $25.22 \pm 2.2$ & $-1.1 \pm 0.14$ & $-0.93 \pm 0.14$ \\
\hline M1 & 0.4250 & $34.13 \pm 1.64$ & $35.08 \pm 2.86$ & $0.69 \pm 0.14$ & $0.49 \pm 0.19$ \\
\hline Pn & 0.4540 & $15.33 \pm 2.06$ & $16.81 \pm 1.98$ & $-1.74 \pm 0.12$ & $-1.95 \pm 0.23$ \\
\hline VL & 0.4967 & $24.91 \pm 1.95$ & $27.68 \pm 2.45$ & $-0.6 \pm 0.1$ & $-0.49 \pm 0.11$ \\
\hline S2 & 0.4974 & $30.23 \pm 1.65$ & $33.04 \pm 2.63$ & $0.18 \pm 0.13$ & $0.05 \pm 0.13$ \\
\hline SO & 0.5624 & $28.71 \pm 1.99$ & $30.66 \pm 2.86$ & $-0.14 \pm 0.11$ & $-0.24 \pm 0.15$ \\
\hline SR & 0.5775 & $26.15 \pm 1.95$ & $28.01 \pm 2.61$ & $-0.46 \pm 0.13$ & $-0.57 \pm 0.15$ \\
\hline LSO & 0.5816 & $30.4 \pm 2.66$ & $35.61 \pm 3.47$ & $0.18 \pm 0.2$ & $0.38 \pm 0.28$ \\
\hline $\mathbf{V M}$ & 0.6569 & $26.65 \pm 2.11$ & $28.01 \pm 2.34$ & $-0.39 \pm 0.1$ & $-0.43 \pm 0.04$ \\
\hline CIC & 0.6717 & $39.22 \pm 2.93$ & $43.94 \pm 4.21$ & $1.23 \pm 0.25$ & $1.38 \pm 0.26$ \\
\hline MG & 0.6852 & $30.79 \pm 2.1$ & $33.44 \pm 2.72$ & $0.15 \pm 0.12$ & $0.09 \pm 0.1$ \\
\hline PAG & 0.6866 & $24.6 \pm 1.93$ & $27.39 \pm 2.29$ & $-0.61 \pm 0.08$ & $-0.66 \pm 0.08$ \\
\hline MVe & 0.7003 & $23.84 \pm 3.29$ & $26.68 \pm 4.56$ & $-0.66 \pm 0.25$ & $-0.82 \pm 0.34$ \\
\hline
\end{tabular}


Table 3-3. (Continued).

\begin{tabular}{llllll}
\hline \multirow{2}{*}{ ROI } & \multicolumn{1}{c}{$\boldsymbol{P}$} & \multicolumn{2}{c}{ CO activity $(\boldsymbol{\mu m o l} / \mathbf{m i n} / \mathbf{g})$} & \multicolumn{2}{c}{ Z-score } \\
\cline { 3 - 6 } & (Z-score) & \multicolumn{1}{c}{ Control } & \multicolumn{1}{c}{ hMT1 } & \multicolumn{1}{c}{ Control } & \multicolumn{1}{c}{ hMT1 } \\
\hline H & 0.7014 & $23.76 \pm 1.77$ & $26.18 \pm 2.83$ & $-0.74 \pm 0.1$ & $-0.81 \pm 0.14$ \\
PnO & 0.7136 & $23.93 \pm 2.01$ & $27.42 \pm 2.17$ & $-0.71 \pm 0.08$ & $-0.66 \pm 0.1$ \\
InG & 0.7151 & $30.84 \pm 2.2$ & $33.11 \pm 3.04$ & $0.14 \pm 0.1$ & $0.06 \pm 0.18$ \\
LD & 0.7523 & $29.4 \pm 2.45$ & $31.91 \pm 2.75$ & $-0.04 \pm 0.1$ & $-0.09 \pm 0.13$ \\
oDG & 0.7837 & $27.46 \pm 2.26$ & $30.07 \pm 2.47$ & $-0.26 \pm 0.12$ & $-0.31 \pm 0.09$ \\
RMC & 0.8130 & $37.59 \pm 1.91$ & $41.37 \pm 2.91$ & $1.04 \pm 0.19$ & $1.13 \pm 0.33$ \\
STh & 0.8254 & $45.46 \pm 2.83$ & $48.49 \pm 3.17$ & $1.95 \pm 0.11$ & $1.99 \pm 0.16$ \\
SLM & 0.8510 & $47.88 \pm 2.72$ & $50.19 \pm 3.61$ & $2.26 \pm 0.15$ & $2.22 \pm 0.15$ \\
DLG & 0.8533 & $30.58 \pm 2.21$ & $33.17 \pm 2.62$ & $0.1 \pm 0.08$ & $0.08 \pm 0.1$ \\
RMg & 0.8642 & $14.08 \pm 1.24$ & $17.13 \pm 1.98$ & $-1.9 \pm 0.1$ & $-1.93 \pm 0.12$ \\
VA & 0.8840 & $30.58 \pm 2.37$ & $32.15 \pm 2.51$ & $0.09 \pm 0.1$ & $0.11 \pm 0.06$ \\
APTD & 0.9249 & $29.76 \pm 2.19$ & $32.6 \pm 2.84$ & $-0.01 \pm 0.08$ & $0.01 \pm 0.14$ \\
LC & 0.9434 & $23.39 \pm 2.14$ & $26.58 \pm 2.59$ & $-0.78 \pm 0.11$ & $-0.77 \pm 0.13$ \\
iDG & 0.9576 & $34.61 \pm 2.36$ & $37.44 \pm 3.33$ & $0.58 \pm 0.14$ & $0.59 \pm 0.13$ \\
SuG & 0.9897 & $27.45 \pm 2.02$ & $30.31 \pm 3.11$ & $-0.29 \pm 0.13$ & $-0.29 \pm 0.2$ \\
\hline
\end{tabular}


Table 3-4. GU distribution in ROIs in DYT1 transgenic mice.

\begin{tabular}{|c|c|c|c|c|c|}
\hline \multirow{2}{*}{ ROI } & \multirow{2}{*}{$\begin{array}{c}P \\
\text { (Z-score) }\end{array}$} & \multicolumn{2}{|c|}{ GU (nCi/g) } & \multicolumn{2}{|c|}{ Z-score } \\
\hline & & control & hMT1 & control & hMT1 \\
\hline MGP & 0.0011 & $164.84 \pm 11.91$ & $154.64 \pm 12.09$ & $-1.53 \pm 0.06$ & $-1.88 \pm 0.06$ \\
\hline IOM & 0.0018 & $225.91 \pm 13.23$ & $269.48 \pm 18.13$ & $-0.59 \pm 0.07$ & $-0.22 \pm 0.07$ \\
\hline IOD & 0.0063 & $183 \pm 13.41$ & $220.78 \pm 14.27$ & $-1.26 \pm 0.08$ & $-0.93 \pm 0.07$ \\
\hline SNpc & 0.0077 & $235.33 \pm 14.85$ & $271.21 \pm 16.43$ & $-0.46 \pm 0.08$ & $-0.2 \pm 0.04$ \\
\hline LGP & 0.0097 & $184.25 \pm 11.95$ & $182.5 \pm 14.19$ & $-1.22 \pm 0.06$ & $-1.49 \pm 0.07$ \\
\hline $\mathbf{V M}$ & 0.0226 & $282.09 \pm 16.73$ & $321.88 \pm 18$ & $0.26 \pm 0.06$ & $0.56 \pm 0.1$ \\
\hline IPC & 0.0265 & $305.68 \pm 20.73$ & $305.04 \pm 20.69$ & $0.61 \pm 0.11$ & $0.29 \pm 0.07$ \\
\hline STh & 0.0430 & $284.99 \pm 16.96$ & $295.72 \pm 19.07$ & $0.3 \pm 0.05$ & $0.15 \pm 0.04$ \\
\hline Lat & 0.0745 & $286.87 \pm 16.52$ & $320.02 \pm 20.51$ & $0.33 \pm 0.08$ & $0.5 \pm 0.04$ \\
\hline RMCR & 0.0863 & $283.83 \pm 16.57$ & $294.31 \pm 21.4$ & $0.28 \pm 0.03$ & $0.12 \pm 0.08$ \\
\hline CHem & 0.1134 & $224.74 \pm 13.66$ & $251.99 \pm 16.94$ & $-0.61 \pm 0.04$ & $-0.48 \pm 0.06$ \\
\hline CVer & 0.1158 & $240.14 \pm 12.99$ & $270.75 \pm 17.24$ & $-0.37 \pm 0.06$ & $-0.21 \pm 0.08$ \\
\hline $\mathbf{S 2}$ & 0.1719 & $269.37 \pm 15.03$ & $281.07 \pm 16.75$ & $0.08 \pm 0.07$ & $-0.05 \pm 0.05$ \\
\hline SO & 0.1743 & $350.22 \pm 17.8$ & $346.05 \pm 18.6$ & $1.32 \pm 0.13$ & $0.92 \pm 0.24$ \\
\hline Med & 0.1972 & $273.69 \pm 15.92$ & $303.08 \pm 19.09$ & $0.13 \pm 0.09$ & $0.26 \pm 0.03$ \\
\hline $\mathrm{Cg}$ & 0.2290 & $271.43 \pm 15.95$ & $279.64 \pm 21.04$ & $0.1 \pm 0.11$ & $-0.09 \pm 0.11$ \\
\hline PAG & 0.2423 & $150.44 \pm 10.3$ & $157.52 \pm 13.81$ & $-1.73 \pm 0.08$ & $-1.85 \pm 0.06$ \\
\hline $\mathbf{V L}$ & 0.2446 & $256.73 \pm 15.8$ & $286.89 \pm 17.51$ & $-0.13 \pm 0.08$ & $0.07 \pm 0.14$ \\
\hline SuG & 0.2881 & $226.78 \pm 17.49$ & $232.41 \pm 17.57$ & $-0.61 \pm 0.12$ & $-0.76 \pm 0.07$ \\
\hline AInt & 0.3113 & $290.78 \pm 16.6$ & $320.08 \pm 22.12$ & $0.39 \pm 0.07$ & $0.49 \pm 0.06$ \\
\hline IC & 0.3603 & $500.71 \pm 24.13$ & $546.82 \pm 41.84$ & $3.56 \pm 0.09$ & $3.73 \pm 0.15$ \\
\hline M1 & 0.3666 & $254.09 \pm 14.81$ & $277.18 \pm 17.29$ & $-0.17 \pm 0.06$ & $-0.1 \pm 0.05$ \\
\hline SNR & 0.4315 & $176.44 \pm 15.04$ & $183.86 \pm 16.81$ & $-1.37 \pm 0.09$ & $-1.47 \pm 0.09$ \\
\hline Pn & 0.4436 & $178.05 \pm 15.44$ & $200.94 \pm 18.82$ & $-1.34 \pm 0.09$ & $-1.23 \pm 0.1$ \\
\hline M2 & 0.5350 & $283.14 \pm 15.73$ & $300.19 \pm 20.64$ & $0.28 \pm 0.09$ & $0.21 \pm 0.06$ \\
\hline RMCC & 0.5357 & $281.25 \pm 17.8$ & $296.72 \pm 21.16$ & $0.23 \pm 0.07$ & $0.16 \pm 0.09$ \\
\hline PnO & 0.5581 & $220.91 \pm 17.16$ & $243.15 \pm 16.44$ & $-0.68 \pm 0.08$ & $-0.61 \pm 0.09$ \\
\hline S1BF & 0.5738 & $320.91 \pm 16.57$ & $338.78 \pm 19.07$ & $0.87 \pm 0.08$ & $0.79 \pm 0.09$ \\
\hline CPuRV & 0.6788 & $258.39 \pm 16.79$ & $271.97 \pm 15.75$ & $-0.11 \pm 0.1$ & $-0.17 \pm 0.1$ \\
\hline LC & 0.7010 & $230.53 \pm 14.07$ & $256.78 \pm 21.73$ & $-0.5 \pm 0.1$ & $-0.43 \pm 0.17$ \\
\hline Mve & 0.7422 & $323.03 \pm 18.28$ & $349.86 \pm 24.12$ & $0.87 \pm 0.08$ & $0.93 \pm 0.14$ \\
\hline RMg & 0.7548 & $235.12 \pm 16.58$ & $250.19 \pm 17.96$ & $-0.45 \pm 0.12$ & $-0.51 \pm 0.13$ \\
\hline VP & 0.7591 & $318.19 \pm 17.07$ & $337.13 \pm 17.19$ & $0.81 \pm 0.08$ & $0.78 \pm 0.08$ \\
\hline $\mathrm{CPuC}$ & 0.8067 & $251.74 \pm 14.78$ & $271.14 \pm 14.94$ & $-0.21 \pm 0.08$ & $-0.18 \pm 0.08$ \\
\hline DC & 0.8361 & $306.96 \pm 16.08$ & $325.65 \pm 24.74$ & $0.63 \pm 0.11$ & $0.58 \pm 0.21$ \\
\hline VA & 0.9079 & $339.91 \pm 19.22$ & $362.17 \pm 17.83$ & $1.13 \pm 0.07$ & $1.16 \pm 0.16$ \\
\hline S1HL & 0.9513 & $264.41 \pm 14.87$ & $285.63 \pm 22.4$ & $0 \pm 0.09$ & $-0.01 \pm 0.09$ \\
\hline CPuRD & 0.9768 & $274.32 \pm 14.68$ & $294.23 \pm 17.14$ & $0.15 \pm 0.09$ & $0.14 \pm 0.04$ \\
\hline LVe & 0.9897 & $330.62 \pm 19.6$ & $351.85 \pm 20.72$ & $0.97 \pm 0.07$ & $0.97 \pm 0.08$ \\
\hline S1FL & 0.9921 & $267.1 \pm 14.73$ & $287.52 \pm 18.82$ & $0.04 \pm 0.09$ & $0.04 \pm 0.07$ \\
\hline
\end{tabular}


and MGP (0.64), and LGP and MGP (0.77) in control but not hMT1 mice. In addition, significant negative correlations were noted between rostral caudate-putamen and subthalamic nucleus (STh; -0.70), and MGP and STh (-0.51) in control but not in hMT1 mice (Table 3-5). The loss of correlations indicated the functional abnormalities in these pathways in hMT1 mice.

\subsection{DISCUSSION}

Several murine models of DYT1 dystonia have been developed and characterized to varying degrees (Dang et al., 2005, Goodchild et al., 2005; Sharma et al., 2005; Shashidharan et al., 2005; Dang et al., 2006; Grundmann et al., 2007; Table 1-2). Although some common themes exist among these models, substantial discordance has been apparent in morphological findings, and robust behavioral and neurochemical characterizations have been largely incomplete. In our study, detailed genetic, behavioral, morphological, neurochemical, and brain metabolical analyses were performed in a human $\triangle \mathrm{GAG}$ transgenic mouse model of DYT1 dystonia. Our results demonstrated a high-level mutant transgene expression in hMT1 mice, in addition to distinct motor, neurochemical, and brain metabolical abnormalities in the hMT1 line. These findings demonstrate that the human mutant torsinA transgenic mouse (hMT1) is a valid model for the study of DYT1 dystonia. Of utmost importance, our results indicate that defective nigrostriatal signaling, as demarcated with an increased striatal DA turnover might be critical to the pathobiology of DYT1 dystonia.

Transgenic models of DYT1 dystonia have been developed by Sharma et al. (2005), Shashidharan et al. (2005), and Grundmann et al. (2007). Using quantitative analysis of Western blots, Sharma and colleagues (2005) showed that hMT1, hMT2, and hWT transgenic mice express torsinA at 2.1X, 1.3X, and 2.3X that of WT littermates. Similarly, Shashidharan and co-workers (2005) showed an increased torsinA protein expression in four transgenic lines (TG\#13, TG\#22, TG\#35, and TG\#49). In more recent work, Grundmann and colleagues (2007) analyzed normal and mutant human torsinA transgene expression at the transcript and protein levels. Human torsinA transcript levels were referenced to the hWT24 line of mice. The largest fold increase in transcript levels was noted in the $\mathrm{h} \triangle \mathrm{GAG} 3$ line of torsinA mutant mice (1.30X). In a more functional assay, we showed that striatal torsinA transcript expression was 3.90X higher in hMT1 mice than in human brain. Because current thinking indicates that a single mutant torsinA molecule can disrupt assembly of a mature hexameric molecular motor (Breakefield et al. 2001), stoichiometric considerations would suggest that an increase in the cellular burden of mutant torsinA would decrease the probability of hexamer formation. Apparently, a minimal number of functional torsinA hexamers are required for normal neural function and organismal survival because DYT1 knockout and homozygous DYT1 knock-in mice die shortly after birth (Goodchild et al. 2005). Therefore, robust transgenic expression of mutant torsin A as seen in hMT1 mice might be the most viable means to model human DYT1 dystonia. 
Table 3-5. Pearson correlations between neuroanatomically-connected nuclei in DYT1 transgenic mice.

\begin{tabular}{|c|c|c|c|c|c|c|c|c|c|c|}
\hline \multirow{3}{*}{ ROI } & \multicolumn{5}{|c|}{ CO Activity } & \multicolumn{5}{|c|}{ 2-DG Autoradiography } \\
\hline & \multicolumn{2}{|c|}{ Control } & \multicolumn{2}{|c|}{ hMT1 } & \multirow{2}{*}{$\begin{array}{c}P \\
\text { (Ratio) }\end{array}$} & \multicolumn{2}{|c|}{ Control } & \multicolumn{2}{|c|}{ hMT1 } & \multirow{2}{*}{$\begin{array}{c}P \\
\text { (Ratio) }\end{array}$} \\
\hline & $\mathbf{r}$ & $P(r)$ & $\mathbf{r}$ & $P(r)$ & & $\mathbf{r}$ & $P(r)$ & $\mathbf{r}$ & $P(r)$ & \\
\hline AInt / RMC & 0.54 & 0.0264 & -0.01 & 0.9818 & 0.2335 & 0.22 & 0.4503 & 0.48 & 0.2312 & 0.0412 \\
\hline Med / RMC & 0.67 & 0.0036 & -0.51 & 0.1574 & 0.1151 & 0.21 & 0.4802 & 0.38 & 0.3522 & 0.0298 \\
\hline RVCPu / LGP & 0.74 & 0.0007 & 0.56 & 0.117 & 0.1579 & 0.22 & 0.45 & -0.03 & 0.944 & 0.1676 \\
\hline RVCPu / MGP & 0.64 & 0.0061 & 0.44 & 0.234 & 0.5142 & 0.06 & 0.8348 & -0.67 & 0.0703 & 0.0867 \\
\hline RVCPu / STh & -0.7 & 0.0017 & 0.28 & 0.463 & 0.1109 & -0.47 & 0.0934 & -0.77 & 0.0244 & 0.6592 \\
\hline RDCPu / LGP & 0.83 & $<0.0001$ & 0.36 & 0.3401 & 0.4022 & 0.25 & 0.3888 & -0.05 & 0.9054 & 0.0593 \\
\hline RDCPu / MGP & 0.79 & 0.0001 & 0.48 & 0.1899 & 0.6819 & 0.04 & 0.8863 & -0.49 & 0.2181 & 0.0257 \\
\hline RDCPu / STh & -0.7 & 0.0016 & -0.13 & 0.7389 & 0.2526 & -0.6 & 0.0232 & -0.63 & 0.0937 & 0.6592 \\
\hline CCPu / LGP & 0.72 & 0.0012 & 0.84 & 0.0044 & 0.0213 & 0.19 & 0.5075 & -0.79 & 0.0189 & 0.1038 \\
\hline $\mathrm{CCPu} / \mathrm{MGP}$ & 0.5 & 0.0399 & 0.69 & 0.0395 & 0.2707 & 0.13 & 0.6525 & -0.39 & 0.3446 & 0.0264 \\
\hline LGP / MGP & 0.77 & 0.0003 & 0.63 & 0.0668 & 0.5528 & 0.49 & 0.0738 & 0.39 & 0.3338 & 0.2189 \\
\hline MGP / STh & -0.51 & 0.0364 & 0.4 & 0.2918 & 0.3354 & 0.03 & 0.9187 & 0.46 & 0.2481 & 0.0211 \\
\hline Lat / IOM & 0.59 & 0.0134 & 0.13 & 0.7463 & 0.0243 & 0.1 & 0.7258 & 0.32 & 0.4358 & 0.0406 \\
\hline
\end{tabular}

Notes: r, pearson correlation coefficient; $P(r)$, significant value for the correlation coefficient; $P$ (Ratio), significant value for the ratios between the two groups. 
Genetically engineered mice cannot accurately model all of the molecular, cellular, and physiological features of human neurogenetic disorders. Individual models have their own distinct limitations and utilities. In transgenic models, the promoter, construct design and insertion site dictate the temporal and spatial regulation of transgene expression. Moreover, transgenic models might be associated with locus-specific insertional effects. In a comparative analysis of torsinA transgenic models, several points must be considered. First, utilization of a neuron-specific promoter like neuron-specific enolase precludes consideration of glial-specific and glial-neuronal interactions as contributors to the pathophysiology of DYT1 dystonia (Shashidharan et al., 2005). Furthermore, the mice generated by Shashidharan and colleagues (2005) exhibited bizarre circling behavior that is not seen in other murine models of DYT1 dystonia. In the transgenic mice generated by Grundmann et al. (2007), the expression of mutant torsin A that contained a V5-his tag was driven by the murine prion protein promoter (Grundmann et al., 2007). It is possible that even a small V5-his tag could interfere with one or more functional properties of torsinA. In contrast to other transgenic models of DYT1 dystonia, the expression of untagged mutant torsinA in hMT1 mice is driven by the cytomegalovirus (CMV) promoter, which is well-known for its ability to drive widespread transgene expression (Boshart et al., 1985; Sharma et al., 2005).

Similar to other models of DYT1 dystonia, none of the transgenic mice used in our study (hMT1, hMT2, and hWT) showed overt evidence of dystonia. The response of hMT1 mice to tail suspension and performance on vertical-rope climbing and the accelerating rotarod were all similar to WT littermates. However, hMT1 mice exhibited a mildly abnormal motor phenotype characterized by an increased hind-base width and an impaired performance on the raised-beam task. These findings are consistent with previous reports of heterozygous DYT1 knock-in and DYT1 knock-down mice (Dang et al., 2005; 2006), as well as hWT24 transgenic mice (Grundmann et al., 2007). DYT1 knock-in mice display an abnormal gait with a significant overlap in paw placement, as well as motor coordination deficits on the raised-beam task (Dang et al., 2005). DYT1 knock-down mice also demonstrated motor-coordination deficits on the raised-beam task (Dang et al., 2006). The raised-beam task integrates multiple components of the sensorimotor system, and has been used for functional evaluation of the nigrostriatal pathway (Dluzen et al., 2001) and to estimate the deficits induced by sensorimotor cortex ablation (Goldstein \& Davis, 1990) and ischemic stroke (Brown et al., 2004). The raisedbeam task has also been used to characterize motor dysfunction in murine models of "basal ganglia" disorders such as Huntington and Parkinson diseases (Carter et al., 1999; Strome et al., 2006). Because abnormalities in dopaminergic neurotransmission in mice have been associated with hypoactivity, stride-length reduction, and poor performance on the raised-beam task, an explanation for the motor abnormalities of hMT1 transgenic mice might be derived, in part, from the observed increase in striatal DA turnover (Dluzen et al. 2001; Fernagut et al. 2002; 2003).

Footprint analysis is another useful tool used to evaluate motor and gait abnormalities in murine models of movement disorders. Footprint analysis along with digital surrogates have been used to examine gait alterations induced by striatal damage (Teunissen et al., 2001), genetic defects of Purkinje cells (Jiao et al., 2005), sensory 
neuropathy (Wietholter et al., 1990), and diffuse cerebral disease (McGavern et al., 1999). As is the case for human gait disorders, distinct footprint patterns can be ascribed to lesions of specific neural subsystems in mice. Animals with cerebellar defects, for instance, often display considerable increases in front- and hind-base widths (Wietholter et al., 1990; Jiao et al., 2005). In agreement with functional-imaging studies, the increased hind-base width noted in hMT1 mice suggested that mutant torsinA might contribute to cerebellar dysfunction in humans with DYT1 dystonia (Carbon et al., 2004a).

Work in Drosophila suggests that torsinA could play a role at the mammalian neuromuscular junction (Koh et al., 2004). In our study, the performance of torsinA mutant mice on vertical-rope climbing does not entirely dismiss this possibility because hMT1 mice tended to perform worse than WT littermates. Vertical-rope climbing requires substantial motor strength, and is likely to illicit abnormalities in mice with disorders of muscle, the neuromuscular junction, or anterior horn cells (Anderson et al., 2005).

Unlike two previous studies with torsinA transgenic mice, we were unable to identify rotarod abnormalities in either hMT1 or hWT mice (see Table 1-2). In this regard, several points are worthy of note. First, Grundmann et al. (2007) employed 6month old mice and Sharma and colleagues (2005) only found rotarod abnormalities in mice at 9 months of age. In contrast, our studies were performed in much younger adult mice. Second, Sharma et al. (2005) pooled results from hMT1 and hMT2 mice, whereas we restricted our behavioral experiments to hMT1 mice. Finally, all of our experiments were performed with mice backcrossed (C57BL/6J) at least 8 generations, whereas Sharma et al. (2005) combined F5 and F6 progeny for their experiments. Grundmann et al. (2007) did not comment on the genetic uniformity of their mice. In this context, it should be emphasized that our hWT mice are not a viable model of human wild-type torsinA overexpression. Similarly, with regards to the hMT2 mice, it is likely that mutant transgene expression is too low to significantly disrupt cellular pathways that are dependent on torsinA. It is possible that transgene repression or inactivation, which has been described in numerous plant and animal models, is responsible for the Northern blot and QRT-PCR results seen in hWT and hMT2 mice (Kilby et al., 1992; ChevalierMariette et al., 2003; Thomas et al. 2005). DNA methylation, which might occur over several generations, appears to be the most common mechanism of transgene repression/inactivation.

Although to a lesser degree than the hMT1 mice, the hWT line of mice also exhibited prolonged traversal times and more slips on the round raised-beam tasks. These abnormalities in the hWT mice might be an insertional effect of the transgene since expression of the wild-type torsinA was negligible in these mice. Alternatively, a deleterious effect of small amounts of wild-type human torsinA cannot be excluded since Grundmann and colleagues also noted behavior abnormalities in mice expressing wildtype human torsinA (Grundmann et al., 2007). 
Laser-scanning confocal and electron microscopy were used to search for cellular and ultrastructural abnormalities in torsinA transgenic mice. Our results are compatible with the initial report of Sharma and colleagues (2005), but differ from findings in other DYT1 transgenic, knock-in, and knock-out models. (Shashidharan et al., 2005; Dang et al., 2005; Goodchild et al., 2005; Grundmann et al., 2007). Morphological analysis of other DYT1 models has revealed ubiquitin- and torsinA-positive cytoplasmic inclusion bodies (Shashidharan et al., 2005; Dang et al., 2005; Grundmann et al., 2007), as well as bleb formation at the nuclear envelope (Goodchild et al., 2005; Grundmann et al., 2007;

Table 1-2). It is likely that technical factors related to tissue processing, rodent age, and relative cytoplasmic concentration of endogenous torsinA contributed to the appearance of cytoplasmic inclusions and nuclear envelope bleb formation. Because DYT1 dystonia rarely appears after 28 years of age, we chose to use young adult mice for our studies. Because inclusion formation in most neurodegenerative diseases is closely tied to the aging process, our failure to detect cytoplasmic inclusions in young adult mice is not surprising. With regard to nuclear envelope bleb formation, it should be emphasized that our mice were perfused with a fixative (4\% paraformaldehyde $/ 2.5 \%$ glutaraldehyde $/ 15 \%$ picric acid), which is well-known to preserve ultrastructural morphology. Marked reduction in functional torsinA is also required for the appearance of nuclear envelope blebs because structural abnormalities of the nuclear envelope were described in homozygous DYT1 knock-in and knock-out mice, but not in their heterozygote DYT1 littermates (Goodchild et al., 2005). In aggregate, motor and neurochemical abnormalities were observed in DYT1 models that demonstrated cellular pathology, as well as in those that do not. Thus, causal relationships among morphological, motor, and neurochemical phenotypes remain unclear.

To investigate the possibility of a neurochemical abnormality in torsin A mutant mice, we performed HPLC-EC analysis of monoamine transmitters and their metabolites. The most striking findings were significantly increased DOPAC/DA and HVA/DA ratios (measures of DA turnover) in hMT1 striatum. Increases in DOPAC/DA and HVA/DA turnover can manifest from a number of scenarios, including an increased DA release, a decreased DA uptake due to abnormal functioning of the dopamine and/or vesicular monoamine transporters, or an increased monoamine oxidase (MAO) activity. Our findings in DYT1 transgenic mice are compatible with previous neuroimaging and postmortem neurochemical studies of human DYT1 dystonia. For example, Augood and colleagues (2002) observed a significantly increased DOPAC/ DA ratio, along with a trend toward reduction in D1 and D2 receptor binding in the striatum of human postmortem DYT1 dystonia brains. A corresponding decrease in striatal D2 receptor binding has been described in non-manifesting DYT1 mutation carriers (Asanuma et al., 2005). Increased striatal DA turnover and down-regulation of striatal D2 receptors suggests that functional and/or morphological anomalies of the nigrostriatal pathway might be important to the pathobiology of DYT1 dystonia.

Quite variable results have been reported from the neurochemical analyses of other DYT1 mouse models (Table 1-2). In transgenic mice generated by Shashidharan and colleagues (2005), decreased striatal DA levels were observed in mice with motor abnormalities (i.e., "affected" mice), whereas increased striatal DA levels were detected 
in mice without motor abnormalities (i.e., "unaffected" mice). Despite these differences in absolute DA levels, DOPAC/DA ratios were decreased in "affected" and "unaffected" mice compared to wild-type controls; those data suggested an overall decrease in DA turnover (Shashidharan et al., 2005). In heterozygote DYT1 knock-in mice, striatal HVA levels were found to be significantly decreased with no alterations of DA and DOPAC content (Dang et al., 2005), and DYT1 knock-down mice demonstrated significantly reduced DOPAC levels, with only a slight decrease in striatal DA (Dang et al. 2006). In addition to decreased striatal DA, decreases in 5-HT and 5-HIAA were also noted in the hWT transgenic mice generated by Grundmann and colleagues (2007). In the brainstem only, a decrease in HVA levels and an increase in DOPAC, 5-HT and 5-HIAA levels were noted in $\mathrm{h} \triangle \mathrm{GAG} 3$ transgenic mice (Grundmann et al., 2007). Taken together, these mixed neurochemical findings in DYT1 mouse models suggest that mutant and WT torsinA can both influence striatal dopaminergic neurotransmission.

$\mathrm{GU}$ and $\mathrm{CO}$ activity serve as surrogate and indirect markers of acute and chronic metabolic activities in the brain. The systems-level information derived from metabolic mapping can be integrated with behavioral, neurochemical, and electrophysiological alterations in DYT1 mice. For comparisons with hMT1 mice, the control group included data from WT and hWT mice because hWT show negligible transgene expression, and ROI GU and CO activity from hWT and WT were highly correlated. CO activity was significantly increased in the IOM and Purkinje cell layer of cerebellar cortex and decreased in caudal caudate-putamen, SNR, and S1HL of hMT1 mice in comparison to the control group. Similarly, GU was significantly increased in IOM, IOD, and SNC, and was decreased in MGP and LGP in hMT1 mice.

Given that $\mathrm{GU}$ and $\mathrm{CO}$ activity measure distinct metabolic processes on different time scales, it is not surprising that these two metabolic mapping methods generated both overlapping and unique results. Similar inconsistencies between GU and CO metabolic patterns have also been reported in the mutant dystonic hamster (Nobrega et al., 1998, Richter et al., 1998). Moreover, functional neuroanatomical studies have shown that measures of GU and $\mathrm{CO}$ activity capture different aspects of network activity (Jacquin et al., 1993). As noted, signals derived from CO histochemistry are concentrated at sites with mitochondrial density, whereas the signals of 2-DG autoradiography predominate at axon terminals with high $\mathrm{Na}+-\mathrm{K}+-\mathrm{ATPase}$ activity (Di Rocco et al., 1989).

Overall, functional brain mapping in hMT1 mice demonstrated a shift of metabolic demand from the basal ganglia to the cerebellum. In the basal ganglia, the decreased GU noted in the MGP and LGP might be due, in part, to decreased CO activity in $\mathrm{CPu}$ neurons, which send GABAergic projections to MGP, LGP, and SNR. In MGP and SNR, $\mathrm{CO}$ was also reduced. In agreement with these findings, independent studies in human subjects with generalized and focal dystonias have found significantly reduced mean GPi firing rates (Starr et al., 2005; Tang et al., 2007). These changes in CO activity in MGP and SNR mirror complicated results in the dystonic hamster (Nobrega et al., 1998). Although likely associated, our approach does not allow us to ascribe the hMT1 metabolic abnormalities in the basal ganglia to the increased nigrostriatal dopaminergic turnover in hMT1 mice. 
Interestingly, hypermetabolism in the cerebellar hemispheres has been reported in non-manifesting DYT1 carriers (Eidelberg, 1998; Trost et al., 2002; Carbon et al., 2004a). Compatible with these clinical results, we identified hypermetabolism in the Purkinje cell layer (PCL) of cerebellum in hMT1 mice. In our model, increased GU/CO activity in the inferior olive, which sends excitatory input to cerebellar Purkinje cells via the climbing fiber pathway, might alter the firing properties of Purkinje cells-as has been described in the $d t$ rat (LeDoux and Lorden, 2002). Elevated Purkinje cell firing rates would be associated with an enhanced metabolic activity at GABAergic synaptic terminals in the cerebellar nuclei; similar results have been identified in the $d t$ rat (Ledoux, 2004). Although it is not possible to specifically attribute the gait abnormalities in hMT1 mice to dysfunction of either the basal ganglia or cerebellum, increased hindbase width is classically associated with dysfunction of the latter. Theoretically, this cerebellar abnormality could be primary or secondary to dysfunction of the basal ganglia. However, in DYT1 carriers, functional imaging suggests the primary dysfunction of the basal ganglia leads to compensatory maladaptive neural output from the cerebellum (Ghilardi et al., 2003; Carbon et al., 2008b).

The inferior olive may play a central node in communication between the basal ganglia-thalamocortical and olivocerebellar circuits (Alexander and Crutcher, 1990; Marshall and Lang, 2004). The inferior olive receives a wide variety of excitatory and GABAergic projections (Walberg, 1956, , 1974; Berkley and Hand, 1978; Berkley and Worden, 1978; Saint-Cyr and Courville, 1981; Swenson and Castro, 1983). Inferior olivary afferents arise from the spinal cord, medulla, pons, midbrain, cerebellar nuclei, and cerebral cortex. Projections from the red nucleus, periaqueductal gray, and other midbrain nuclei such as the interstitial nucleus of Cajal, nucleus of Bechterew, and nucleus of Darkschewitsch enter the central tegmental tract, descend uncrossed, and terminate in the inferior olive. Fibers, which ascend in the spinal cord, reach the inferior olive either directly through the spino-olivary tract that courses through the anterior funiculus or indirectly via the dorsal column nuclei. Dysfunction of one or more of these afferents might induce hypermetabolism and altered neuronal activity in the IO. Alternatively, a defect intrinsic to the IO could be causally associated with pathophysiology of DYT1 dystonia because climbing fiber dysfunction is critical to the dystonic movement disorders of the $d t$ rat and rats treated with the neurotoxin 3acetylpyridine (Sukin et al., 1987; Ledoux, 2004).

With a 2-DG autoradiography protocol similar to our own, striking increases in GU were detected in the cerebellar nuclei of the $d t$ rat (Brown and Lorden, 1989). In the $d t$ rat, correlations for GU in regions with known anatomical connections also suggested that basal ganglia efferents might be abnormal. The GU metabolism pattern identified in hMT1 transgenic mice show important qualitative similarities to patterns described in $d t$ rats. However, the magnitude of the changes in hMT1 mice was small relative to alterations seen in the $d t$ rat-probably due to the fact that the latter model exhibits a profound generalized dystonia. Clearly, the cerebellum contributes to the dystonic movement disorder of the $d t$ rat, which is eliminated by cerebellectomy (LeDoux et al., 1993; LeDoux et al., 1995). 
Our correlation analysis supports the validity of our findings. In particular, the correlations that we obtained in control mice are similar to values previously reported in hamsters and rats (Brown and Lorden, 1989; Richter et al., 1998). For specific examples, mice, rats, and hamsters show positive correlations between the cerebellar nuclei (medial and interpositus) and the red nucleus. In addition, positive correlations between the striatum and LGP have been described in all three species of rodents. These and several other correlations in control mice, including positive correlations of rostral caudateputamen to MGP, negative correlations of rostral caudate-putamen to subthalamic nucleus, and negative correlations of MGP to STh, were disrupted in hMT1 mice.

Reduced GPi output to the thalamus might result in enhanced thalamocortical activation. In similar fashion, reduced SNR output might result in enhanced activity in the tectal and tegmental pathways, which receive inhibitory projections from SNR. Clearly, DYT1 dystonia is a network disorder of similar topography among manifest and non-manifest carriers of the $\triangle \mathrm{GAG}$ mutation.

\subsection{CONCLUSIONS}

In summary, our study has provided a vigorous analysis of the genetic, motoric, morphological, neurochemical, and brain metabolic features of the hMT1 transgenic mouse model of DYT1 dystonia. The hMT1 model exhibits distinct motor, neurochemical, and brain metabolical phenotypes that result from the cellular burden of mutant torsinA. The increased DA turnover identified in hMT1 mice is noteworthy because tetrabenazine, a dopamine-depleting drug, has been used successfully in patients with generalized dystonia (Jankovic and Orman, 1988). Furthermore, mutant torsinA appears to interfere with the dopamine and vesicular monoamine transporters (Torres et al., 2004; Cao et al., 2005; Misbahuddin et al., 2005). Thus, the hMT1 mouse might be used to study the systems and cellular biology of torsinA and to evaluate potential therapeutics for DYT1 dystonia. 


\section{CHAPTER 4. SUMMARY AND DISCUSSION}

\subsection{SUMMARY}

In the research presented in the dissertation, the systems biology of torsinA was examined with two approaches. First, perturbation models were used to examine the systems biology of torsinA. Transient forebrain ischemia was used as a CNS perturbation and sciatic nerve transection as a PNS perturbation. The temporal and spatial responses of torsinA transcript and protein expression in neural tissues were evaluated with QRT-PCR, in situ hybridization, and immunohistochemistry. Upregulation of torsinA expression in neural tissues was found after central and peripheral insults. The initial up-regulation of torsinA transcript after ischemia was localized to the major neuronal populations that expressed high levels of torsinA even in the control tissues. However, the delayed component of torsinA up-regulation included prominent expression in reactive astrocytes in regions of hippocampus (e.g., CA1) known to undergo neuron loss and synaptic reorganization after ischemia. The up-regulation of torsin A in DRG showed similar temporal and spatial patterns to the CNS. Up-regulation of torsinA was detected in ganglion cells and satellite cells in ipsilateral DRG; however, torsinA was preferentially concentrated in satellite cells in the contralateral DRG. Our perturbation models have provided the first descriptions of torsinA expression in reactive glial elements. Overall, our findings suggest that torsinA participates in the response of neural tissue to central and peripheral insults. Moreover, the sustained up-regulation of torsin A in interneurons and reactive astrocytes in the regions with significant neuron loss and putative synaptic reorganization indicates that torsinA might contribute to the remodeling of neuronal circuitry. In addition, the striking induction of torsinA in astrocytes and satellite cells points to the potential involvement of glial elements in the pathobiology of DYT1 dystonia.

DYT1 transgenic mouse models were used to examine the systems biology of torsinA. We performed an analysis of the motor behavioral, morphological, neurochemical, and brain metabolical features of the hMT1 transgenic mouse model of DYT1 dystonia. The hMT1 model exhibits distinct motor, neurochemical, and metabolical phenotypes that result from the cellular burden of mutant torsinA. Compared to WT littermates, hMT1 mice showed prolonged traversal times on square and round raised-beam tasks, more slips on the round raised-beam task, and increased hind-base widths in foot-print analysis. No distinguishing cytoplasmic torsinA-positive inclusion bodies or nuclear envelop abnormalities were noted in hMT1 mice. However, significant increases of striatal DOPAC, HVA, and DA turnover (DOPAC/DA and HVA/DA) were found in hMT1 mice. Brain metabolic abnormalities include a shift of metabolic demand from structures of basal ganglia to olivocerebellar pathways in hMT1 mice compared to controls. Our findings in DYT1 transgenic mice are compatible with previous postmortem neurochemical studies of human DYT1 dystonia. Increased striatal DA turnover in hMT1 mice suggests that the nigrostriatal pathway might be a site of functional neuropathology in DYT1 dystonia. Increased activity in the direct and indirect pathways, and the relatively attenuated metabolic demand in basal ganglia output regions, 
might be the primary consequence of a functional defect in the dopaminergic nigrostriatal system in DYT1 mutation carriers. The increased metabolic demands in olivocerebellar pathways (inferior olive, Purkinje cells, cerebellar nuclei) might be a compensatory network response to increases thalamocortical activity. Alternatively, hypermetabolism in olivocerebellar pathways might be largely independent of basal gangliathalamocortical dysfunction, in which case interactions between these two sensorimotor networks contribute to the generation of a dystonic phenotype. In aggregate, our data provide evidence that the hMT1 mouse might be used to study the systems and cellular biology of torsinA, and to evaluate potential therapeutics for DYT1 dystonia.

\subsection{DISCUSSION}

Our findings of torsinA up-regulation after central and peripheral insults are compatible with studies of developmental expression because up-regulation was also noted during the period of neurogenesis and synaptic reorganization after forebrain ischemia. In the hippocampus, an increased level of torsinA-IR was prominent in the subgranular proliferative zone, which is the site of neuroblast proliferation after ischemia. Increased torsinA-IR was also localized to cell populations in the SR, SO, and SLM in regions of hippocampus (e.g., CA1) known to undergo neuron loss and synaptic reorganization. Many of the cells in the CA1 region that showed overt up-regulation of torsinA-IR were found to be GFAP-IR reactive astrocytes, somatostatin-IR interneurons, and parvalbumin-IR interneurons. Glia may facilitate synaptic formation and synaptic neurotransmitter release, and direct neuronal migration and neurite extension (Powell et al., 1997; Araque et al., 1999; Grosche et al., 1999; Ventura and Harris, 1999; Riquelme et al., 2002; Liu et al., 2004; Sobkowicz et al., 2006; Bystron et al., 2008). The upregulation of torsin $\mathrm{A}$ in reactive astrocytes might facilitate neuronal-network reorganization by guidance of neuronal migration, neurite extension, or enwrapping many pre- and post-synaptic terminals. Alternatively, torsinA might contribute to the morphological and topological changes that reactive astrocytes must undergo in order to facilitate synaptogenesis and network reorganization (Lepekhin et al., 2001; Witcher et al., 2007). The surviving interneurons in the CA1 region also undergo significant morphological changes, and might serve as substitute targets for Schaffer collateral and other excitatory synaptic input after hippocampal ischemia (Arabadzisz and Freund, 1999). Accordingly, it is rational to postulate that torsinA might participate in structural changes and/or transport of cell surface receptors in these hippocampal interneurons.

Via indirect cytoskeletal interactions, torsinA might also participate in the formation of neurotransmitter vesicles and vesicular recycling (Augood et al., 2002; Asanuma et al., 2005; Shashidharan et al., 2005; Dang et al., 2005; 2006; Balcioglu et al., 2007; Grundmann et al., 2007). In support of this concent, Augood and colleagues (2002) found a significantly increased DOPAC/ DA ratio, along with a trend toward reduction in D1 and D2 receptor binding in the striatum in postmortem DYT1 dystonia brains. Moreover, a variety of neurochemical alterations have been described in DYT1 knock-in, knock-down, and transgenic mice (Shashidharan et al., 2005; Dang et al., 2005; 2006; Balcioglu et al., 2007; Grundmann et al., 2007). Finally, Granata and co-workers 
(2008) found that synaptic vesicle recycling is regulated by torsinA expression. Endogenous torsinA plays an important role to regulate the rate of synaptic vesicle turnover. Importantly, overexpression of mutant torsinA significantly impaired the process of vesicular endocytosis.

In line with previous human work and the recent publication by Granata et al. (2008), our studies revealed significant increases of striatal DOPAC, HVA, and DA turnover (DOPAC/DA and HVA/DA) in hMT1 mice. Increases in the DOPAC/DA and HVA/DA ratios could be the manifestation of increased DA release, decreased DA uptake due to abnormal functioning of the dopamine and/or vesicular monoamine transporters or increased monoamine oxidase activity. In another study with hMT1 mice, normal basal levels of striatal extracellular DA and decreased amphetamine-induced DA release were identified (Balcioglu et al., 2007). Taken together, these findings suggest that mutant torsinA disrupts nigrostriatal dopaminergic neurotransmission by interfering with the normal biology of dopamine-containing vesicles and dopamine transporters at the axon terminal.

In conclusion, the body of work included in this dissertation provides important new insights into the systems biology of torsinA. The burden of mutant torsinA on motor, neurochemical, morphological, and metabolic phenotypes was characterized in mice and the role of normal torsinA in the central and peripheral nervous systems was explored in perturbation models. Although our findings do not provide definitive roles for wild-type and mutant torsinA in normal neural function and the pathobiology of DTY1 dystonia, they do point out clear avenues for future study. In particular, the neurochemical and metabolic abnormalities in hMT1 mice suggest that the metabolic topography of the DYT1 carrier state might be due to a primary defect in nigrostriatal neurotransmission. Furthermore, the appearance of dystonia might be due to compensatory and maladaptive changes by the olivocerebellar network. Perturbation models suggest that torsinA participates in reparative responses of the nervous system. Thus, DYT1 dystonia appears to be a network disorder of reduced penetrance, which could require an environmental perturbation to become clinically manifest. Given this conceptualization, it may be useful to determine if perturbations such as transient cerebral ischemia, hyperthermia or repetitive sensorimotor tasks can precipitate the appearance of a dystonic phenotype in hMT1 mice. 


\section{LIST OF REFERENCES}

Ahmad F, Davis MB, Waddy HM, Oley CA, Marsden CD, Harding AE (1993) Evidence for locus heterogeneity in autosomal dominant torsion dystonia. Genomics. 15: 9-12.

Alarcon F, Zijlmans JC, Duenas G, Cevallos N (2004) Post-stroke movement disorders: report of 56 patients. J Neurol Neurosurg Psychiatry 75: 1568-1574.

Alexander GE, Crutcher MD (1990) Functional architecture of basal ganglia circuits: neural substrates of parallel processing. Trends Neurosci 13:266-271.

Almasy L, Bressman SB, Raymond D, Kramer PL, Greene PE, Heiman GA, Ford B, Yount J, de Leon D, Chouinard S, Saunders-Pullman R, Brin MF, Kapoor RP, Jones AC, Shen H, Fahn S, Risch NJ, Nygaard TG (1997) Idiopathic torsion dystonia linked to chromosome 8 in two Mennonite families. Ann Neurol 42(4): 670-673.

Anderson KD, Gunawan A, Steward O (2005) Quantitative assessment of forelimb motor function after cervical spinal cord injury in rats: relationship to the corticospinal tract. Exp Neurol 194: 161-174.

Arabadzisz D, Freund TF (1999) Changes in excitatory and inhibitory circuits of the rat hippocampus 12-14 months after complete forebrain ischemia. Neuroscience 92: 27-45.

Araque A, Parpura V, Sanzgiri RP, Haydon PG (1999) Tripartite synapses: glia, the unacknowledged partner. Trends Neurosci 22: 208-215.

Asanuma K, Ma Y, Okulski J, Dhawan V, Chaly T, Carbon M, Bressman SB, Eidelberg D (2005) Decreased striatal D2 receptor binding in non-manifesting carriers of the DYT1 dystonia mutation. Neurology 64:347-349.

Auburger G, Ratzlaff T, Lunkes A, Nelles HW, Leube B, Binkofski F, Kugel H, Heindel W, Seitz R, Benecke R, Witte OW, Voit T (1996) A gene for autosomal dominant paroxysmal choreoathetosis/spasticity (CSE) maps to the vicinity of a potassium channel gene cluster on chromosome 1p, probably within $2 \mathrm{cM}$ between D1S443 and D1S197. Genomics 31(1): 90-94.

Augood SJ, Hollingsworth Z, Albers DS, Yang L, Leung JC, Muller B, Klein C, Breakefield XO, Standaert DG (2002) Dopamine transmission in DYT1 dystonia: a biochemical and autoradiographical study. Neurology 59:445-448.

Augood SJ, Keller-McGandy CE, Siriani A, Hewett J, Ramesh V, Sapp E, DiFiglia M, Breakefield XO, Standaert DG (2003) Distribution and ultrastructural localization of torsinA immunoreactivity in the human brain. Brain Res 986: 12-21. 
Balcioglu A, Kim MO, Sharma N, Cha JH, Breakefield XO, Standaert DG (2007) Dopamine release is impaired in a mouse model of DYT1 dystonia. J Neurochem 102: 783-788.

Basham SE, Rose LS (1999) Mutations in ooc-5 and ooc-3 disrupt oocyte formation and the reestablishment of asymmetric PAR protein localization in two-cell Caenorhabditis elegans embryos. Dev Biol 215:253-263.

Basham SE, Rose LS (2001) The Caenorhabditis elegans polarity gene ooc-5 encodes a Torsin-related protein of the AAA ATPase superfamily. Development 128: 4645-4656.

Bering R, Draguhn A, Diemer NH, Johansen FF (1997) Ischemia changes the coexpression of somatostatin and neuropeptide $\mathrm{Y}$ in hippocampal interneurons. Exp Brain Res 115: 423-429.

Bering R, Johansen FF (1993) Expression of somatostatin mRNA and peptide in rat hippocampus after cerebral ischemia. Regul Pept 49: 41-48.

Berkley KJ, Hand PJ (1978) Projections to the inferior olive of the cat. II. Comparisons of input from the gracile, cuneate and the spinal trigeminal nuclei. J Comp Neurol 180:253-264.

Berkley KJ, Worden IG (1978) [Projections to the inferior olive of the cat. I. Comparisons of input from the dorsal column nuclei, the lateral cervical nucleus, the spino-olivary pathways, the cerebral cortex and the cerebellum.]. J Comp Neurol 180:237-251.

Boshart M, Weber F, Jahn G, Dorsch-Häsler K, Fleckenstein B, Schaffner W (1985) A very strong enhancer is located upstream of an immediate early gene of human cytomegalovirus. Cell 41: 521-530.

Bragg DC, Camp SM, Kaufman CA, Wilbur JD, Boston H, Schuback DE, Hanson PI, Sena-Esteves M, Breakefield XO (2004) Perinuclear biogenesis of mutant torsin-A inclusions in cultured cells infected with tetracycline-regulated herpes simplex virus type 1 amplicon vectors. Neuroscience 125: 651-661.

Braun N, Zhu Y, Krieglstein J, Culmsee C, Zimmermann H (1998) Upregulation of the enzyme chain hydrolyzing extracellular ATP after transient forebrain ischemia in the rat. J Neurosci 18: 4891-4900.

Breakefield XO, Blood AJ, Li Y, Hallett M, Hanson PI, Standaert DG (2008) The pathophysiological basis of dystonias. Nat Rev Neurosci 9:222-234.

Breakefield XO, Kamm C, Hanson PI (2001) TorsinA: movement at many levels. Neuron 31: 9-12. 
Bressman SB, de Leon D, Raymond D, Ozelius LJ, Breakefield XO, Nygaard TG, Almasy L, Risch NJ, Kramer PL (1998) Clinical-genetic spectrum of primary dystonia. Adv Neurol 78:79-91.

Bressman SB, Sabatti C, Raymond D, de Leon D, Klein C, Kramer PL, Brin MF, Fahn S, Breakefield X, Ozelius LJ, Risch NJ (2000) The DYT1 phenotype and guidelines for diagnostic testing. Neurology 54: 1746-1752.

Briones TL, Suh E, Jozsa L, Hattar H, Chai J, Wadowska M (2004) Behaviorally-induced ultrastructural plasticity in the hippocampal region after cerebral ischemia. Brain Res 997: 137-146.

Brown AW, Bjelke B, Fuxe K (2004) Motor response to amphetamine treatment, taskspecific training, and limited motor experience in a postacute animal stroke model. Exp Neurol 190: 102-108.

Brown LL, Lorden JF (1989) Regional cerebral glucose utilization reveals widespread abnormalities in the motor system of the rat mutant dystonic. J Neurosci 9: 4033-4041. Bystron I, Blakemore C, Rakic P (2008) Development of the human cerebral cortex: Boulder Committee revisited. Nat Rev Neurosci 9: 110-122.

Caldwell GA, Cao S, Sexton EG, Gelwix CC, Bevel JP, Caldwell KA (2003) Suppression of polyglutamine-induced protein aggregation in Caenorhabditis elegans by torsin proteins. Hum Mol Genet 12: 307-319.

Callan AC, Bunning S, Jones OT, High S, Swanton E (2007) Biosynthesis of the dystonia-associated AAA + ATPase torsin A at the endoplasmic reticulum. Biochem $\mathrm{J}$ 401: 607-612.

Camargos S, Scholz S, Simón-Sánchez J, Paisán-Ruiz C, Lewis P, Hernandez D, Ding J, Gibbs JR, Cookson MR, Bras J, Guerreiro R, Oliveira CR, Lees A, Hardy J, Cardoso F, Singleton AB (2008) DYT16, a novel young-onset dystonia-parkinsonism disorder: identification of a segregating mutation in the stress-response protein PRKRA. Lancet Neurol 7(3):207-15.

Cao S, Gelwix CC, Caldwell KA, Caldwell GA (2005) Torsin-mediated protection from cellular stress in the dopaminergic neurons of Caenorhabditis elegans. J Neurosci 25:3801-3812.

Carbon M, Ghilardi MF, Argyelan M, Dhawan V, Bressman SB, Eidelberg D (2008b) Increased cerebellar activation during sequence learning in DYT1 carriers: an equiperformance study. Brain 131:146-154.

Carbon M, Kingsley PB, Su S, Smith GS, Spetsieris P, Bressman S, Eidelberg D (2004b) Microstructural white matter changes in carriers of the DYT1 gene mutation. Ann Neurol 56:283-286. 
Carbon M, Kingsley PB, Tang C, Bressman S, Eidelberg D (2008a) Microstructural white matter changes in primary torsion dystonia. Mov Disord 23:234-239.

Carbon M, Su S, Dhawan V, Raymond D, Bressman S, Eidelberg D (2004a) Regional metabolism in primary torsion dystonia: effects of penetrance and genotype. Neurology 62:1384-1390.

Carter RJ, Lione LA, Humby T, Mangiarini L, Mahal A, Bates GP, Dunnett SB, Morton AJ (1999) Characterization of progressive motor deficits in mice transgenic for the human Huntington's disease mutation. J Neurosci 19: 3248-3257.

Cerovac N, Petrović I, Klein C, Kostić VS (2007) Delayed-onset dystonia due to perinatal asphyxia: a prospective study. Mov Disord 22: 2426-2429.

Chen R, Hallett M (1998) Focal dystonia and repetitive motion disorders. Clin Orthop Relat Res: 102-106.

Chevalier-Mariette C, Henry I, Montfort L, Capgras S, Forlani S, Muschler J, Nicolas JF (2003) CpG content affects gene silencing in mice: evidence from novel transgenes. Genome Biol 4(9): R53.

Dang MT, Yokoi F, McNaught KS, Jengelley TA, Jackson T, Li J, Li Y (2005) Generation and characterization of Dyt1 DeltaGAG knock-in mouse as a model for earlyonset dystonia. Exp Neurol 196: 452-463.

Dang MT, Yokoi F, Pence MA, Li Y (2006) Motor deficits and hyperactivity in Dyt1 knockdown mice. Neurosci Res 56:470-474.

de Carvalho Aguiar P, Sweadner KJ, Penniston JT, Zaremba J, Liu L, Caton M, Linazasoro G, Borg M, Tijssen MA, Bressman SB, Dobyns WB, Brashear A, Ozelius LJ (2004) Mutations in the $\mathrm{Na}+/ \mathrm{K}+-\mathrm{ATPase}$ alpha3 gene ATP1A3 are associated with rapid-onset dystonia parkinsonism. Neuron 43(2): 169-175.

de Carvalho Aguiar PM, Ozelius LJ (2002) Classification and genetics of dystonia. Lancet Neurol 1:316-325.

Defazio G, Abbruzzese G, Girlanda P, Buccafusca M, Curra A, Marchese R, Martino D, Masi G, Mazzella L, Vacca L, Livrea P, Berardelli A (2003) Primary cervical dystonia and scoliosis: a multicenter case-control study. Neurology 60: 1012-1015.

Defazio G, Berardelli A, Abbruzzese G, Coviello V, Carella F, De Berardinis MT, Galardi G, Girlanda P, Maurri S, Mucchiut M, Albanese A, Basciani M, Bertolasi L, Liguori R, Tambasco N, Santoro L, Assennato G, Livrea P (1999) Risk factors for spread of primary adult onset blepharospasm: a multicentre investigation of the Italian movement disorders study group. J Neurol Neurosurg Psychiatry 67: 613-619. 
Defazio G, Berardelli A, Abbruzzese G, Lepore V, Coviello V, Acquistapace D, Capus L, Carella F, De Berardinis MT, Galardi G, Girlanda P, Maurri S, Albanese A, Bertolasi L, Liguori R, Rossi A, Santoro L, Tognoni G, Livrea P (1998) Possible risk factors for primary adult onset dystonia: a case-control investigation by the Italian Movement Disorders Study Group. J Neurol Neurosurg Psychiatry 64: 25-32.

Di Rocco RJ, Kageyama GH, Wong-Riley MT (1989) The relationship between CNS metabolism and cytoarchitecture: a review of 14C-deoxyglucose studies with correlation to cytochrome oxidase histochemistry. Comput Med Imaging Graph 13:81-92.

Diemer NH, Siemkovicz E (1981) Regional neurone damage after cerebral ischemia in the normo- and hypoglycemic rat. Neuropathol Appl Neurobiol 7: 217-227.

Djarmati A, Svetel M, Momcilovic D, Kostic V, Klein C (2005) Significance of recurrent mutations in the myofibrillogenesis regulator 1 gene. Arch Neurol 62(10): 1641.

Dluzen DE, Gao X, Story GM, Anderson LI, Kucera J, Walro JM (2001) Evaluation of nigrostriatal dopaminergic function in adult $+/+$ and $+/$ - BDNF mutant mice. Exp Neurol 1: $121-128$.

Dublin P, Hanani M (2007) Satellite glial cells in sensory ganglia: their possible contribution to inflammatory pain. Brain Behav Immun 21: 592-598.

Duncan GE, Stumpf WE (1991) Brain activity patterns: assessment by high resolution autoradiographic imaging of radiolabeled 2-deoxyglucose and glucose uptake. Prog Neurobiol 37:365-382.

Eidelberg D (1998) Abnormal brain networks in DYT1 dystonia. Adv Neurol 78:127133.

Eidelberg D, Moeller JR, Antonini A, Kazumata K, Nakamura T, Dhawan V, Spetsieris P, deLeon D, Bressman SB, Fahn S (1998) Functional brain networks in DYT1 dystonia. Ann Neurol 44:303-312.

Esapa CT, Waite A, Locke M, Benson MA, Kraus M, McIlhinney RA, Sillitoe RV, Beesley PW, Blake DJ (2007) SGCE missense mutations that cause myoclonus-dystonia syndrome impair epsilon-sarcoglycan trafficking to the plasma membrane: modulation by ubiquitination and torsinA. Hum Mol Genet 16: 327-342.

Fahn S (1988) Concept and classification of dystonia. Adv Neurol 50:1-8.

Fahn S, Bressman SB, Marsden CD (1998) Classification of dystonia. Adv Neurol 78: 110 . 
Fernagut PO, Chalon S, Diguet E, Guilloteau D, Tison F, Jaber M (2003) Motor behavior deficits and their histopathological and functional correlates in the nigrostriatal system of dopamine transporter knockout mice. Neuroscience 116: 1123-1130.

Fernagut PO, Diguet E, Stefanova N, Biran M, Wenning GK, Canioni P, Bioulac B, Tison F (2002) Subacute systemic 3-nitropropionic acid intoxication induces a distinct motor disorder in adult C57B1/6 mice: behavorial and histopathological characterization. Neuroscience 114: 1005-1017.

Ferrari-Toninelli G, Paccioretti S, Francisconi S, Uberti D, Memo M (2004) TorsinA negatively controls neurite outgrowth of SH-SY5Y human neuronal cell line. Brain Res 1012:75-81.

Ferrari-Toninelli G, Spano P, Memo M (2003) TorsinA, microtubules and cell polarity. Funct Neurol 18(1): 7-10.

Ferrer I, Soriano MA, Vidal A, Planas AM (1995) Survival of parvalbuminimmunoreactive neurons in the gerbil hippocampus following transient forebrain ischemia does not depend on HSP-70 protein induction. Brain Res 692: 41-46.

Fontanesi F, Soto IC, Horn D, Barrientos A (2006) Assembly of mitochondrial cytochrome c-oxidase, a complicated and highly regulated cellular process. Am J Physiol Cell Physiol 291:C1129-1147.

Franklin K, Paxinos G (1997) The mouse brain atlas in stereotaxic coordinates. San Diego: Academic Press.

Franklin K, Paxinos G (1997) The mouse brain atlas in stereotaxic coordinates. San Diego: Academic Press.

Fritschy JM, Brandner S, Aguzzi A, Koedood M, Luscher B, Mitchell PJ (1996) Brain cell type specificity and gliosis-induced activation of the human cytomegalovirus immediate-early promoter in transgenic mice. J Neurosci 16:2275-2282.

Furukawa Y, Hornykiewicz O, Fahn S, Kish SJ (2000) Striatal dopamine in early-onset primary torsion dystonia with the DYT1 mutation. Neurology 54:1193-1195.

Ghilardi MF, Carbon M, Silvestri G, Dhawan V, Tagliati M, Bressman S, Ghez C, Eidelberg D (2003) Impaired sequence learning in carriers of the DYT1 dystonia mutation. Ann Neurol 54:102-109.

Goldman RD, Khuon S, Chou YH, Opal P, Steinert PM (1996) The function of intermediate filaments in cell shape and cytoskeletal integrity. J Cell Biol 134: 971-983.

Goldstein LB, Davis JN (1990) Clonidine impairs recovery of beam-walking after a sensorimotor cortex lesion in the rat. Brain Res 508: 305-309. 
Gonzalez-Lima F, Garrosa M (1991) Quantitative histochemistry of cytochrome oxidase in rat brain. Neurosci Lett 123:251-253.

Goodchild RE, Dauer WT (2004) Mislocalization to the nuclear envelope: an effect of the dystonia-causing torsinA mutation. Proc Natl Acad Sci U S A 101: 847-852.

Goodchild RE, Dauer WT (2005) The AAA+ protein torsinA interacts with a conserved domain present in LAP1 and a novel ER protein. J Cell Biol 168: 855-862.

Goodchild RE, Kim CE, Dauer WT (2005) Loss of the dystonia-associated protein torsinA selectively disrupts the neuronal nuclear envelope. Neuron 48: 923-932.

Gottlieb M, Matute C (1999) Expression of nerve growth factor in astrocytes of the hippocampal CA1 area following transient forebrain ischemia. Neuroscience 91: 10271034.

Granata A, Watson R, Collinson LM, Schiavo G, Warner TT (2008) The dystoniaassociated protein torsinA modulates synaptic vesicle recycling. J Biol Chem 283: 75687579 .

Grimes DA, Han F, Lang AE, St George-Hyssop P, Racacho L, Bulman DE (2002) A novel locus for inherited myoclonus-dystonia on 18p11. Neurology 59(8): 1183-1186.

Grosche J, Matyash V, Moller T, Verkhratsky A, Reichenbach A, Kettenmann H (1999) Microdomains for neuron-glia interaction: parallel fiber signaling to Bergmann glial cells. Nat Neurosci 2: 139-143.

Grundmann K, Laubis-Herrmann U, Bauer I, Dressler D, Vollmer-Haase J, Bauer P, Stuhrmann M, Schulte T, Schols L, Topka H, Riess O (2003) Frequency and phenotypic variability of the GAG deletion of the DYT1 gene in an unselected group of patients with dystonia. Arch Neurol. 60: 1266-1270.

Grundmann K, Reischmann B, Vanhoutte G, Hubener J, Teismann P, Hauser TK, Bonin M, Wilbertz J, Horn S, Nguyen HP, Kuhn M, Chanarat S, Wolburg H, Van der Linden A, Riess O (2007) Overexpression of human wildtype torsinA and human DeltaGAG torsin A in a transgenic mouse model causes phenotypic abnormalities. Neurobiol Dis 27: 190-206.

Hanson PI, Whiteheart SW (2005) AAA+ proteins: have engine, will work. Nat Rev Mol Cell Biol 6: 519-529.

He F, Zhang S, Qian F, Zhang C (1995) Delayed dystonia with striatal CT lucencies induced by a mycotoxin (3-nitropropionic acid). Neurology 45: 2178-2183. 
Hevner RF, Liu S, Wong-Riley MT (1995) A metabolic map of cytochrome oxidase in the rat brain: histochemical, densitometric and biochemical studies. Neuroscience 65:313-342.

Hewett J, Gonzalez-Agosti C, Slater D, Ziefer P, Li S, Bergeron D, Jacoby DJ, Ozelius LJ, Ramesh V, Breakefield XO (2000) Mutant torsinA, responsible for early-onset torsion dystonia, forms membrane inclusions in cultured neural cells. Hum Mol Genet 9: 1403-1413.

Hewett JW, Kamm C, Boston H, Beauchamp R, Naismith T, Ozelius L, Hanson PI, Breakefield XO, Ramesh V (2004) TorsinB--perinuclear location and association with torsinA. J Neurochem 89:1186-1194.

Hewett JW, Nery FC, Niland B, Ge P, Tan P, Hadwiger P, Tannous BA, Sah DW, Breakefield XO (2008) siRNA knock-down of mutant torsinA restores processing through secretory pathway in DYT1 dystonia cells. Hum Mol Genet 17:1436-1445.

Hewett JW, Tannous B, Niland BP, Nery FC, Zeng J, Li Y, Breakefield XO (2007) Mutant torsinA interferes with protein processing through the secretory pathway in DYT1 dystonia cells. Proc Natl Acad Sci U S A 104:7271-7276.

Hewett JW, Zeng J, Niland BP, Bragg DC, Breakefield XO (2006) Dystonia-causing mutant torsin $\mathrm{A}$ inhibits cell adhesion and neurite extension through interference with cytoskeletal dynamics. Neurobiol Dis 22: 98-111.

Hewett JW, Ziefer P, Bergeron D, Naismith T, Boston H, Slater D, Wilbur J, Schuback D, Kamm C, Smith N, Camp S, Ozelius LJ, Ramesh V, Hanson PI, Breakefield XO (2003) Torsin A in PC12 cells: localization in the endoplasmic reticulum and response to stress. J Neurosci Res 72: 158-168.

Hollinger P, Burgunder J (2000) Posttraumatic focal dystonia of the shoulder. Eur Neurol 44: $153-155$.

Holton JL, Schneider SA, Ganesharajah T, Gandhi S, Strand C, Shashidharan P, Barreto J, Wood NW, Lees AJ, Bhatia KP, Revesz T (2008) Neuropathology of primary adultonset dystonia. Neurology 70:695-699.

Hong SW, Vierling E (2000) Mutants of Arabidopsis thaliana defective in the acquisition of tolerance to high temperature stress. Proc Natl Acad Sci U S A 97: 4392-4397.

Hornykiewicz O, Kish SJ, Becker LE, Farley I, Shannak K (1986) Brain

neurotransmitters in dystonia musculorum deformans. N Engl J Med 315: 347-353.

Hu P, McLachlan EM (2000) Distinct sprouting responses of sympathetic and peptidergic sensory axons proximal to a sciatic nerve transection in guinea pigs and rats. Neurosci Lett 295: 59-63. 
Hummel SM, Lucking CH (2001) [Posttraumatic dystonia. Review and legal aspects]. Nervenarzt 72: 93-99.

Hutchins JB, Casagrande VA (1989) Vimentin: changes in distribution during brain development. Glia 2: 55-66.

Ichinose H, Ohye T, Takahashi E, Seki N, Hori T, Segawa M, Nomura Y, Endo K, Tanaka H, Tsuji S, et al (1994) Hereditary progressive dystonia with marked diurnal fluctuation caused by mutations in the GTP cyclohydrolase I gene. Nat Genet 8(3):236242.

Ilardi JM, Mochida S, Sheng ZH (1999) Snapin: a SNARE-associated protein implicated in synaptic transmission. Nat Neurosci 2(2): 119-124.

Jacquin MF, McCasland JS, Henderson TA, Rhoades RW, Woolsey TA (1993) 2-DG uptake patterns related to single vibrissae during exploratory behaviors in the hamster trigeminal system. J Comp Neurol 332:38-58.

Jankovic J, Orman J (1988) Tetrabenazine therapy of dystonia, chorea, tics, and other dyskinesias. Neurology 38: 391-394.

Jankovic J, Van der Linden C (1988) Dystonia and tremor induced by peripheral trauma: predisposing factors. J Neurol Neurosurg Psychiatry 51: 1512-1519.

Jiao Y, Yan J, Zhao Y, Donahue LR, Beamer WG, Li X, Roe BA, Ledoux MS, Gu W (2005) Carbonic anhydrase-related protein VIII deficiency is associated with a distinctive lifelong gait disorder in waddles mice. Genetics 171: 1239-1246.

Johnson JR, Robinson BL, Ali SF, Binienda Z (2000) Dopamine toxicity following long term exposure to low doses of 3-nitropropionic acid (3-NPA) in rats. Toxicol Lett 116: 113-118.

Joshi SA, Baker TA, Sauer RT (2003) C-terminal domain mutations in ClpX uncouple substrate binding from an engagement step required for unfolding. Mol Microbiol 48: 6776.

Kamal A, Goldstein LS (2002) Principles of cargo attachment to cytoplasmic motor proteins. Curr Opin Cell Biol 14:63-68.

Kamm C (2006) Early onset torsion dystonia (Oppenheim's dystonia). Orphanet J Rare Dis 1: 48.

Kamm C, Boston H, Hewett J, Wilbur J, Corey DP, Hanson PI, Ramesh V, Breakefield XO (2004) The early onset dystonia protein torsinA interacts with kinesin light chain 1. J Biol Chem 279: 19882-19892. 
Kawagoe J, Abe K, Sato S, Nagano I, Nakamura S, Kogure K (1992) Distributions of heat shock protein-70 mRNAs and heat shock cognate protein-70 mRNAs after transient global ischemia in gerbil brain. J Cereb Blood Flow Metab 12:794-801.

Khanna R, Das A, Damodaran SS (1992) Prospective study of neuroleptic-induced dystonia in mania and schizophrenia. Am J Psychiatry 149: 511-513.

Kilby NJ, Leyser HM, Furner IJ (1992) Promoter methylation and progressive transgene inactivation in Arabidopsis. Plant Mol Biol 20: 103-112.

Kindy MS, Bhat AN, Bhat NR (1992) Transient ischemia stimulates glial fibrillary acid protein and vimentin gene expression in the gerbil neocortex, striatum and hippocampus. Brain Res Mol Brain Res 13: 199-206.

Klein C, Ozelius LJ (2002) Dystonia: clinical features, genetics, and treatment. Curr Opin Neurol 15: 491-497.

Koh YH, Rehfeld K, Ganetzky B (2004) A Drosophila model of early onset torsion dystonia suggests impairment in TGF-beta signaling. Hum Mol Genet 13: 2019-2030.

Kokaia Z, Lindvall O (2003) Neurogenesis after ischaemic brain insults. Curr Opin Neurobiol 13: 127-132.

Konakova M, Huynh DP, Yong W, Pulst SM (2001) Cellular distribution of torsin A and torsin B in normal human brain. Arch Neurol 58:921-927.

Konakova M, Pulst SM (2001) Immunocytochemical characterization of torsin proteins in mouse brain. Brain Res 922:1-8.

Konakova M, Pulst SM (2005) Dystonia-associated forms of torsinA are deficient in ATPase activity. J Mol Neurosci 25:105-117.

Koukouni V, Martino D, Arabia G, Quinn NP, Bhatia KP (2007) The entity of young onset primary cervical dystonia. Mov Disord 22:843-847.

Kramer PL, Mineta M, Klein C, Schilling K, de Leon D, Farlow MR, Breakefield XO, Bressman SB, Dobyns WB, Ozelius LJ, Brashear A (1999) Rapid-onset dystoniaparkinsonism: linkage to chromosome 19q13. Ann Neurol. 46: 176-182.

Krystkowiak P, Martinat P, Defebvre L, Pruvo JP, Leys D, Destee A (1998) Dystonia after striatopallidal and thalamic stroke: clinicoradiological correlations and pathophysiological mechanisms. J Neurol Neurosurg Psychiatry 65:703-708. 
Kuner R, Teismann P, Trutzel A, Naim J, Richter A, Schmidt N, Bach A, Ferger B, Schneider A (2004) TorsinA, the gene linked to early-onset dystonia, is upregulated by the dopaminergic toxin MPTP in mice. Neurosci Lett 355: 126-130.

Kuner R, Teismann P, Trutzel A, Naim J, Richter A, Schmidt N, von Ahsen O, Bach A, Ferger B, Schneider A (2003) TorsinA protects against oxidative stress in COS-1 and PC12 cells. Neurosci Lett 350: 153-156.

Kuo LT, Groves MJ, Scaravilli F, Sugden D, An SF (2007) Neurotrophin-3 administration alters neurotrophin, neurotrophin receptor and nestin mRNA expression in rat dorsal root ganglia following axotomy. Neuroscience 147: 491-507.

Kyllerman M (1982) Dyskinetic cerebral palsy. II. Pathogenetic risk factors and intrauterine growth. Acta Paediatr Scand 71: 551-558.

Ledoux MS (2004) Animal Models of Movement Disorders. Amsterdam, Netherlands: Elsevier.

LeDoux MS, Brady KA (2003) Secondary cervical dystonia associated with structural lesions of the central nervous system. Mov Disord 18: 60-69.

LeDoux MS, Lorden JF (2002) Abnormal spontaneous and harmaline-stimulated Purkinje cell activity in the awake genetically dystonic rat. Exp Brain Res 145:457-467.

LeDoux MS, Lorden JF, Ervin JM (1993) Cerebellectomy eliminates the motor syndrome of the genetically dystonic rat. Exp Neurol 120:302-310.

LeDoux MS, Lorden JF, Meinzen-Derr J (1995) Selective elimination of cerebellar output in the genetically dystonic rat. Brain Res 697:91-103.

LeDoux MS, Xu L, Xiao J, Ferrell B, Menkes DL, Homayouni R (2006) Murine central and peripheral nervous system transcriptomes: comparative gene expression. Brain Res 1107: 24-41.

Lee MS, Rinne JO, Ceballos-Baumann A, Thompson PD, Marsden CD (1994) Dystonia after head trauma. Neurology 44: 1374-1378.

Lepekhin EA, Eliasson C, Berthold CH, Berezin V, Bock E, Pekny M (2001) Intermediate filaments regulate astrocyte motility. J Neurochem 79: 617-625.

Leube B, Kessler KR, Ferbert A, Ebke M, Schwendemann G, Erbguth F, Benecke R, Auburger G (1999) Phenotypic variability of the DYT1 mutation in German dystonia patients. Acta Neurol Scand 99: 248-251.

Leube B, Rudnicki D, Ratzlaff T, Kessler KR, Benecke R, Auburger G (1996) Idiopathic torsion dystonia: assignment of a gene to chromosome 18p in a German family with adult 
onset, autosomal dominant inheritance and purely focal distribution. Hum Mol Genet 5(10): 1673-1677.

Leung JC, Klein C, Friedman J, Vieregge P, Jacobs H, Doheny D, Kamm C, DeLeon D, Pramstaller PP, Penney JB, Eisengart M, Jankovic J, Gasser T, Bressman SB, Corey DP, Kramer P, Brin MF, Ozelius LJ, Breakefield XO (2001) Novel mutation in the TOR1A (DYT1) gene in atypical early onset dystonia and polymorphisms in dystonia and early onset parkinsonism. Neurogenetics 3:133-143.

Liu CG, Maercker C, Castanon MJ, Hauptmann R, Wiche G (1996) Human plectin: organization of the gene, sequence analysis, and chromosome localization (8q24). Proc Natl Acad Sci U S A 93: 4278-4283.

Liu QS, Xu Q, Kang J, Nedergaard M (2004) Astrocyte activation of presynaptic metabotropic glutamate receptors modulates hippocampal inhibitory synaptic transmission. Neuron Glia Biol 1: 307-316.

Liu X, Luo X, Hu W (1992) Studies on the epidemiology and etiology of moldy sugarcane poisoning in China. Biomed Environ Sci 5: 161-177.

Liu Z, Zolkiewska A, Zolkiewski M (2003) Characterization of human torsinA and its dystonia-associated mutant form. Biochem J 374: 117-122.

Lüdecke B, Dworniczak B, Bartholomé K (1995) A point mutation in the tyrosine hydroxylase gene associated with Segawa's syndrome. Hum Genet 95: 123-125.

Magistretti PJ, Pellerin L, Rothman DL, Shulman RG (1999) Energy on demand. Science 283: 496-497.

Makino S, Kaji R, Ando S, Tomizawa M, Yasuno K, Goto S, Matsumoto S, Tabuena MD, Maranon E, Dantes M, Lee LV, Ogasawara K, Tooyama I, Akatsu H, Nishimura M, Tamiya G (2007) Reduced neuron-specific expression of the TAF1 gene is associated with X-linked dystonia-parkinsonism. Am J Hum Genet 80: 393-406.

Marshall SP, Lang EJ (2004) Inferior olive oscillations gate transmission of motor cortical activity to the cerebellum. J Neurosci 24:11356-11367.

McCasland JS, Graczyk GM (2001) Metabolic mapping. In: Curr Protoc Neurosci. New York: John Wiley \& Sons, Inc.

McGavern DB, Zoecklein L, Drescher KM, Rodriguez M (1999) Quantitative assessment of neurologic deficits in a chronic progressive murine model of CNS demyelination. Exp Neurol 158: 171-181. 
McLean PJ, Kawamata H, Shariff S, Hewett J, Sharma N, Ueda K, Breakefield XO, Hyman BT (2002) TorsinA and heat shock proteins act as molecular chaperones: suppression of alpha-synuclein aggregation. J Neurochem 83: 846-854.

McNaught KS, Kapustin A, Jackson T, Jengelley TA, Jnobaptiste R, Shashidharan P, Perl DP, Pasik P, Olanow CW (2004) Brainstem pathology in DYT1 primary torsion dystonia. Ann Neurol 56: 540-547.

Misbahuddin A, Placzek MR, Taanman JW, Gschmeissner S, Schiavo G, Cooper JM, Warner TT (2005) Mutant torsinA, which causes early-onset primary torsion dystonia, is redistributed to membranous structures enriched in vesicular monoamine transporter in cultured human SH-SY5Y cells. Mov Disord 20: 432-440.

Morioka T, Kalehua AN, Streit WJ (1991) The microglial reaction in the rat dorsal hippocampus following transient forebrain ischemia. J Cereb Blood Flow Metab 11: 966973.

Naismith TV, Heuser JE, Breakefield XO, Hanson PI (2004) TorsinA in the nuclear envelope. Proc Natl Acad Sci U S A 101: 7612-7617.

Naismith TV, Heuser JE, Breakefield XO, Hanson PI (2004) TorsinA in the nuclear envelope. Proc Natl Acad Sci U S A 101: 7612-7617.

Nakatomi H, Kuriu T, Okabe S, Yamamoto S, Hatano O, Kawahara N, Tamura A, Kirino T, Nakafuku M (2002) Regeneration of hippocampal pyramidal neurons after ischemic brain injury by recruitment of endogenous neural progenitors. Cell 110: 429-441.

Nemeth AH (2002) The genetics of primary dystonias and related disorders. Brain 125: 695-721.

Nery FC, Hewett J, Niland B, Zeng J, Li Y, Wiche G, Sharma N, Breakefield XO (2007) Partcipation of torsinA in linking the nuclear envelope to the cytoskeleton. In: Society for Neuroscience. San Diego.

Neuwald AF, Aravind L, Spouge JL, Koonin EV (1999) AAA+: A class of chaperonelike ATPases associated with the assembly, operation, and disassembly of protein complexes. Genome Res 9: 27-43.

Nishino K, Nowak TS Jr (2004) Time course and cellular distribution of hsp27 and hsp72 stress protein expression in a quantitative gerbil model of ischemic injury and tolerance: thresholds for hsp 72 induction and hilar lesioning in the context of ischemic preconditioning. J Cereb Blood Flow Metab 24: 167-178.

Nitsch C, Scotti A, Sommacal A, Kalt G (1989) GABAergic hippocampal neurons resistant to ischemia-induced neuronal death contain the $\mathrm{Ca} 2(+)$-binding protein parvalbumin. Neurosci Lett 105: 263-268. 
Nobrega JN, Richter A, Jiwa D, Raymond R, Loscher W (1998) Regional alterations in neuronal activity in dystonic hamster brain determined by quantitative cytochrome oxidase histochemistry. Neuroscience 83: 1215-1223.

Nowak TS Jr (1991) Localization of $70 \mathrm{kDa}$ stress protein mRNA induction in gerbil brain after ischemia. J Cereb Blood Flow Metab 11: 432-439.

Nowak TS Jr, Kiessling M (1999) Reprogramming of gene expression after ischemia. In: Cerebral Ischemia. Molecular and Cellular Pathology (Walz W, ed), pp 145-215 Totowa: Humana Press.

Nygaard TG, Wilhelmsen KC, Risch NJ, Brown DL, Trugman JM, Gilliam TC, Fahn S, Weeks DE (1993) Linkage mapping of dopa-responsive dystonia (DRD) to chromosome 14q. Nat Genet 5: 386-391.

Oberlin SR, Konakova M, Pulst S, Chesselet MF (2004) Development and anatomic localization of torsinA. Adv Neurol 94: 61-65.

O'Farrell C, Lockhart PJ, Lincoln S, De Lucia M, Singleton AB, Dickson DW, Cookson MR (2004) Biochemical characterization of torsinB. Brain Res Mol Brain Res 127: 1-9.

Ogura T, Wilkinson AJ (2001) AAA+ superfamily ATPases: common structure--diverse function. Genes Cells 6: 575-597.

Ozelius LJ, Hewett JW, Page CE, Bressman SB, Kramer PL, Shalish C, de Leon D, Brin MF, Raymond D, Corey DP, Fahn S, Risch NJ, Buckler AJ, Gusella JF, Breakefield XO (1997) The early-onset torsion dystonia gene (DYT1) encodes an ATP-binding protein. Nat Genet 17: 40-48.

Ozelius LJ, Page CE, Klein C, Hewett JW, Mineta M, Leung J, Shalish C, Bressman SB, de Leon D, Brin MF, Fahn S, Corey DP, Breakefield XO (1999) The TOR1A (DYT1) gene family and its role in early onset torsion dystonia. Genomics 62: 377-384.

Panickar KS, Norenberg MD (2005) Astrocytes in cerebral ischemic injury: Morphological and general considerations. Glia 50: 287-298.

Pham P, Frei KP, Woo W, Truong DD (2006) Molecular defects of the dystonia-causing torsinA mutation. Neuroreport 17: 1725-1728.

Pisani A, Martella G, Tscherter A, Bonsi P, Sharma N, Bernardi G, Standaert DG (2006) Altered responses to dopaminergic D2 receptor activation and N-type calcium currents in striatal cholinergic interneurons in a mouse model of DYT1 dystonia. Neurobiol Dis 24: 318-325. 
Powell EM, Meiners S, DiProspero NA, Geller HM (1997) Mechanisms of astrocytedirected neurite guidance. Cell Tissue Res 290: 385-393.

Pulsinelli WA, Brierley JB (1979) A new model of bilateral hemispheric ischemia in the unanesthetized rat. Stroke 10: 267-272.

Pulsinelli WA, Brierley JB, Plum F (1982a) Temporal profile of neuronal damage in a model of transient forebrain ischemia. Ann Neurol 11: 491-498.

Pulsinelli WA, Levy DE, Duffy TE (1982b) Regional cerebral blood flow and glucose metabolism following transient forebrain ischemia. Ann Neurol 11: 499-509.

Rainier S, Thomas D, Tokarz D, Ming L, Bui M, Plein E, Zhao X, Lemons R, Albin R, Delaney C, Alvarado D, Fink JK (2004) Myofibrillogenesis regulator 1 gene mutations cause paroxysmal dystonic choreoathetosis. Arch Neurol 61: 1025-1029.

Raymond K, Sonnenberg A (2005) Nesprin-3, a novel outer nuclear membrane protein, associates with the cytoskeletal linker protein plectin. J Cell Biol 171: 799-810.

Remington GJ, Voineskos G, Pollock B, Reed K, Coulter K (1990) Prevalence of neuroleptic-induced dystonia in mania and schizophrenia. Am J Psychiatry 147: 12311233.

Richter A, Brotchie JM, Crossman AR, Loscher W (1998) [3H]-2-deoxyglucose uptake study in mutant dystonic hamsters: abnormalities in discrete brain regions of the motor system. Mov Disord 13: 718-725.

Riquelme R, Miralles CP, De Blas AL (2002) Bergmann glia GABA(A) receptors concentrate on the glial processes that wrap inhibitory synapses. J Neurosci 22: 1072010730.

Rostasy K, Augood SJ, Hewett JW, Leung JC, Sasaki H, Ozelius LJ, Ramesh V, Standaert DG, Breakefield XO, Hedreen JC (2003) TorsinA protein and neuropathology in early onset generalized dystonia with GAG deletion. Neurobiol Dis 12:11-24.

Ruohonen S, Jagodi M, Khademi M, Taskinen HS, Ojala P, Olsson T, Roytta M (2002) Contralateral non-operated nerve to transected rat sciatic nerve shows increased expression of IL-1beta, TGF-beta1, TNF-alpha, and IL-10. J Neuroimmunol 132:11-17.

Ryoke K, Ochi M, Iwata A, Uchio Y, Yamamoto S, Yamaguchi H (2000) A conditioning lesion promotes in vivo nerve regeneration in the contralateral sciatic nerve of rats. Biochem Biophys Res Commun 267: 715-718.

Saint-Cyr JA, Courville J (1981) Sources of descending afferents to the inferior olive from the upper brain stem in the cat as revealed by the retrograde transport of horseradish peroxidase. J Comp Neurol 198: 567-581. 
Sancho-Tello M, Valles S, Montoliu C, Renau-Piqueras J, Guerri C (1995)

Developmental pattern of GFAP and vimentin gene expression in rat brain and in radial glial cultures. Glia 15: 157-166.

Sankhla C, Lai EC, Jankovic J (1998) Peripherally induced oromandibular dystonia. J Neurol Neurosurg Psychiatry 65: 722-728.

Schmidt-Kastner R, Szymas J, Hossmann KA (1990) Immunohistochemical study of glial reaction and serum protein extravasation in relation to neuronal damage in rat hippocampus after ischemia. Neuroscience 38: 527-540.

Schott GD (1985) The relationship of peripheral trauma and pain to dystonia. J Neurol Neurosurg Psychiatry 48: 698-701.

Schweinfurth JM, Billante M, Courey MS (2002) Risk factors and demographics in patients with spasmodic dysphonia. Laryngoscope 112: 220-223.

Sharma N, Baxter MG, Petravicz J, Bragg DC, Schienda A, Standaert DG, Breakefield XO (2005) Impaired motor learning in mice expressing torsinA with the DYT1 dystonia mutation. J Neurosci 25: 5351-5355.

Sharma N, Hewett J, Ozelius LJ, Ramesh V, McLean PJ, Breakefield XO, Hyman BT (2001) A close association of torsinA and alpha-synuclein in Lewy bodies: a fluorescence resonance energy transfer study. Am J Pathol 159: 339-344.

Sharp FR, Liu J, Bernabeu R (2002) Neurogenesis following brain ischemia. Brain Res Dev Brain Res 134: 23-30.

Shashidharan P, Good PF, Hsu A, Perl DP, Brin MF, Olanow CW (2000b) TorsinA accumulation in Lewy bodies in sporadic Parkinson's disease. Brain Res 877: 379-381.

Shashidharan P, Kramer BC, Walker RH, Olanow CW, Brin MF (2000a)

Immunohistochemical localization and distribution of torsin A in normal human and rat brain. Brain Res 853: 197-206.

Shashidharan P, Paris N, Sandu D, Karthikeyan L, McNaught KS, Walker RH, Olanow CW (2004) Overexpression of torsin A in PC12 cells protects against toxicity. J Neurochem 88: 1019-1025.

Shashidharan P, Sandu D, Potla U, Armata IA, Walker RH, McNaught KS, Weisz D, Sreenath T, Brin MF, Olanow CW (2005) Transgenic mouse model of early-onset DYT1 dystonia. Hum Mol Genet 14: 125-133. 
Sobkowicz HM, Waclawik AJ, August BK (2006) The astroglial cell that guides nerve fibers from growth cone to synapse in organotypic cultures of the fetal mouse spinal cord. Synapse 59: 183-200.

Starr PA, Rau GM, Davis V, Marks WJ, Jr., Ostrem JL, Simmons D, Lindsey N, Turner RS (2005) Spontaneous pallidal neuronal activity in human dystonia: comparison with Parkinson's disease and normal macaque. J Neurophysiol 93: 3165-3176.

Strome EM, Cepeda IL, Sossi V, Doudet DJ (2006) Evaluation of the integrity of the dopamine system in a rodent model of Parkinson's disease: small animal positron emission tomography compared to behavioral assessment and autoradiography. Mol Imaging Biol 8: 292-299.

Sukin D, Skedros DG, Beales M, Stratton SE, Lorden JF, Oltmans GA (1987) Temporal sequence of motor disturbances and increased cerebellar glutamic acid decarboxylase activity following 3-acetylpyridine lesions in adult rats. Brain Res 426: 82-92.

Swenson RS, Castro AJ (1983) The afferent connections of the inferior olivary complex in rats: a study using the retrograde transport of horseradish peroxidase. Am J Anat 166: 329-341.

Tanaka S, Kitagawa K, Ohtsuki T, Yagita Y, Takasawa K, Hori M, Matsumoto M (2002) Synergistic induction of HSP40 and HSC70 in the mouse hippocampal neurons after cerebral ischemia and ischemic tolerance in gerbil hippocampus. J Neurosci Res 67: 3747.

Tang JK, Moro E, Mahant N, Hutchison WD, Lang AE, Lozano AM, Dostrovsky JO (2007) Neuronal firing rates and patterns in the globus pallidus internus of patients with cervical dystonia differ from those with Parkinson's disease. J Neurophysiol 98: 720-729.

Tarsy D, Simon DK (2006) Dystonia. N Engl J Med 355: 818-829.

Teunissen CE, Steinbusch HW, Angevaren M, Appels M, de Bruijn C, Prickaerts J, de Vente J (2001) Behavioural correlates of striatal glial fibrillary acidic protein in the 3nitropropionic acid rat model: disturbed walking pattern and spatial orientation.

Neuroscience 105: 153-167.

Thomas AD, Murray JD, Oberbauer AM (2005) Transgene transmission to progeny by oMt1a-oGH transgenic mice. Transgenic Res 14: 441-448.

Tomita H, Nagamitsu S, Wakui K, Fukushima Y, Yamada K, Sadamatsu M, Masui A, Konishi T, Matsuishi T, Aihara M, Shimizu K, Hashimoto K, Mineta M, Matsushima M, Tsujita T, Saito M, Tanaka H, Tsuji S, Takagi T, Nakamura Y, Nanko S, Kato N, Nakane Y, Niikawa N (1999) Paroxysmal kinesigenic choreoathetosis locus maps to chromosome 16p11.2-q12.1. Am J Hum Genet 65: 1688-1697. 
Torres GE, Sweeney AL, Beaulieu JM, Shashidharan P, Caron MG (2004) Effect of torsinA on membrane proteins reveals a loss of function and a dominant-negative phenotype of the dystonia-associated DeltaE-torsinA mutant. Proc Natl Acad Sci U S A 101: $15650-15655$.

Treves T, Korczyn AD (1986) Progressive dystonia and paraparesis in cerebral palsy. Eur Neurol 25: 148-153.

Trost M, Carbon M, Edwards C, Ma Y, Raymond D, Mentis MJ, Moeller JR, Bressman SB, Eidelberg D (2002) Primary dystonia: is abnormal functional brain architecture linked to genotype? Ann Neurol 52: 853-856.

Ueda M, Nowak TS, Jr. (2005) Protective preconditioning by transient global ischemia in the rat: components of delayed injury progression and lasting protection distinguished by comparisons of depolarization thresholds for cell loss at long survival times. J Cereb Blood Flow Metab 25: 949-958.

Ung L, Ignatius R, Whan-Suk H, Larkindale J, Waters E, Vierling E (2007) The Arabidopsis $\mathrm{ClpB} / \mathrm{Hsp} 100$ family of proteins: chaperones for stress and chloroplast development. The Plant Journal 49: 115-127.

Vale RD (2000) AAA proteins. Lords of the ring. J Cell Biol 150: F13-19.

Valente EM, Bentivoglio AR, Cassetta E, Dixon PH, Davis MB, Ferraris A, Ialongo T, Frontali M, Wood NW, Albanese A (2001) DYT13, a novel primary torsion dystonia locus, maps to chromosome 1p36.13--36.32 in an Italian family with cranial-cervical or upper limb onset. Ann Neurol 49: 362-366.

van den Pol AN, Ghosh PK (1998) Selective neuronal expression of green fluorescent protein with cytomegalovirus promoter reveals entire neuronal arbor in transgenic mice. $\mathrm{J}$ Neurosci 18: 10640-10651.

van Harten PN, Hoek HW, Kahn RS (1999) Acute dystonia induced by drug treatment. BMJ. 319: 623-626.

van Harten PN, van Trier JC, Horwitz EH, Matroos GE, Hoek HW (1998) Cocaine as a risk factor for neuroleptic-induced acute dystonia. J Clin Psychiatry 59: 128-130.

Vasudevan A, Breakefield XO, Bhide PG (2006) Developmental patterns of torsinA and torsinB expression. Brain Res 1073-1074: 139-145.

Ventura R, Harris KM (1999) Three-dimensional relationships between hippocampal synapses and astrocytes. J Neurosci 19: 6897-6906.

Walberg F (1956) Descending connections to the inferior olive; an experimental study in the cat. J Comp Neurol 104: 77-173. 
Walberg F (1974) Descending connections from the mesencephalon to the inferior olive: an experimental study in the cat. Exp Brain Res 20: 145-156.

Walker RH, Brin MF, Sandu D, Gujjari P, Hof PR, Warren Olanow C, Shashidharan P (2001) Distribution and immunohistochemical characterization of torsinA immunoreactivity in rat brain. Brain Res 900: 348-354.

Walker RH, Good PF, Shashidharan P (2003) TorsinA immunoreactivity in inclusion bodies in trinucleotide repeat diseases. Mov Disord 18: 1041-1044.

Weibezahn J, Tessarz P, Schlieker C, Zahn R, Maglica Z, Lee S, Zentgraf H, Weber-Ban EU, Dougan DA, Tsai FT, Mogk A, Bukau B (2004) Thermotolerance requires refolding of aggregated proteins by substrate translocation through the central pore of ClpB. Cell 119: 653-665.

Wietholter H, Eckert S, Stevens A (1990) Measurement of atactic and paretic gait in neuropathies of rats based on analysis of walking tracks. J Neurosci Methods 32: 199205.

Wilhelmsen K, Litjens SH, Kuikman I, Tshimbalanga N, Janssen H, van den Bout I, Raymond K, Sonnenberg A (2005) Nesprin-3, a novel outer nuclear membrane protein, associates with the cytoskeletal linker protein plectin. J Cell Biol 171:799-810.

Witcher MR, Kirov SA, Harris KM (2007) Plasticity of perisynaptic astroglia during synaptogenesis in the mature rat hippocampus. Glia 55: 13-23.

Wong-Riley MT (1989) Cytochrome oxidase: an endogenous metabolic marker for neuronal activity. Trends Neurosci 12:94-101.

Wree A (1990) Principles of the 2-deoxyglucose method for the determination of the local cerebral glucose utilization. Eur J Morphol 28:132-138.

Wree A, Schleicher A (1988) The determination of the local cerebral glucose utilization with the 2-deoxyglucose method. Histochemistry 90: 109-121.

Xiao J, Gong S, Zhao Y, LeDoux MS (2004) Developmental expression of rat torsinA transcript and protein. Brain Res Dev Brain Res 152: 47-60.

Xue JH, Fukuyama H, Nonoguchi K, Kaneko Y, Kido T, Fukumoto M, Fujibayashi Y, Itoh K, Fujita J (1998) Induction of Apg-1, a member of the heat shock protein 110 family, following transient forebrain ischemia in the rat brain. Biochem Biophys Res Commun 247: 796-801. 
Yagita Y, Kitagawa K, Ohtsuki T, Tanaka S, Hori M, Matsumoto M (2001) Induction of the HSP110/105 family in the rat hippocampus in cerebral ischemia and ischemic tolerance. J Cereb Blood Flow Metab 21: 811-819.

Yokoi F, Dang MT, Mitsui S, Li J, Li Y (2008) Motor deficits and hyperactivity in cerebral cortex-specific Dyt1 conditional knockout mice. J Biochem 143: 39-47.

Zimprich A, Grabowski M, Asmus F, Naumann M, Berg D, Bertram M, Scheidtmann K, Kern P, Winkelmann J, Müller-Myhsok B, Riedel L, Bauer M, Müller T, Castro M, Meitinger T, Strom TM, Gasser T (2001) Mutations in the gene encoding epsilonsarcoglycan cause myoclonus-dystonia syndrome. Nat Genet 29(1): 66-69.

Zlotogora J (2004) Autosomal recessive, DYT2-like primary torsion dystonia: a new family. Neurology 63: 1340 .

Zweig RM, Hedreen JC, Jankel WR, Casanova MF, Whitehouse PJ, Price DL (1988)

Pathology in brainstem regions of individuals with primary dystonia. Neurology 38: 702706. 


\section{VITA}

Yu Zhao was born in Harbin, China on April 17, 1975. After graduating from high school in 1994, she attended the 7-year program of clinical medicine in Harbin Medical University, where she received two degrees, Bachelor of Medicine and Master of Medicine, in 2001. After graduation, she received one year of residency training in the First Hospital of Harbin Medical University. In August 2002, she began her doctoral education in the Neuroscience Program in the University of Tennessee, Health Science Center. Her doctoral dissertation research was carried out in Dr. LeDoux's Lab in the Department of Neurology. 